\title{
Formation and metamorphism of stratified firn at sites located under spatial variations of accumulation rate and wind speed on the East Antarctic ice divide near Dome Fuji
}

S. Fujita ${ }^{1}$, H. Enomoto ${ }^{2,1}$, K. Fukui ${ }^{1,{ }^{*}}$, Y. lizuka ${ }^{3}$, H. Motoyama ${ }^{1}$, F. Nakazawa ${ }^{1}$, S. Sugiyama ${ }^{3}$, and S. Surdyk ${ }^{1}$

${ }^{1}$ National Institute of Polar Research, Research Organization of Information and Systems, Tokyo, Japan

${ }^{2}$ Kitami Institute of Technology, Kitami, Japan

${ }^{3}$ Institute of Low Temperature Science, Hokkaido University, Sapporo, Japan "now at: Tateyama Caldera Sabo Museum, Toyama, Japan

Received: 12 February 2012 - Accepted: 11 March 2012 - Published: 26 March 2012 Correspondence to: S. Fujita (sfujita@nipr.ac.jp)

Published by Copernicus Publications on behalf of the European Geosciences Union.
6, 1205-1267, 2012

Metamorphism of firn in Dronning Maud Land, East Antarctica

S. Fujita et al.
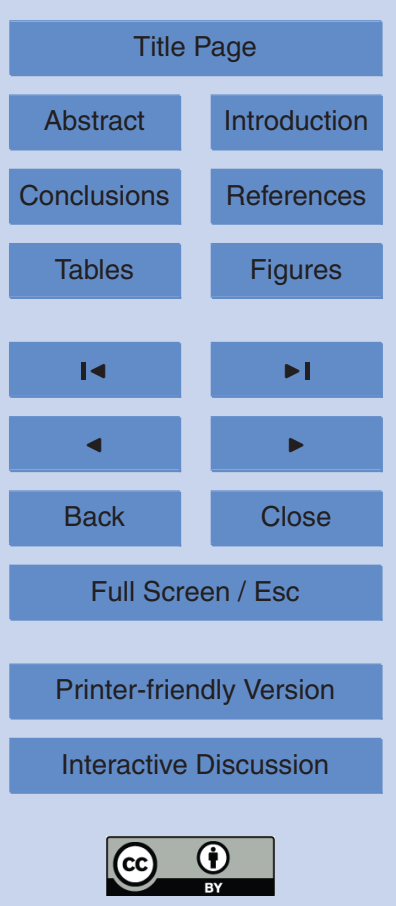


\section{Abstract}

The initial stage of postdepositional metamorphism in polar firn was investigated at sites located under spatial variations of accumulation rate and wind speed along the East Antarctic ice divide near Dome Fuji. A better understanding of this process is

5 important for interpreting local insolation proxies used for astronomical dating of deep ice cores. Three $2-4 \mathrm{~m}$ deep pits were excavated and physical properties, including density $\rho$, grain size $D$, reflectance $R$ of near infrared light and microwave dielectric anisotropy $\Delta \varepsilon$, were investigated at high spatial resolution. We found that $\Delta \varepsilon$ ranges between 0.028 and 0.067 and that such high values occur in the surface $\sim 0.1 \mathrm{~m}$. In addition, short scale variations of $\rho$ are correlated with those of $\Delta \varepsilon$, and inversely correlated with those of $D$, confirming contrasting development of initially higher density layers and initially lower density layers. Moreover, postdepositional metamorphism makes these contrasts more distinct with increasing depths. Both the contrasts and $\Delta \varepsilon$ for given values of $\rho$ are higher under lower accumulation rate conditions and under less windy conditions. Insolation efficiently causes evolution of strata of firn at the ice sheet surface under such conditions. Under more windy conditions, the strata contain more wind-driven hard layers with higher $\rho$ and $\Delta \varepsilon$ and thus have larger fluctuations of $\rho$ and $\Delta \varepsilon$. We suggest that the initial variability of $\rho$ at the surface and the duration of exposure to diurnal and seasonal temperature gradients play sequential roles in determining the physical/mechanical properties of firn, which is retained throughout the densification process.

\section{Introduction and background}

\subsection{Metamorphism of the stratified firn on a polar plateau}

Ice cores from polar ice sheets preserve proxies of past climatic conditions. Ice within

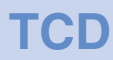

$6,1205-1267,2012$

\section{Metamorphism of firn in Dronning Maud Land, East Antarctica}

S. Fujita et al.

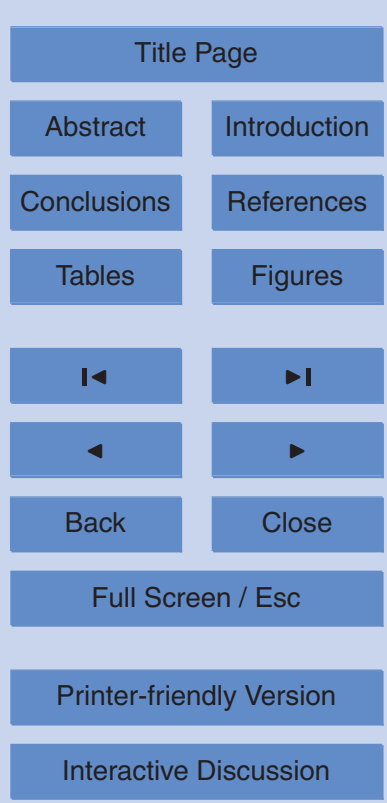


ical processes of formation, metamorphism and deformation in the firn of ice sheets (e.g., Alley, 1988; Alley et al., 1982; Arnaud et al., 2000; Colbeck, 1983; Courville et al., 2007; Dang et al., 1997; Fujita et al., 2009; Gow, 1965; Hörhold et al., 2009, 2011; Hondoh, 2000; Maeno and Ebinuma, 1983; Salamatin et al., 2009; Salamatin and Lipenkov, 5 2008). The physical processes of formation, metamorphism and deformation have a causal chain: initial formation of strata determines the firn types characterized by density, grain size, bonding between ice particles and crystal orientation, and thus affects physical/mechanical properties of the firn throughout the densification processes (e.g., Alley et al., 1982; Freitag et al., 2004; Fujita et al., 2009; Hörhold et al., 2011). For ex-

10 ample, crossover of the firn density has been reported; that is, the initially less dense firn layer becomes denser than the initially denser firn layer (Freitag et al., 2004; Fujita et al., 2009; Gerland et al., 1999; Hawley and Morris, 2006; Hörhold et al., 2011) at a common crossover density of $600-650 \mathrm{~kg} \mathrm{~m}^{-3}$ (Hörhold et al., 2011). This crossover of density is known to occur widely both in Antarctica and in Greenland. Studies of 15 the density crossover have suggested that the firn processes could be better understood using high-resolution data resolvable for the components within the firn strata. For example, at low accumulation rate sites such as the interior of East Antarctica, millimetre and centimetre scales are suitable resolutions. In addition, Hörhold et al. (2011) demonstrated that mean density profiles obtained from high-resolution measurements only partly show clear transitions in the densification rate at densities of either 550, 730, or $820-840 \mathrm{~kg} \mathrm{~m}^{-3}$, as these are commonly used in the literature. Their data emphasized the need for a physical model for firn compaction considering the high-resolution data.

\subsection{Transport process of gas molecules in firn during bubble close-off}

25 Transport and fractionation processes of gas molecules in firn during bubble close-off near the bottom of the firn are strongly influenced by the properties of the firn strata. Near the bottom of the firn, firn air is progressively enriched with relatively small atoms and molecules such as $\mathrm{He}, \mathrm{Ne}, \mathrm{O}_{2}$, and Ar relative to $\mathrm{N}_{2}$ with time and depth, whereas

\section{Metamorphism of firn in Dronning Maud Land, East Antarctica}

S. Fujita et al.

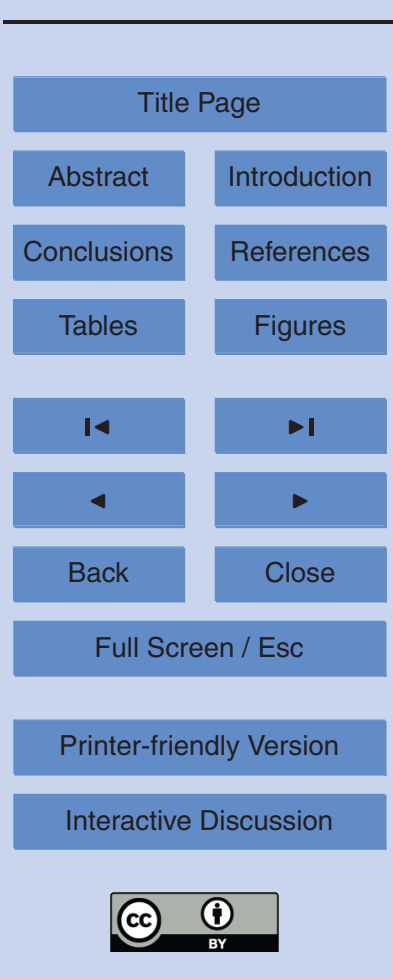


larger gases such as $\mathrm{Kr}, \mathrm{CH}_{4}, \mathrm{CO}_{2}$ and $\mathrm{Xe}$ are not fractionated (Huber et al., 2006; Severinghaus and Battle, 2006). This size-dependent fractionation is thought to occur in response to the preferential exclusion of small gases from shrinking bubbles to the residual firn open pores by molecular diffusion through the polycrystalline ice driven 5 by pressure differences (Huber et al., 2006; Ikeda-Fukazawa et al., 2005; Severinghaus and Battle, 2006). Bender (2002) discovered that variations in the $\mathrm{O}_{2} / \mathrm{N}_{2}$ ratio of trapped gases occur cyclically, with ages between ca. 160-385 ka in the Vostok ice core. He found that these variations corresponded to changes in summer insolation at Vostok, suggesting that the $\mathrm{O}_{2} / \mathrm{N}_{2}$ ratio in trapped gases may provide an accurate as10 tronomical timescale for very old ice cores. In explanation, he proposed that insolation affects snow metamorphism and grain properties in shallow firn, and that the insolation signature is retained throughout the firn, influencing $\mathrm{O}_{2} / \mathrm{N}_{2}$ fractionation during bubble close-off. Kawamura et al. (2007) found essentially the same relationship in the Dome Fuji ice core for the ages between ca 80-340 ka and accurately dated the core 15 by tuning the $\mathrm{O}_{2} / \mathrm{N}_{2}$ record to the local summer insolation. The $\mathrm{O}_{2} / \mathrm{N}_{2}$ chronology was validated by time markers in the core for which radiometric ages are established. In addition, Kawamura et al. (2004) presented the total air content (TAC) from the Dome Fuji ice core for the last $340 \mathrm{ka}$. They found that TAC was also synchronous with local summer solstice insolation: low TAC occurred at times of high summer insolation.

20 They hypothesized that insolation modifies the strength of metamorphism within stratified firn, leading to modification of the gas diffusion paths near the base of the firn. Raynaud et al. (2007) investigated the TAC of the EPICA Dome C ice core over the last $440 \mathrm{ka}$ as a proxy for local insolation, proposing that long-term changes in TAC recorded in ice from the high Antarctic plateau were dominantly imprinted by local 25 summer insolation. The $\mathrm{O}_{2} / \mathrm{N}_{2}$ record and the TAC record from Vostok ice core were studied by Suwa and Bender (2008) and Lipenkov et al. (2011), respectively, showing synchronicity with local summer solstice insolation.

Firn properties that affect both close-off fractionation and TAC have been extensively discussed (e.g., Bender, 2002; Fujita et al., 2009; Hutterli et al., 2008; Kawamura et al.,

\section{Metamorphism of firn in Dronning Maud Land, East Antarctica}

S. Fujita et al.

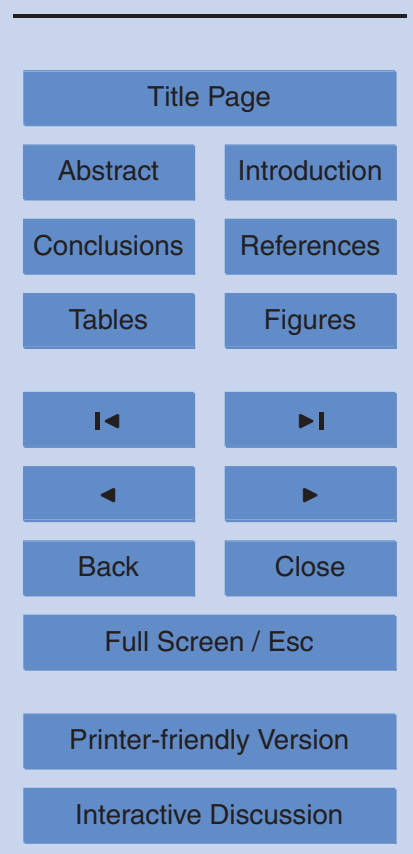

Interactive Discussion 
2004; Lipenkov et al., 2011; Raynaud et al., 2007). Fujita et al. (2009) proposed a physical model based on the high-resolution firn properties at Dome Fuji. The crossover of density is an important process within the model. They discussed how earlier hypotheses could be interpreted (Sect. 4.4.3 in Fujita et al., 2009). On the other hand, 5 both Raynaud et al. (2007) and Lipenkov et al. (2011) gave conceptual explanations in terms of grain growth. They hypothesized that more intense insolation could cause grain growth near the surface, leading to decreased porosity at close-off (see Sect. 5 in Lipenkov et al. (2011) for their latest discussions). We note that the process of density crossover was not introduced or used in their concept.

$10 \quad$ Fujita et al. (2009) investigated the evolution of the firn structure of a 112.59-m-long firn core recovered at Dome Fuji. They found that the firn at Dome Fuji contains horizontal strata with thicknesses of several centimetres. Near the surface of the ice sheet, the strata were characterized by contrasting bulk density. It was known from earlier field studies of the East Antarctic plateau (Koerner, 1971; Shiraiwa et al., 1996) that summer insolation causes densification of surface firn. In the Dome Fuji firn, Fujita et al. (2009) found numerous examples of textures indicating that destructive deformation preferentially occurred in the initially less dense firn (henceforth, ILDF) and that the initially higher density firn (henceforth, IHDF) layers were more permeable to air near the bottom of firn. We note that there is no distinct boundary density value between the IHDF and ILDF because there should be a variety of intermediate states between them. Nevertheless, these alternate conditions, initially high density or initially low density, are commonly termed in recent high-resolution studies of firn (Hörhold et al., 2011). Fujita et al. (2009) proposed a model forming a link between local insolation and the fractionation of the trapped gas and also TAC in the ice as follows:

(i) The annual alternation of firn types develops in response to summer insolation. Therefore, the firn contains horizontal strata with thicknesses of several centimetres. Summer insolation creates the IHDF layer of the surface firn. ILDF forms as winter layers that did not receive direct irradiation from summer insolation at the surface of the ice sheet.

\section{TCD}

$6,1205-1267,2012$

\section{Metamorphism of firn in Dronning Maud Land, East Antarctica}

S. Fujita et al.

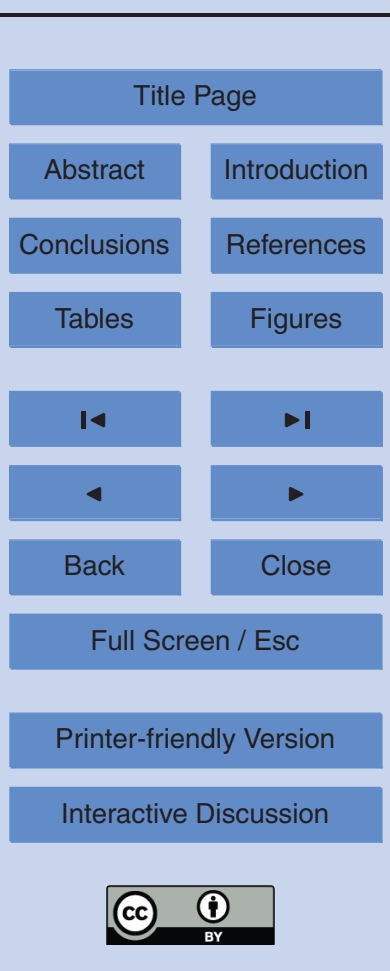


(ii) The IHDF is initially harder than the ILDF due to ice bonding between grains, structural anisotropy and effect of crystal orientation fabrics (COF). The difference in mechanical strength allows preferential deformation of weaker layers, causing the ILDF to become denser than the IHDF.

(iii) During the bubble close-off process from its starting depth to its completion depth, the ILDF continues to be denser than the IHDF by $\sim 10 \mathrm{~kg} \mathrm{~m}^{-3}$ due to preferential deformation. Air bubbles in the ILDF tend to form earlier and at shallower depths than those in the IHDF. The IHDF layers tend to remain permeable to air for longer. In addition, the IHDF constitutes a 3-D network in the firn. The persistence of the IHDF determines the deepest limit of vertical permeable firn in the bubble closeoff zone.

(iv) A pressure lag occurs between the air in open pores and air in both closing and closed air bubbles due to overburden pressure (Lipenkov, 2000). Thus, transportation of gas molecules occurs through polycrystalline ice (both ice lattice and grain boundaries) in the bubble formation zone. During this transportation, fractionation of the gas occurs. TAC also decreases in the bubble formation zone. Strata composed of the two types of firn can act as a centimetre-scale macroscopic zone for the transport of gas molecules. The mechanical persistence of paths for the vertical diffusion of gas through open pores depends on the distinctness of the alternation in firn type due to variations in the intensity of insolation.

In summary, modulation of the duration of the bubble close-off process from its starting depth to its completion depth and the pressure lag $\Delta p$ are hypothesized to be the factors controlling the total amount of gas transport. The model both qualitatively and quantitatively explains how stronger insolation can lead to bulk ice with a lower $\mathrm{O}_{2} / \mathrm{N}_{2}$ ratio and smaller total air content.

\section{Metamorphism of firn in Dronning Maud Land, East Antarctica}

S. Fujita et al.

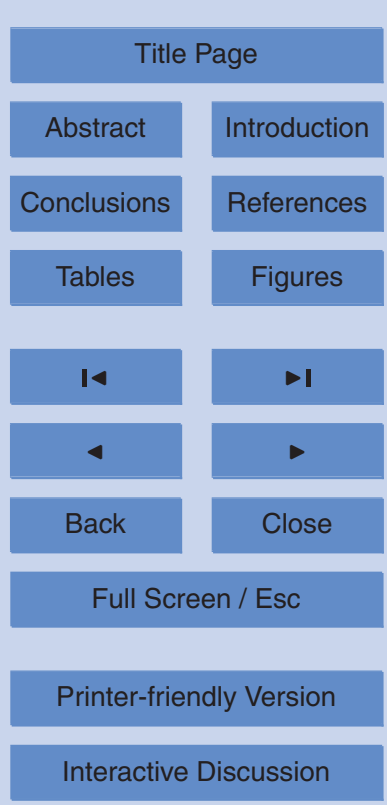




\subsection{Modelling a phase link between summer insolation and ice core gas records}

A current issue in ice core studies is the further examination of the reliability of the $\mathrm{O}_{2} / \mathrm{N}_{2}$ ratio and TAC as local insolation proxies used for astronomical dating of deep ice cores (e.g., Bender, 2002; Fujita et al., 2009; Hörhold et al., 2011; Hutterli et al.,

5 2009; Kawamura et al., 2007; Lipenkov et al., 2011; Raynaud et al., 2007; Suwa and Bender, 2008). Kawamura et al. (2007) empirically determined that the $\mathrm{O}_{2} / \mathrm{N}_{2}$-based astronomical time markers have low uncertainty, typically less than $2 \mathrm{ka}$. Hutterli et al. (2009) proposed a physically based model that calculates insolation-induced relative changes in vapour transport caused by the temperature gradient within snow and firn in the past. They estimated that changes in the accumulation rate determines the exposure time of a snow layer to the vapour transport. Hutterli et al. (2009) then claimed that, at Dome Fuji, phase shifts between the development of vapour transport and local summer solstice insolation could be as large as several ka. This claim was based on their Fig. 9b which actually showed only two cases of significant phase shift: at $15 \sim 20 \mathrm{ka} \mathrm{BP}$ and $\sim 125 \mathrm{ka} \mathrm{BP}$, among the total of 27 insolation peaks/troughs during the past $340 \mathrm{ka}$. The remaining 25 cases showed small phase shifts of less than $1 \sim 2$ $\mathrm{ka}$, which are within the typical uncertainty of $\mathrm{O}_{2} / \mathrm{N}_{2}$ tuning, supporting Kawamura's empirical approach (Kawamura et al., 2007). Moreover, the result is sensitive to the choice of relationship between temperature and accumulation rate. Their alternative model run with slightly reduced accumulation rates (within the uncertainty of accumulation reconstruction) eliminated the phase shifts between the peaks of metamorphism and summer insolation for the past $340 \mathrm{ka}$. S. Fujita (in the editor's comment of Hutterli et al., 2009) suggested that we need to consider the fact that summer insolation initially causes rapid densification and hardening in the summit region of polar ice sheets (e.g., 25 Fujita et al., 2008; Koerner, 1971). Fujita et al. (2009) discussed particular issues that should be investigated to improve our understanding of the related physical processes. The issues include: (i) how the initial densification evolves in the top few metres of the

\section{Metamorphism of firn in Dronning Maud Land, East Antarctica}

S. Fujita et al.

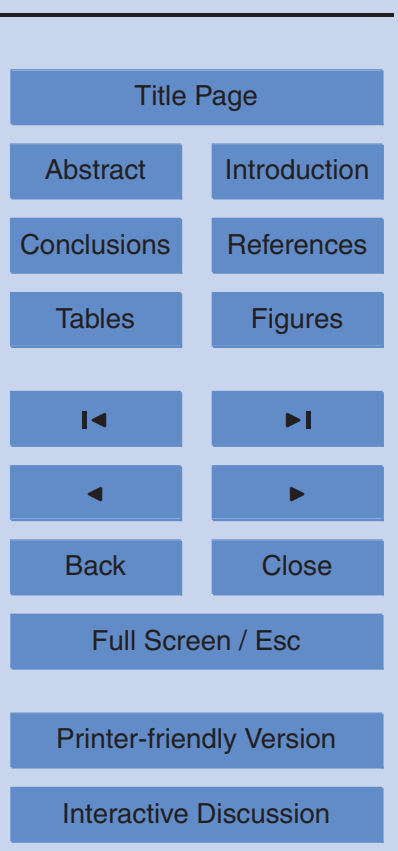


ice sheet after initial formation, and (ii) how these processes differ at sites with different accumulation environments. These topics are developed in this paper.

\subsection{The Japanese Swedish Antarctic Expedition in IPY 2007/2008}

The issues outlined above were investigated during the Japanese Swedish Antarctic

5 Expedition (henceforth, JASE traverse) across Dronning Maud Land (DML) in austral summer 2007/2008 (Holmlund and Fujita, 2009; Fujita et al., 2011). The routes of the traverse are shown in Fig. 1. The general purpose of the traverse was to form a better understanding of the spatio-temporal variability of the ice sheet environment in DML. The snow metamorphism process was one of the main scientific topics and is dis10 cussed in the present paper. Based on the traverse, several papers on the ice sheet environment have been published: on spatial and temporal variability of snow accumulation rate (Fujita et al., 2011), on dielectric permittivity of snow (Sugiyama et al., 2010), on density distribution of surface 1-m-deep snow measured along the JASE traverse and its dependence on wind (Sugiyama et al., 2012), and on snow particle size and its distribution (Ingvander et al., 2012). These studies form an important basis for the study of firn metamorphism at sites along the same traverse route.

In DML, the large-scale distribution of the accumulation rate depends on the surface elevation and continentality, and also that the accumulation rate differs between the windward and leeward sides of ice divides in strong-wind events (Fujita et al., 2011).

20 Along the main ice divide, three $2-4 \mathrm{~m}$ deep pits were excavated at Dome Fuji (henceforth, DF), a site called DK190 and the JASE Meeting point (henceforth, MP) (see Fig. 1 and Table 1). These sites are located under variations of accumulation rate and wind speed (Fig. 1 and Table 1). There are also weak gradients in terms of both elevation and temperature (Table 1). Prevailing windfield of the strong wind events is known based on the glaciological investigations (Fujita et al., 2011), as shown in Fig. 1b. The three pits are equally spaced at $\sim 200 \mathrm{~km}$ intervals within a $\sim 400 \mathrm{~km}$ distance. Using the walls of the pits, the physical properties of the firn were investigated. Measurements of the firn density in the surface $\sim 12 \mathrm{~cm}$ were also made at $10 \mathrm{~km}$ intervals along the

\section{Metamorphism of firn in Dronning Maud Land, East Antarctica}

S. Fujita et al.

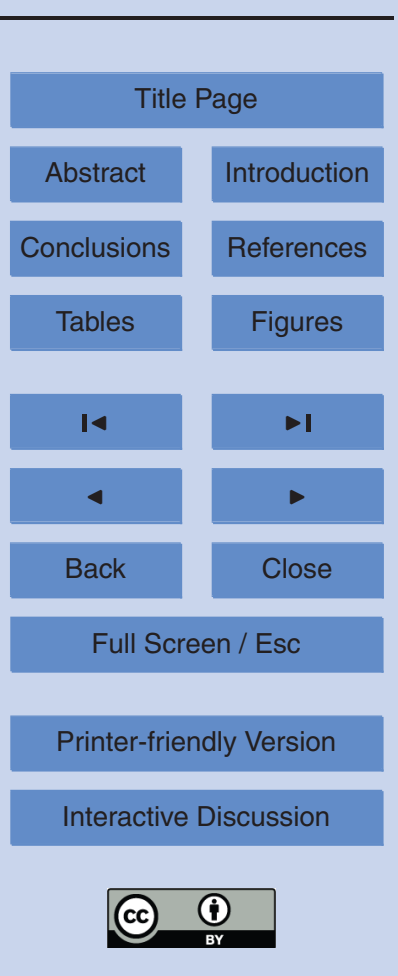


route connecting the three sites in order to understand the gradient of the depositional environment. At the same time, meteorological conditions were continuously recorded to understand factors influencing firn formation and metamorphism. In addition, firn block samples were collected from the three pits. The block samples were transported 5 to Japan and their physical properties were investigated in the cold laboratory of the National Institute of Polar Research (NIPR) in Tokyo. Data from the field and from laboratory measurements are compiled and discussed in this paper.

\section{Study area and methods}

\subsection{The JASE traverse in the study area}

10 In the JASE traverse, the tracked-vehicle-based expedition used two starting points: the S16 site near the Japanese Syowa Station for the Japanese team and the Swedish Wasa Station for the Swedish team (Fig. 1). The JASE traverse traced a route connecting several Antarctic stations: Syowa - DF - EPICA DML (Kohnen) - Wasa. The expedition began on 14 November 2007 for the Japanese team. The first pit study near

DF was made on 10-11 December 2007. The second and the third pit studies were made at DK190 and MP on 20 December 2007 and 24-26 December 2007, respectively. Measurements of the surface snow density along the traverse route were made between these dates. The meteorological conditions during the investigation period are given in Fig. 2. The weather was clear sky most of the day, although sometimes cloud cover increased and visibility decreased, in particular at timings when wind direction has a northerly component. Drifting snow was observed in the period between 20 and 23 December. Synchronized diurnal cycles are apparent both in air temperature and wind speed. The temperature at $3.9 \mathrm{~m}$ height ranged between $-18^{\circ} \mathrm{C}$ (max.) and $-38^{\circ} \mathrm{C}$ (min.), and was $-30^{\circ} \mathrm{C}$ on average. Wind speed at $4.5 \mathrm{~m}$ height ranged between s $\mathrm{m}^{-1}$ (min.) and $9.4 \mathrm{~m} \mathrm{~s}^{-1}$ (max.), and was $4.1 \mathrm{~m} \mathrm{~s}^{-1}$ on average, which is less than the wind speed threshold for dune formation $\left(>10 \mathrm{~m} \mathrm{~s}^{-1}\right)$ (Birnbaum et al., 2010). We

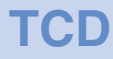

$6,1205-1267,2012$

Metamorphism of firn in Dronning Maud Land, East Antarctica

S. Fujita et al.

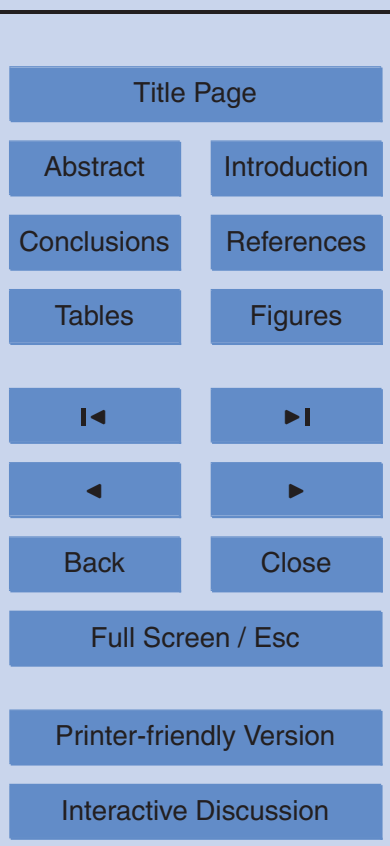

Interactive Discussion 
assume that weather conditions during the measurement period did not cause dramatic temporal changes such as dune formation events (Birnbaum et al., 2010) or strong wind events (Van As et al., 2007) influencing the near-surface snow conditions. However, the summer period including the summer solstice is the time when metamorphism mostly 5 develops, and temporal changes of the snow properties should mostly relate to diurnal cycles of the meteorological conditions in the absence of extreme weather events. We did not perform any systemic measurement of precipitation and sublimation during the JASE traverse. However, twice-monthly continuous snow stake measurements over four years made at DF (Kameda et al., 2008) have demonstrated that there is no 10 seasonality in the accumulation rate at DF under the present climate. This fact is discussed in Fig. 15 later in this paper. We therefore assume that a monthly accumulation rate of the order of $\sim 2 \mathrm{~kg} \mathrm{~m}^{-1}$ month $^{-1}$ occurred during the JASE traverse due to the release of moisture from the air to the ice sheet.

\subsection{Investigated properties, methods and sample transportation}

\subsubsection{Density measurements along the traverse route}

In order to understand the spatial distribution of the depositional environment between DF and MP, surface density was measured using two methods of firn sampling: (i) use of a cylindrical $\left(100 \mathrm{~cm}^{3}\right)$ sampler of $0-11 \mathrm{~cm}$ depth, and (ii) use of a box $\left(100 \mathrm{~cm}^{3}\right)$ sampler with $3-\mathrm{cm}$ depth resolution. The first method was used to measure density

averaged over $11 \mathrm{~cm}$ depth. A calibrated mechanical balance was used to measure the weight of the sampled firn. At each site, the sampling points were randomly selected to avoid unconscious bias in the selection of sampling points by the observer. Measurements were made using at least three samples at a site. For the second type of sampler, sampling points were again selected randomly at each site. Firstly, a 30-

pit, the density of snow was measured at $3-\mathrm{cm}$ intervals to a depth of at least $18 \mathrm{~cm}$. Both types of measurements were performed at $20 \mathrm{~km}$ intervals along the traverse.

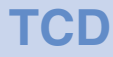

$6,1205-1267,2012$

Metamorphism of firn in Dronning Maud Land, East Antarctica

S. Fujita et al.

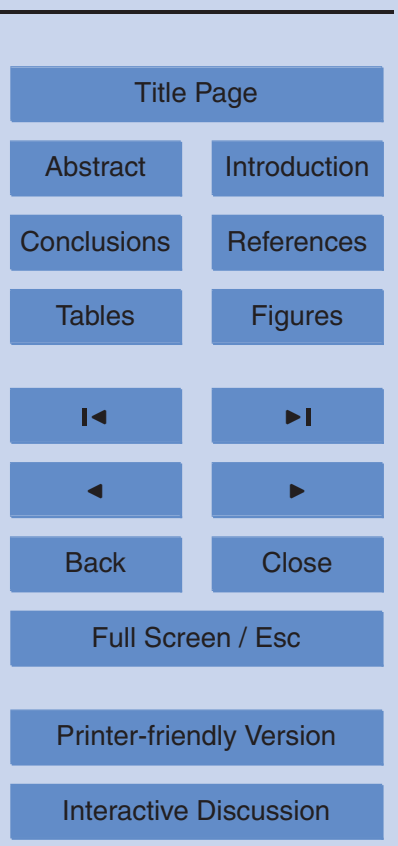

Interactive Discussion 
Finally, these two types of measurement were performed alternately every $10 \mathrm{~km}$. In each measurement, the surface snow type was recorded as either soft new snow or compacted hard snow. When the surface was wind slab or dune, they were recorded as compacted hard snow. The thickness of the surface unit layer of a homogeneous snow type was also observed and recorded.

\subsubsection{Pit studies and firn block sampling}

Pit studies were performed in order to understand the depth profile of both the physical and chemical strata. In this paper, only physical properties are discussed. Two 4-m deep pits were excavated at DF and at MP. In addition, a 2-m deep pit was excavated at the DK190 site (Fig. 1 and Table 1). The DF pit was located at $77.298^{\circ} \mathrm{S}, 39.786^{\circ} \mathrm{E}$, about $3 \mathrm{~km}$ northeast and upwind of the Dome Fuji deep ice coring site relative to the prevailing wind direction. By analysis of the major ions, we identified age markers of the Pinatubo (Philippines) 1991 eruption to estimate the ages of the strata (Table 1 and Fujita et al., 2011). A picture of the wall within the pit at DF is shown in Fig. 3. Using the wall of the pits, several measurements and sampling were made as follows (Table 2):

i. Dielectric permittivity at frequencies of $500-900 \mathrm{MHz}$ was measured using a parallel lines resonator on a snow fork (Sihvola and Tiuri, 1986) at 3-cm depth intervals. Sugiyama et al. (2010) has reported how the snow fork measurements were carried out in the JASE traverse. At each depth, the snow fork sensor was penetrated horizontally into the vertical pit wall twice. In addition, Sugiyama et al. (2010) examined the relation between the dielectric permittivity $\varepsilon$ and the bulk density $\rho$ at many sites along the traverse route. In the three pits in this study, the bulk density $\rho$ was also measured at 3-cm depth resolution using a 3-cm thick box sampler. However, the snow-fork-based $\varepsilon$ and direct $\rho$ measurements basically produced duplicate data. Thus, only the results of the snow-fork-based $\varepsilon$ are discussed in this paper. Another reason for choosing this method is that the location of the snow fork measurements is closer to the location of the firn blocks (Fig. 3).

\section{TCD}

$6,1205-1267,2012$

Metamorphism of firn in Dronning Maud Land, East Antarctica

S. Fujita et al.

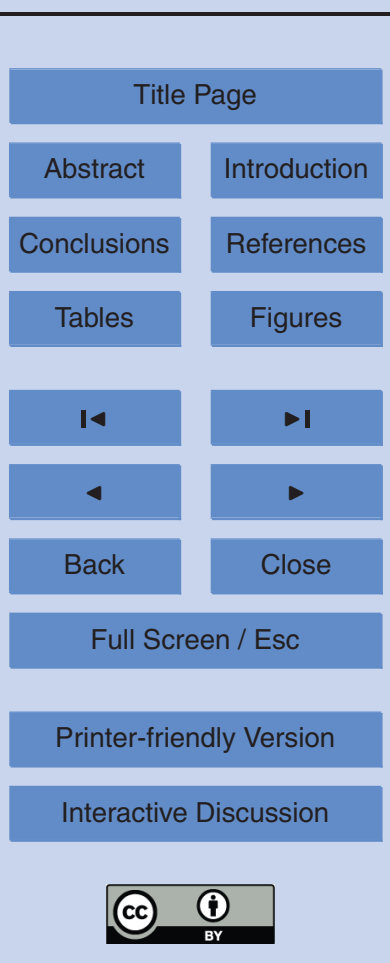


ii. Snow grain size $D$ was determined visually using a reference gauge to determine the approximate range of grain size. Grain size in this case reflects the size of the agglomerates.

iii. Stratigraphy was observed visually. Distribution of the depth hoar, compacted hard snow, crust layers and layer boundaries were observed and recorded. In addition, the temperature profile was measured in $10 \mathrm{~cm}$ intervals using a calibrated thermometer with Pt100 sensors.

iv. Using the same pit wall, snow block samples were collected for further measurements of physical properties. They were collected at $0.5 \mathrm{~m}$ depth intervals. The typical size of the snow block was $0.5 \mathrm{~m}$ in depth and $0.25 \mathrm{~m}$ by $0.3 \mathrm{~m}$ in horizontal cross section. The samples were transported to Japan via ground transportation to the Antarctic coast and then by ship.

v. Snow was sampled for analyses of water isotope, major ions and trace metal elements. Results from these chemistry samples will be discussed elsewhere.

15 As seen in Fig. 3, a pit width of about $2 \mathrm{~m}$ was necessary because the pit wall was used for multiple items of measurement and sampling. The variability of the stratigraphy within a pit means that the thickness of each layer is not exactly the same from one measurement/sampling to another. Such small gaps (to a few centimetres) are evident when we compare depths of different items.

\subsubsection{Transportation of the firn block samples}

The last firn sampling was completed on 26 December 2007 at MP. Because deterioration of the firn sample was a concern, the boxes containing them were kept deep within the sample sledge covered with aluminium-coated heat insulating material. In addition, the samples were transported with large amount of boxes containing the 3035-m deep Dome Fuji Station ice cores that the traverse team had a task to transport on

\section{Metamorphism of firn in Dronning Maud Land, East Antarctica}

S. Fujita et al.

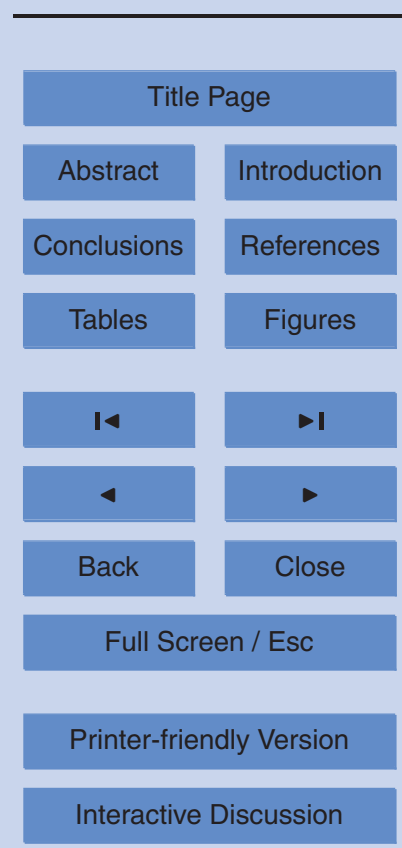

Interactive Discussion 
the ground (Motoyama, 2007). Thus, the samples were kept basically in an isothermal condition with only slow changes of temperature. The progress of the transportation was as follows. During the JASE traverse, the ambient temperature was approximately $-30^{\circ} \mathrm{C}$ with diurnal cycles of about $\pm 5^{\circ} \mathrm{C}$ on the Antarctic plateau (see Fig. 2, for ex-

5 ample). On 25 January 2008, the samples were transported from a site S30 on the continent $\left(69.05^{\circ} \mathrm{S}, 40.69^{\circ} \mathrm{E} ; 1015 \mathrm{~m}\right.$ a.s.I.) to the cold storage of $-28^{\circ} \mathrm{C}$ aboard the Ice Breaker Ship Shirase by helicopter. The samples experienced the highest ambient temperature between $-15^{\circ} \mathrm{C}$ and $-10^{\circ} \mathrm{C}$ for a few days just before being picked up by helicopter. After the samples arrived in Japan by ship, they were stored isothermally 10 at a temperature of $-50^{\circ} \mathrm{C}$ at the Institute of Low Temperature Science in Hokkaido University, Sapporo, until analysis in 2010 and 2011 at the National Institute of Polar Research, Tokyo. To avoid possible effects of sample deterioration, the surface $3 \mathrm{~cm}$ of the samples were rejected from the measurements as described below.

\subsubsection{Measurements of the physical properties of the firn blocks}

15 Physical properties of the firn blocks were investigated using the methods listed in Table 3. These methods are described as follows.

i. Dielectric permittivity tensor measurement using an open resonator

Earlier studies have shown that dielectric anisotropy is a measure of geometrical anisotropy in firn (Lytle and Jezek, 1994; Fujita et al., 2009). The dielectric permittivity tensor with the dielectric anisotropy was measured using an open resonator. The experimental procedure has been previously described (Fujita et al., 2009; Jones, 1976; Matsuoka et al., 1997, 1998). This method enables precise measurement of the dielectric permittivity tensor and the dielectric anisotropy if appropriate sets of frequency and sample thickness are selected to reduce errors (Jones, 1976; Komiyama et al., 1991). The open resonator and the slab-shaped sample were placed in a cold room at a constant temperature of $-15^{\circ} \mathrm{C}$. The electrical field in the resonator has a Gaussian distribution with a half-power diameter

Metamorphism of firn in Dronning Maud Land, East Antarctica

S. Fujita et al.

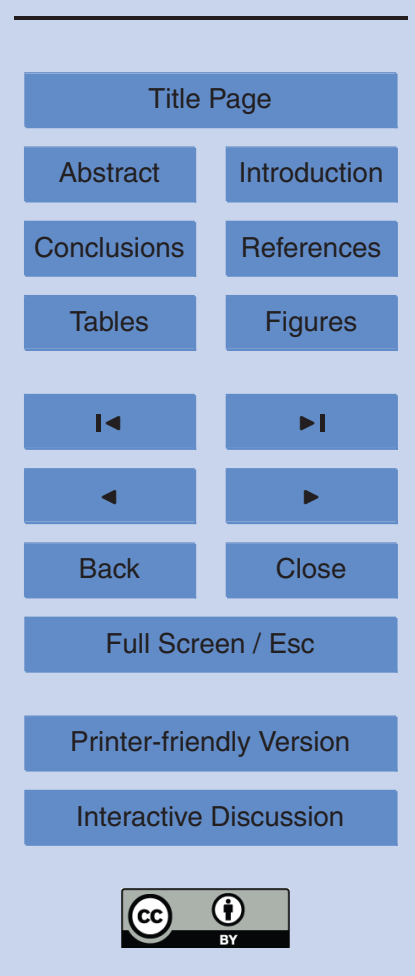


of $\sim 20 \mathrm{~mm}$ parallel to the slab-shaped sample and normal to the incident wave. The measured permittivity is thus a volume-weighted average within this Gaussian distribution in the slab-shaped sample. Source signals for the measurements were generated using a synthesized sweeper. Each sample slab was translated into the centre of the electrical field in increments of $5 \mathrm{~mm}$. Permittivity components were measured in both the vertical and horizontal planes of the ice sheet ( $\varepsilon_{\mathrm{v}}$ and $\varepsilon_{\mathrm{h}}$, respectively). For all measurements, $\varepsilon_{\mathrm{v}}$ and $\varepsilon_{\mathrm{h}}$ were obtained simultaneously using a single frequency sweep without physical movement of the sample (Jones, 1976; Matsuoka et al., 1997, 1998). Only the real part of the complex permittivity was investigated. A resonant frequency of $\sim 34 \mathrm{GHz}$ was chosen from many other measured resonant frequencies between 30 and $40 \mathrm{GHz}$. Accurate and precise values for the dielectric anisotropy $\Delta \varepsilon\left(=\left|\varepsilon_{\mathrm{v}}-\varepsilon_{\mathrm{h}}\right|\right)$ were then calculated. Errors involved with the measurements are described below.

7-mm thick slab samples were prepared by cutting with a band saw followed by microtoming. The error associated with sample thickness was $\pm 0.2 \mathrm{~mm}$, resulting in systematic errors in measured permittivity and $\Delta \varepsilon$ of approximately \pm 0.02 and \pm 0.002 , respectively. The accidental (random) errors in $\Delta \varepsilon$ within a sample with single thickness were at most \pm 0.001 . Thus, any variations of $\Delta \varepsilon$ larger than the accidental error of 0.001 were considered significant although measurable minimum $\Delta \varepsilon$ is 0.003 . The errors in $\Delta \varepsilon$ were markedly smaller than the permittivity errors due to the physical principle of the measurement (Matsuoka et al., 1997). We note that $\varepsilon$ measured using the snow fork (Sihvola and Tiuri, 1986) in the pit walls or dielectric profiling technique (DEP) (Moore et al., 1989; Wilhelms et al., 1998) for measurements of ice cores is equivalent to $\varepsilon_{\mathrm{h}}$ in terms of the direction of the electrical field vector in samples. Information of $\Delta \varepsilon$ is available if $\varepsilon_{\mathrm{v}}$ is detected. In some cases of less dense firn with coarse grains, resonant signals were too weak to be detected due to scattering loss of microwaves within the sample.

ii. Density measurement using the gamma-ray transmission method

\section{Metamorphism of firn in Dronning Maud Land, East Antarctica}

S. Fujita et al.

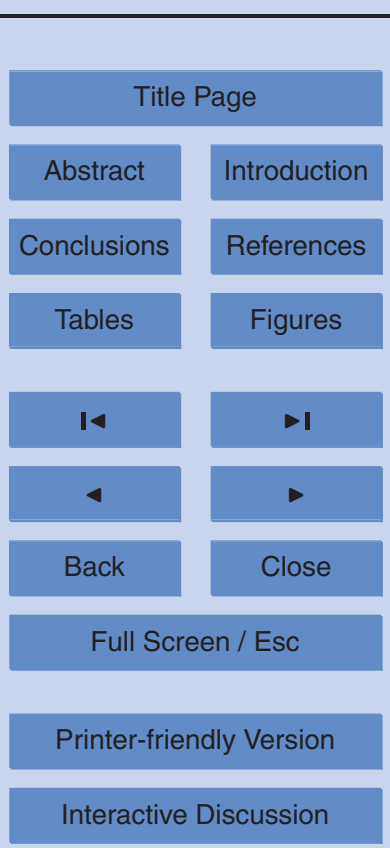


The continuous density profile of the firn was measured using the gamma-ray transmission method. The intensities of gamma-rays transmitted through a firn sample were continuously measured using a gamma-ray detector during translation of the sample across the gamma-ray beam. The gamma-ray intensity profile was converted into a density profile using a calibration curve for gamma-ray absorption based on sample thickness. The spatial resolution of the density profile was $3.33 \mathrm{~mm}$ in depth and $15 \mathrm{~mm}$ in width. Slab-shaped samples of $50 \mathrm{~mm}$ thickness were used.

iii. Measurement of Near-Infrared light reflectance on the firn surface

The reflectance of Near-Infrared (NIR) light is known to be correlated to the grain size and specific surface area of snow (e.g., Aoki et al., 2000; Matzl and Schneebeli, 2006; Wiscombe and Warren, 1980). We used NIR reflectance as a measure of grain size. An optical line scanner system was used. Takata et al. (2004) have described the principle of the optical line scanning device for the transmission of white light. We used NIR light instead of white light, and reflection of the light from the firn sample instead of transmitted light. The light sources of NIR LED are set above the firn sample. We use two rows of 24 NIR light-emitting diodes (LEDs) $100 \mathrm{~mm}$ wide. The light source has a centre wavelength of $940 \mathrm{~nm}$ with half power width of about $50 \mathrm{~nm}$. We used a charge-coupled device (CCD) camera (HAMAMATSU Model: C3077-79) which detects NIR light in a range of wavelengths between $300 \mathrm{~nm}$ and $1100 \mathrm{~nm}$. The light sources and the CCD camera are mounted on a moving stage and moved along the firn sample during the measurements. The distribution of scattered light intensity from the 50- and 60-mm-thick firn sample is measured, and the brightness intensity of each pixel is recorded on a PC. The surfaces of the samples are smoothed with a microtome just before the measurements. The CCD is focused on the top surface of the ice. After a measurement, a scanned image of the whole ice sample is produced. Measurement resolution is adjusted to $25 \mu \mathrm{m}$ pixel $^{-1}$ and the data were averaged over $2.5 \mathrm{~mm}$. We used sample thicknesses of $50 \mathrm{~mm}$ and $65 \mathrm{~mm}$ for the first and the second set

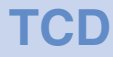

$6,1205-1267,2012$

\section{Metamorphism of firn in Dronning Maud Land, East Antarctica}

S. Fujita et al.

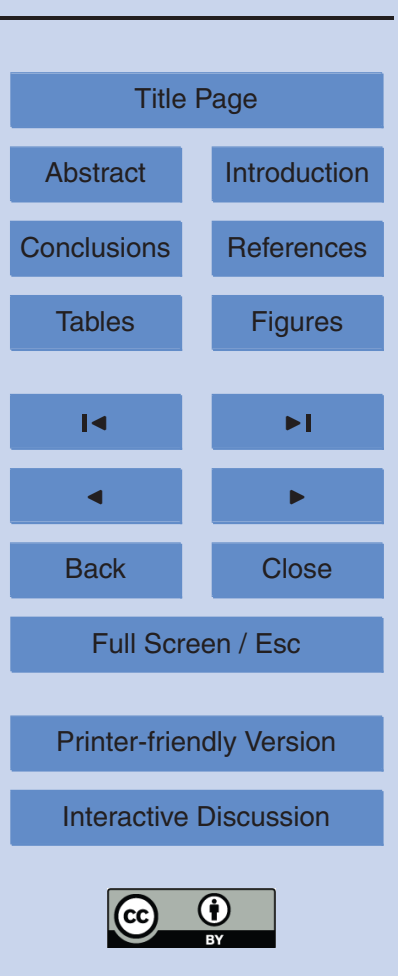


of measurements, respectively. We note that our sample thicknesses are of the order of the penetration depth of NIR light, which is a few centimetres (Tanikawa et al., 2011). Thus, the linescanned image of the NIR reflectance contains qualitative information of relative changes representing the penetration depth. The brightness intensity was converted to values of NIR reflectance (henceforth $R$ ) using two standard reflectors with reflectance of 0.99 and 0.81 . In reality, most of reflectance ranged between 0.6 and 0.8 ; we assumed a linearity of our system to a reflectance of about 0.6 .

iv. Imaging of ice grains and pore spaces using the Large Area Scan Macroscope The Large Area Scan Macroscope (LASM) developed by Schäfter+Kirchhoff $\mathrm{GmbH}$ (Hamburg, Germany) was used to observe the size and shape of ice particles in firn (http://www.sukhamburg.com/produkte/Zeilenkameras_e.html). It is a scanner specialized for ice core research, initially developed for the Alfred Wegener Institute for Polar and Marine Research in Bremerhaven (AWI). The microtomed firn surfaces of the thick sections are automatically scanned at a high resolution of $5 \mu \mathrm{m}$. Using this technique, we can observe features of ice grains and pore spaces as 2-D cross section images. These images were in for the preliminary analysis of the size of ice particles within the firn.

\section{Results}

\subsection{Spatial variations of the depositional environment}

The spatial distribution of the accumulation rate in the study area has previously been presented (Fujita et al., 2011), and the elevation, accumulation rate and surface slope are shown in Fig. $4 \mathrm{a}-\mathrm{c}$ and Table 1 . The density of the surface 11 or $12 \mathrm{~cm}$ thickness of snow is compiled in Fig. 4d. The density and its fluctuation were lowest near DF where

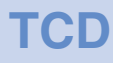

6, 1205-1267, 2012

\section{Metamorphism of} firn in Dronning Maud Land, East Antarctica

S. Fujita et al.

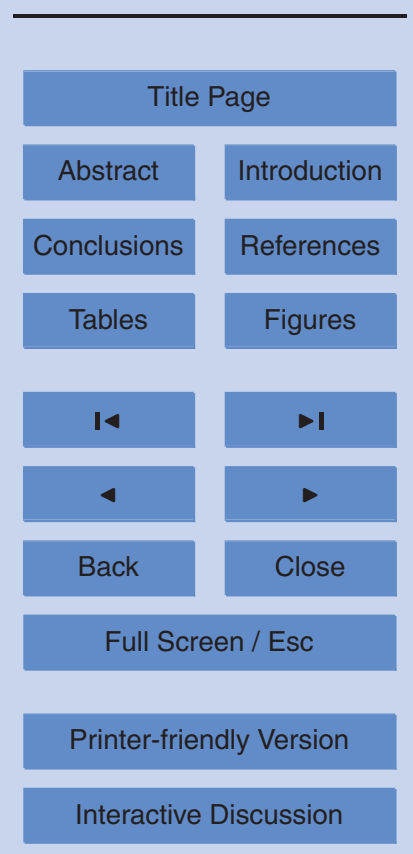

Interactive Discussion 
DK190 and MP along the ice divide, the frequency of encountering hard and compacted snow increases, showing a maximum approximately between DK190 and MP. The thickness of the surface unit layer is compiled in Fig. $4 \mathrm{e}$, and is shown to increase as we move toward DK190 and MP. The depth profile of the density at $3 \mathrm{~cm}$ resolution

5 is compiled in Fig. 4f. Like the distribution of the hard and compacted snow, surface firn is denser and more variable again between DK190 and MP. In the field, the hard and compacted snow along this leg looked like wind slab. Sugiyama et al. (2012) suggested a coefficient between average density and average wind speed $\left(13.5 \mathrm{~kg} \mathrm{~m}^{-3}\left(\mathrm{~m} \mathrm{~s}^{-1}\right)^{-1}\right)$ along the entire JASE traverse route. Based on the coefficient, we deduced spatial 10 distribution of the average wind speed in the right axis of Fig. $4 \mathrm{~d}$. We suggest that DK190 is the windiest site among the three due to topographic effect of the ice sheet. That is, convergence of upslope wind into a trough region between the ice divides $D$ and $E$ occur in the strong wind events (see prevailing wind directions in strong wind events indicated in Fig. 1b). Therefore, there were variations of depositional environ15 ment across the traverse. In the absence of any extreme weather events during the traverse (Fig. 2), we interpret that our observation reflects a spatial distribution rather than temporal changes. This spatial distribution in the depositional environment is also visible in the pit data as we see below.

\subsection{Depth profile of the strata measured in the field}

20 Measured results for the three pits are shown in Fig. 5 for permittivity $\varepsilon$, density $\rho$, grain size $D$ and stratification. We present results to a depth of $\sim 2.5 \mathrm{~m}$ to compare common depths of the three pits. The average densities at MP and DK190 are slightly higher than that at DF (see Table 4). We find more frequent appearance of compacted hard snow in the pits of DK190 and MP than in DF. In particular, the shallowest 1-m of the DK190 pit contains several layers of hard compacted snow. We find a tendency of grain growth with increasing depth like earlier studies (e.g., Alley et al., 1982; Gow, 1965). In addition, we see that $\rho$ and $D$ are often anti-correlated, confirming similar observations in many earlier studies (Alley, 1988; Alley et al., 1982; Freitag et al., 2004; Gow, 1965;

\section{Metamorphism of firn in Dronning Maud Land, East Antarctica}

S. Fujita et al.

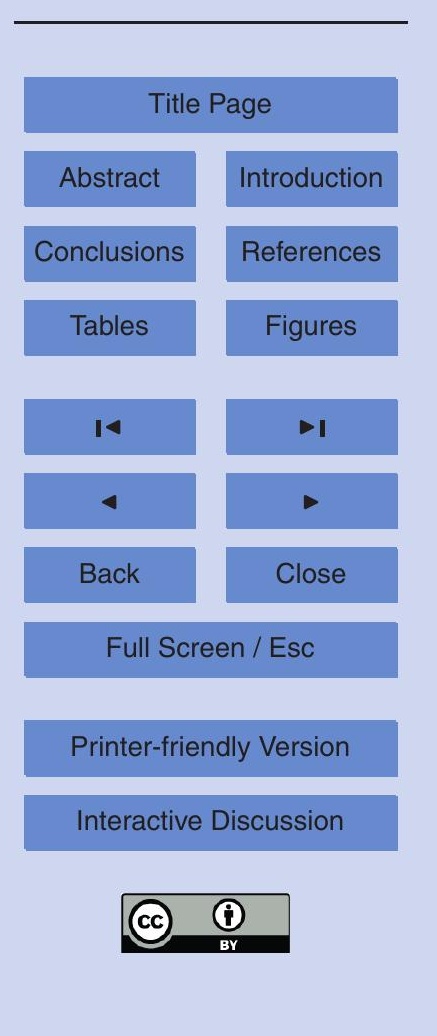


Koerner, 1971; Shiraiwa et al., 1996). Sugiyama et al. (2012) also demonstrated clear anti-correlation between $\rho$ and $D$ in many pits excavated during the JASE traverse. Layers of compacted hard snow are often characterized by higher $\rho$ and smaller $D$. In this way, the spatial distribution of the depositional environment is reflected in the strata 5 in the direction of depth.

Temperature profiles within the three pits are shown in Fig. 6. The variable range of air temperature in the period of mid to late December (as in Fig. 2) is shown at the top as a reference. Temperature gradients are the steepest near the surface and decrease with increasing depth. DF is the coldest and MP the warmest among the three sites. 10 In the late summer such as January, the temperature gradients should be less steep because of the conduction of the summer heat waves to deeper layers and starting of cooler conditions at the surface after the summer solstice.

\subsection{Physical properties of the firn blocks}

Results of the measurements are compiled in Fig. $7 a-c$ for the three pits. Some of the 15 0.5-long blocks were broken during transportation. Thus the shallowest $0.3 \mathrm{~m}$ portion at DK190 and the shallowest $1.0 \mathrm{~m}$ portion at MP were rejected from measurements. In addition, for each block sample, all surface 3-cm thickness portions were rejected from measurements to avoid potential effects of additional metamorphism that may have occurred due to thermally induced deterioration. The value of $\Delta \varepsilon$ should be a good 20 indicator of deterioration; we find no such features in the $\Delta \varepsilon$ data as shown below.

For each site, two components of the dielectric permittivity, $\varepsilon_{\mathrm{h}}$ and $\varepsilon_{\mathrm{v}}$, are shown as blue lines. Density $\rho$ is shown as green lines. Dielectric permittivity and $\rho$ is correlated as found previously (e.g., Kovacs et al., 1995; Lytle and Jezek, 1994; Sugiyama et al., 2010; Tiuri et al., 1984). An example scatter plot for this correlation is given in Fig. 8 25 for the firn at DF. The scatter plot agrees with a scatter plot for the snow-fork-based $\varepsilon$ and $\rho$ for a number of the 1-m pits excavated during the JASE traverse, published by Sugiyama et al. (2010). We also see how $\varepsilon_{\mathrm{h}}$ and $\varepsilon_{\mathrm{v}}$ are distributed. In Fig. $7, \varepsilon_{\mathrm{h}}, \varepsilon_{\mathrm{v}}$ and $\rho$ tend to increase with increasing depth due to densification. This tendency is the same

\section{Metamorphism of firn in Dronning Maud Land, East Antarctica}

S. Fujita et al.

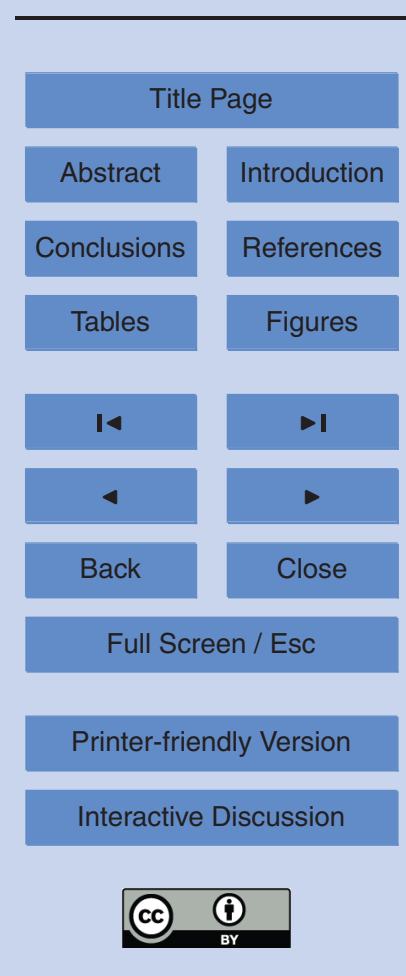


as found in Fig. 5, and the data have finer resolution. $\Delta \varepsilon$ is shown as red lines in Fig. 7 , and ranges between 0.28 and 0.67 for the three sites. Fluctuations of $\Delta \varepsilon$ are positively correlated with fluctuations of $\varepsilon_{\mathrm{h}}, \varepsilon_{\mathrm{v}}$ and $\rho$. The NIR reflectance, $R$, is shown as purple lines. Over the scale of metres, $R$ decreases with increasing depth. However, small5 scale fluctuations of $R$ are also positively correlated with the other variables: $\varepsilon_{\mathrm{h}}, \varepsilon_{\mathrm{v}}, \rho$ and $\Delta \varepsilon$. We note that higher $R$ should have correlation with finer grain size (e.g., Aoki et al., 2000; Matzl and Schneebeli, 2006; Wiscombe and Warren, 1980). The variation of $R$ suggests growth of grain size with increasing depth and short-scale fluctuations: higher $\varepsilon_{\mathrm{h}}, \varepsilon_{\mathrm{v}}, \rho$ and $\Delta \varepsilon$ are associated with finer grains over short scales.

10 Grain size was checked against the images of the LASM for the samples of DF. An example image is shown in Fig. 9. We extract features such as grain size, grain boundaries and micro-bubbles within ice of the microtomed surface of firn. Brighter grey parts are ice and dark parts are pore spaces on the microtomed surface. Average grain size was only preliminarily determined from the images using rulers as a scale, 15 and the depth profile is given in Fig. 7a as a brown line. In Fig. 7a, we find that over a metre scale, grain size increases with increasing depth and that at a finer scale, fluctuations of grain size tend to have a negative correlation with the other variables, as observed in the $R$ data. We note that $R$ represents backscatter of NIR light from within the volume of the firn, thus it has more 3-D volume information than a 2-D image of the microtomed firn surface. In addition, we note that the grain size from an image of the microtomed firn surface represents a cross section of firn, and we often observe necks of ice bonding. In contrast, grain size observed in the field represents the largest diameter of the particles (agglomerates) that the observers could see. This difference has been discussed previously (Freitag et al., 2008), and is the cause of the systematic difference in $D$ between Figs. $5 a$ and $7 a$.

The image in Fig. 9 is from 1.05-1.11 m depth at DF. This depth is characterized by large changes of $\rho$ and $R$, as also shown in Fig. 7a. We chose this example because it can represent numerous such large contrasts observed in the strata (Figs. 5 and 7). On the lower side of Fig. 9a, we observe that ice bonding between smaller grains

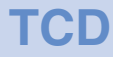

6, 1205-1267, 2012

\section{Metamorphism of firn in Dronning Maud Land, East Antarctica}

S. Fujita et al.

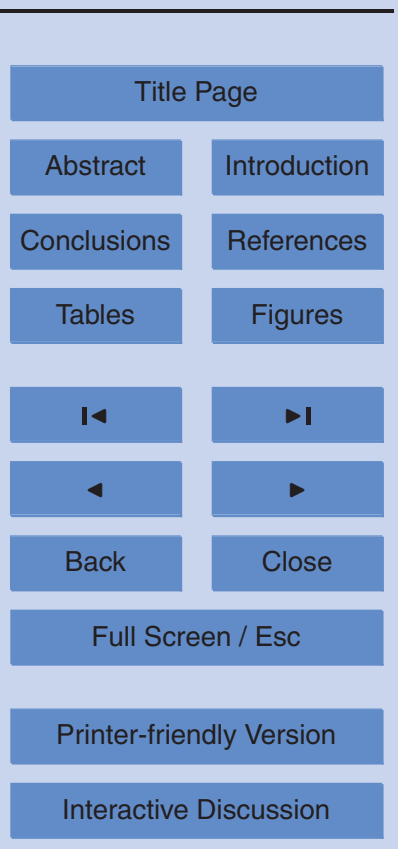


is well established (see Fig. 9b) whereas in the upper side of Fig. 9a, such bonding between larger grains is not visible in the 2-D image. Detailed 3-D analysis for similar contrasting firn was studied by Freitag et al. (2008), and demonstrated that within less dense firn, firn with lower coordination numbers support the overburden weight. This difference in ice bonding between grains in denser firn and less dense firn has been also discussed as one of basic causes of the crossover of density (Freitag et al., 2004; Fujita et al., 2009; Gerland et al., 1999; Hörhold et al., 2011). In particular, numerous centimetre-scale local densifications that occur with drops of $\Delta \varepsilon$ during the crossover of density were discussed as indications of destructive deformation of the initially less 10 dense layer (see Fig. 2 in Fujita et al., 2009).

\section{Discussion}

\subsection{Features indicating evolution of metamorphism}

\subsubsection{High values of $\Delta \varepsilon$ near the surface of the ice sheet}

The depth span of the data in each panel in Fig. 7 contain approximately 30, 21 and 12 annual layers at DF, DK190 and MP, respectively; thus statistics and correlations between variables represent these numbers of annual layers at each site. In this study, $\Delta \varepsilon$ is a measure of geometrical anisotropy within firn composed of an ice matrix and pore spaces. $\Delta \varepsilon$ can be regarded as a measure of the development of metamorphism in each pit. We find that $\Delta \varepsilon$ ranges between 0.028 and 0.067 . These high values can be explained only by geometrical anisotropies, and are not possible to explain via the much smaller effects of crystal orientation fabrics alone (Fujita et al., 2009). Fujita et al. (2009) gave $\Delta \varepsilon$ values for ten selected samples of $\sim 0.5-\mathrm{m}$-long firn from depths of $9.6 \mathrm{~m}$ to $112.6 \mathrm{~m}$ at DF. Our high values of $\Delta \varepsilon$ ranging between 0.028 and 0.067 are almost the same as their highest values obtained from 9.59-9.83-m deep firn (see Fig. 4 in Fujita et al., 2009). In the present study, we find such high values appear at

Metamorphism of firn in Dronning Maud Land, East Antarctica

S. Fujita et al.

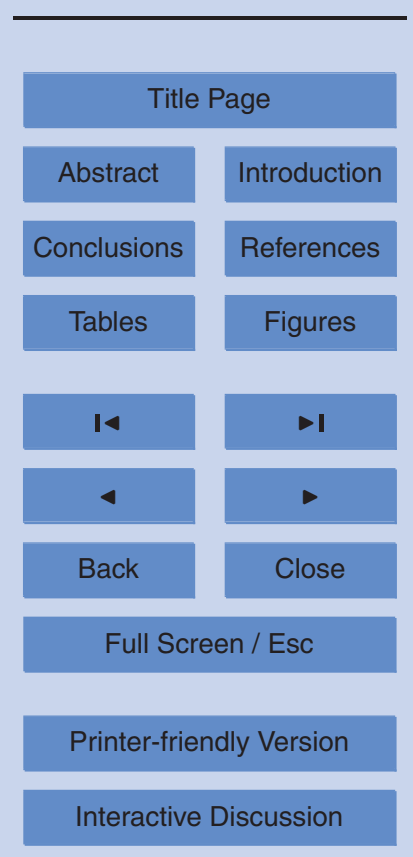

Interactive Discussion 
$\sim 0.1 \mathrm{~m}$ depth of the snow surface at DF, which suggests that metamorphism in terms of vertical anisotropy occurs at or near the very surface of the ice sheet by processes that exist at the surface.

The temperature gradient is one important factor for metamorphism at the surface.

5 The measurements of the temperature gradient (Fig. 6) show that temperature is highest at the surface and that the temperature gradient is steepest there in the daytime in summer. In addition, the variable range of air temperature in Fig. 6 means that the firn is exposed to the highest heat/vapour flux at the surface. Therefore, it is reasonable that metamorphism in terms of vertical anisotropy is highly developed at $\sim 0.1 \mathrm{~m}$ 10 depth. Down to $\sim 2 \mathrm{~m}$, metamorphism proceeds further because this depth still experiences a seasonal temperature gradient and thus is under the relatively strong influence of heat/vapour flux than deeper isothermal conditions (Alley et al., 1982). The grain growth and densification in the uppermost $\sim 2 \mathrm{~m}$ (Figs. 5 and 7 ) are explicable by heat/vapour waves from the surface. Interestingly, we find only weak growth of $\Delta \varepsilon$ 15 with increasing depth, although data of very surface portions are missing at DK190 and MP. This means that the basic anisotropic form is created mostly at the surface or just beneath the surface. The cause of the high $\Delta \varepsilon$ values has been previously discussed (see Sect. 4.1.2. of Fujita et al., 2009). In short, the annual alternation of firn types at Dome Fuji develops in response to summer insolation. In summary, the formation of the density of the strata at the surface is an initial condition of stratified firn, and the insolation-based temperature gradient enhances metamorphism, which will be discussed below.

\subsubsection{Difference in the $\varepsilon_{\mathrm{h}}-\Delta \varepsilon$ correlation between the three pits}

A main focus of this study is to understand how the $\rho-\Delta \varepsilon$ correlation is dependent on 25 the depositional environment, characterized by the accumulation rate, wind speed and so on. Instead of exploring the $\rho-\Delta \varepsilon$ relation, we investigate the $\varepsilon_{\mathrm{h}}-\Delta \varepsilon$ relation because $\varepsilon_{\mathrm{h}}$ is a function of $\rho$. Examining the $\varepsilon_{\mathrm{h}}-\Delta \varepsilon$ relation has an advantage because the sampling volume is exactly the same between the two parameters, whereas the $\rho-\Delta \varepsilon$

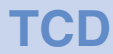

$6,1205-1267,2012$

Metamorphism of firn in Dronning Maud Land, East Antarctica

S. Fujita et al.

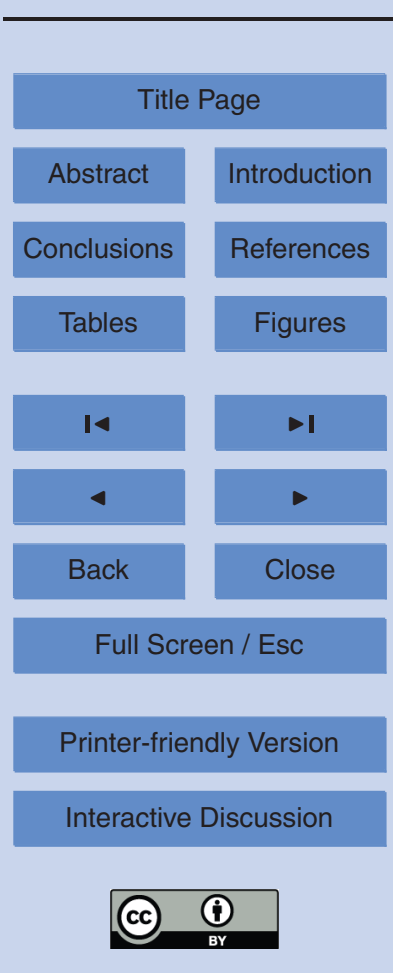


relation is affected by differences in sampling volume between the $\rho$ measurement and the $\Delta \varepsilon$ measurement. The scatter plot of $\varepsilon_{\mathrm{h}}-\Delta \varepsilon$ is shown in Fig. 10 for the three sites. Approximately linear correlations are apparent. An interesting feature is the value of $\Delta \varepsilon$ for given values of $\varepsilon_{\mathrm{h}}$ at each site. $\Delta \varepsilon$ is higher at DF than at DK190 or MP, that 5 is, $\Delta \varepsilon$ is highest at the site where both the accumulation rate and wind speed is lowest among the three. The site DK190 contains many layers of compacted hard snow with $\varepsilon_{\mathrm{h}}$ values of $1.65-1.85$, equivalent to $\rho$ values of $\sim 390-\sim 500 \mathrm{~kg} \mathrm{~m}^{-3}$. These layers also have high values of $\Delta \varepsilon$ ranging from $\sim 0.05$ to 0.067 , causing fluctuations of $\Delta \varepsilon$ with depth. However, at DF, $\Delta \varepsilon$ values ranging from $\sim 0.05$ to 0.067 are attained for much 10 smaller values of $\varepsilon_{\mathrm{h}}$. If we disregard data points of compacted hard snow, the $\varepsilon_{\mathrm{h}}-\Delta \varepsilon$ relation at MP is similar to that at DK190. To demonstrate the sensitivity of $\Delta \varepsilon$ versus accumulation rate and wind speed of the sites, we extracted $\Delta \varepsilon$ values at a constant $\rho$ of $365 \mathrm{~kg} \mathrm{~m}^{-3}$, chosen simply as the mean value at MP. For convenience, we term it as $\Delta \varepsilon_{365}$. The $\Delta \varepsilon_{365}$ values versus accumulation rate and versus wind speed are 15 shown in Fig. 11. We find inverse correlation between $\Delta \varepsilon$ and both accumulation rate and wind speed. The effect of the lower accumulation late is explicable by the idea that longer residence time within the shallow portion of the ice sheet could enhance postdepositional metamorphism, as suggested in earlier studies (Courville et al., 2007; Hutterli et al., 2009; Kawamura et al., 2007). At the same time, the effect of the lower wind speed is also reasonably explicable by an idea that the heat of insolation at the surface of the ice sheet is better preserved near the surface without disturbance or mixing by wind. We will further attempt to analyse possible effects of the accumulation rate and the wind speed later in this paper.

The statistics of physical properties are given in Table 4. These values are compara25 ble with similar statistics of the 112.59-m-deep Dome Fuji firn (Table 2 in Fujita et al., 2009). The coefficients of the regression lines in Fig. 10 are listed in Table 5. At DK190, data points representing hard compacted snow apparently reduce the gradient of the linear regression line. This fact suggests that irregular insertions of the dune slightly reduce formation of vertical anisotropy. It is possible that this phenomenon is associ-

\section{Metamorphism of firn in Dronning Maud Land, East Antarctica}

S. Fujita et al.

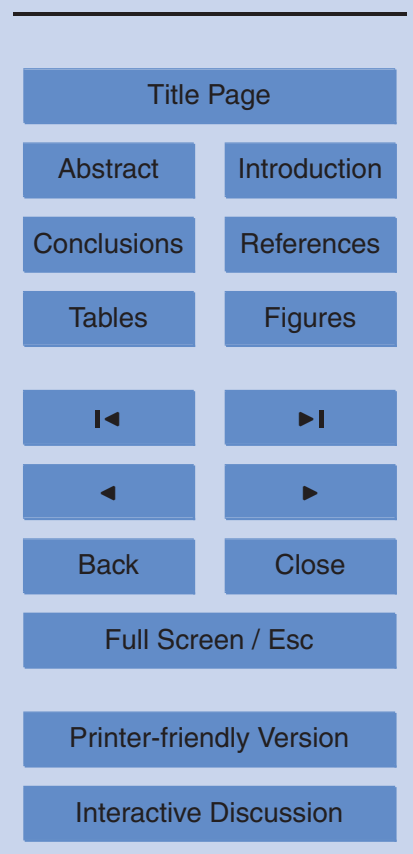


ated with rapid burial of thick dune layers during strong wind events, which reduces the residence time of the firn layer near the surface. It is also possible that such thick dune layers reduce amount of vertical vapour transport in temperature gradients. In the entire data set, we found no features indicating post-sampling deterioration that might 5 have significantly affected measured variables.

\subsubsection{Difference in the grain growth rate at the three pits}

Behaviour of grain size $D$ also indicates development of metamorphism. As a measure of grain growth, the mean grain size at a depth of $2 \mathrm{~m}$ (henceforth $D_{2 \mathrm{~m}}$ ) was calculated. A depth of $2 \mathrm{~m}$ was observed because effects of the temperature gradient are 10 much weaker at this depth than at upper depths. In Fig. $11, D_{2 m}$ is plotted versus accumulation rate and versus wind speed. Again clearly, $D_{2 m}$ increases with decreasing accumulation rate and with decreasing wind speed. We notice that the range of $D_{2 \mathrm{~m}}$ is largest at DF. In Fig. $12 \mathrm{a}, D_{2 \mathrm{~m}}$ is plotted against $\Delta \varepsilon_{365}$. We find that $D_{2 \mathrm{~m}}$ and $\Delta \varepsilon_{365}$ are correlated proportionally, suggesting that both are two different aspects of a series of metamorphism phenomena. $R$ is another measure of grain size. The mean value of $R$ at a depth of $2 \mathrm{~m}$ (henceforth $R_{2 \mathrm{~m}}$ ) was also calculated. In Fig. 12b, we confirm a linear correlation between $D_{2 m}$ and $R_{2 m}$, which is reasonable because $R$ is an indicator of $D$. In this plot, we again observe that the range of $R_{2 m}$ is largest at DF. Then, evolution of the $R-\rho$ relation is investigated in Fig. 13. Trajectories of the $R-\rho$ rela20 tion show how the $R$ - $\rho$ relation evolves with increasing depth. The original data are shown in Fig. 7. Two different trends are apparent in Fig. 13a. One is grain growth and densification as a large scale trend over metres. Another is the development of alternation of firn properties depending on its initial density. Light green arrows in Fig. 13a show suggested directions of alternation between IHDF (initially high density firn) with

higher density and finer grains and ILDF (initially low density firn) with lower density and coarser grains. Light orange arrows in Fig. 13a show the suggested direction of evolution of grain properties for IHDF and ILDF. At DF, a regular cyclic feature is observed in the trajectory. At DK190 and MP, gradients of $\Delta R / \Delta \rho$ (shown as inclination of the 
light green arrows) are apparently lower than $\Delta R / \Delta \rho$ at DF. At DK190 and MP, cyclic features is less clear, probably because of disturbance by very dense $\left(>380 \mathrm{~kg} \mathrm{~m}^{-3}\right)$ layers of hard compacted firn.

We can find many important features in the data of Fig. 13. The features of the 5 IHDF and the ILDF are kept distinct or become more distinct with increasing depth in the surface few metres, that is, their contrast in terms of density and grain size becomes stronger with metamorphism. In addition, this tendency is strongest at DF where both the accumulation rate and the wind speed are the smallest among the three sites. Behaviour of $\Delta \varepsilon$ was also dependent on $\rho$ as found in Fig. 10. All of the 10 parameters, $\rho, \Delta \varepsilon, D$ and hence $R$, show evolution of this contrast depending on the initial density of the firn. A plausible explanation for the evolution of the alternation is density-dependent growth of depth hoar (e.g., Pfeffer and Mrugala, 2002). In addition, the difference in thermal conductivity and air peameability between the IHDF and the ILDF should reinforce the contrasts in a positive sense: because the IHDF should have 15 higher thermal conductivity, the spatial gradient of temperature is steeper in the ILDF than in the IHDF. Then, transport of vapour from the permeable ILDF to less permeable IHDF results in more contrasted firn under the temperature gradient. Where the initial alternation is more distinct, this effect should have a positive feedback. We suggest that numerous strong contrasts of $\rho, \Delta \varepsilon, D$ and $R$, as observed in Figs. 5, 7, 9 and 13 are explicable by this positive feedback.

\subsubsection{Relative roles of accumulation rate and wind speed}

Based on dependencies of the measures of postdepositional metamorphism such as $\Delta \varepsilon_{365}, D_{2 \mathrm{~m}}, R_{2 \mathrm{~m}}$ and $\Delta R / \Delta \rho$ (Fig. 11 and Table 4) on the accumulation rate and the wind speed, we analysed roles of the accumulation rate and the wind speed for the postdepositional metamorphism. We assumed that these two factors act linearly to the metamorphism; simultaneous equations were solved to find linear coefficients for the accumulation rate and the wind speed. Statistical assessment was not possible because number of the data was the same as the number of variables to solve. The

\section{Metamorphism of firn in Dronning Maud Land, East Antarctica}

S. Fujita et al.

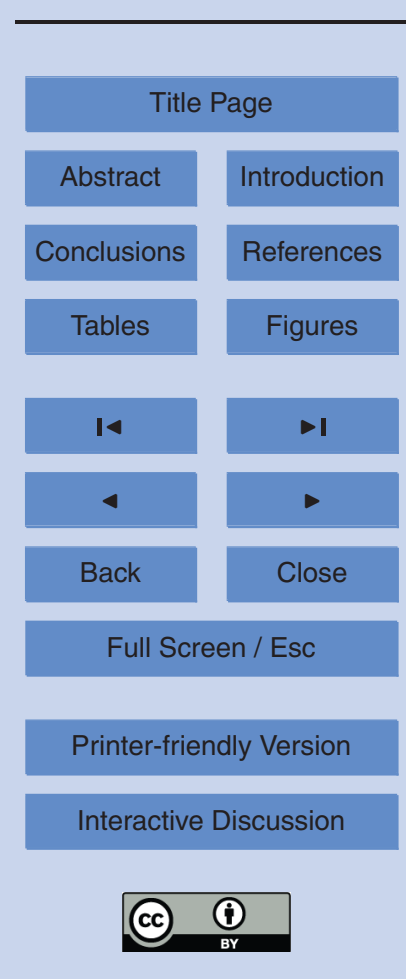


four sets of solutions are given in Table 6 . We note that both $\Delta \varepsilon_{365}$ and $\Delta R / \Delta \rho$ are measures of metamorphism with reference to density. Curiously, for variations of both, the solutions indicate that approximately $30 \%$ and $70 \%$ are explicable by variations of accumulation rate and by variations of wind speed, respectively. For the measures of

5 metamorphism with reference to density, the solutions implied that the wind speed has a dominant role. In contrast, both $D_{2 \mathrm{~m}}$ and $R_{2 \mathrm{~m}}$ are measures of grain growth. For variations of $D_{2 \mathrm{~m}}$, approximately $80 \%$ and $20 \%$ are explicable by variations of accumulation rate and by variations of wind speed, respectively. For variations of $R_{2 \mathrm{~m}}$, approximately $60 \%$ and $40 \%$ are explicable by variations of accumulation rate and by variations of 10 wind speed, respectively. For $D_{2 m}$ and $R_{2 m}$, we can suggest the variations of accumulation rate commonly had larger effect than wind. Although our analysis has a limitation in terms of statistical assessment, we suggest that the postdepositional metamorphism at the study sites is caused by interplay of both variations of accumulation rate and of variations of wind speed. We suggest that both are essential factors to determine the 15 postdepositional metamorphism. For both $\Delta \varepsilon_{365}$ and $\Delta R / \Delta \rho$, reduction of temperature gradient by wind mixing seems to work strongly. In contrast, for $D_{2 \mathrm{~m}}$ and $R_{2 \mathrm{~m}}$, the solutions seem to suggest that residence time near the surface is more influential. This implies that total amount of heat wave by insolation is a primariy controlling factor for grain growth rathar than temperature gradient caused by diurnal cycles.

\subsection{Effect of the strong wind events}

We again note that the depositional environment at DK190 and MP is characterized by more windy conditions than at DF (see Table 1). Birnbaum et al. (2010) have shown that wind-driven dunes have an initial density of $380-500 \mathrm{~kg} \mathrm{~m}^{-3}$ at EPICA DML (Kohnen). This density range is the same as the compacted hard snow observed in the pits and snow surfaces along the JASE traverse (see Figs. 4d,f, 5 and 7). Birnbaum et al. (2010) reported that the formation of snow dunes only occurred with wind speeds of $>10 \mathrm{~m} \mathrm{~s}^{-1}$, which are caused by a low-pressure system at EPICA DML. Based on these observations, we can reasonably assume that the observed compacted hard

\section{Metamorphism of firn in Dronning Maud Land, East Antarctica}

S. Fujita et al.

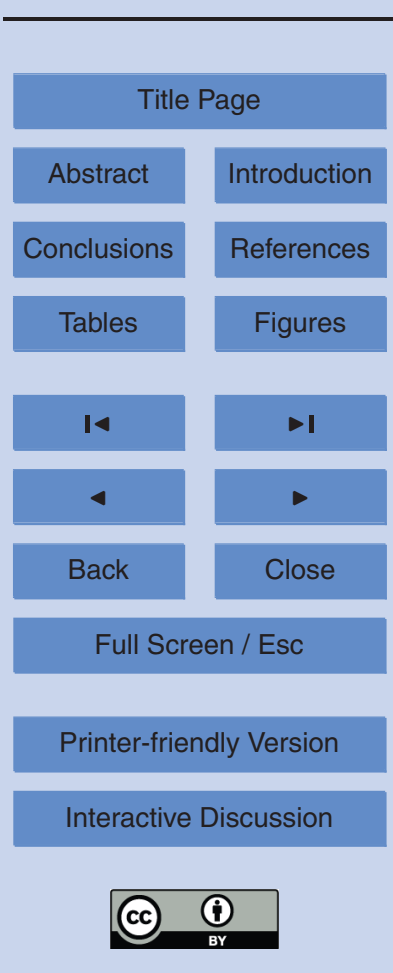


snow layers were formed by the strong wind events. The new data of $\Delta \varepsilon$ show that compacted snow in dunes attain high values of $\Delta \varepsilon$. This suggests that initial $\rho$ is a factor determining $\Delta \varepsilon$ regardless of the causes of the higher density, which could be wind and/or heat/vapour flux. The difference in mean density between the three pits 5 (Table 4) is apparently due to the wind effects and not heat flux considering the small differences in temperature. Heat flux will be discussed in the next section.

\subsection{Densification effects associated with heat flux and weak wind}

Both Koerner (1971) and Shiraiwa et al. (1996) reported that IHDF layers have their origin in surface layers in summer, in Plateau Station (Fig. 1) and Dome Fuji region, 10 respectively. In particular, Koerner (1971) found that the IHDF formed when a drift of surface hoar formed from weak wind (wind velocity $>\sim 4 \mathrm{~m} \mathrm{~s}^{-1}$ ), based on thorough investigation of the effect of summer warmth and solar radiation through stratigraphic comparisons in early December and late January. He found that ice bridges formed between grains. Fujita et al. (2008) also reported in an initial report of the JASE traverse that the IHDF formed in a very short period of time near midsummer through a comparison of snow type and density at the beginning of December 2007 and in mid-January 2008 along a $\sim 300 \mathrm{~km}$ long traverse route between MD364 (see Fig. 1) and DF. The data are similar to that in Fig. 4, but for different legs of the JASE traverse. They made numerous density measurements and found that hard and compacted snow appeared in the top few centimetres of the ice sheet presumably owing to drifted hoar by weak wind (see Fig. 2 for the associated meteorological conditions), and the average snow density changed from $\sim 300 \mathrm{~kg} \mathrm{~m}^{-3}$ to $\sim 370 \mathrm{~kg} \mathrm{~m}^{-3}$ in the top $3 \mathrm{~cm}$ between the two sets of measurements. Koerner (1971) observed this annual alternation of firn types down to a depth of $10 \mathrm{~m}$. Our data at DF (Figs. 7a and 14a) support Koerner (1971)'s
Metamorphism of firn in Dronning Maud Land, East Antarctica

S. Fujita et al.

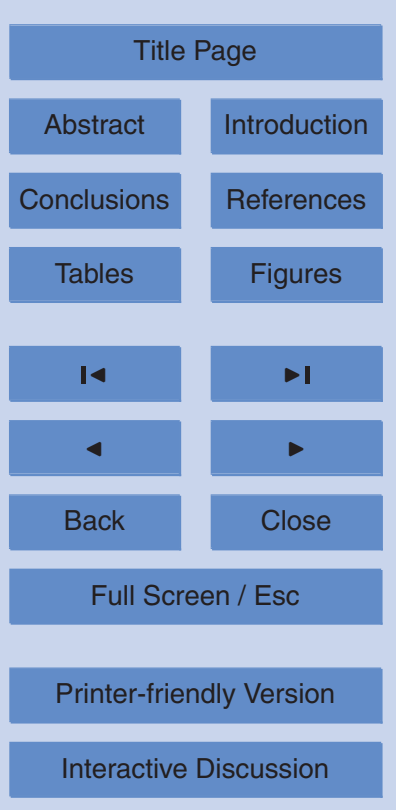

Interactive Discussion 
We again note that the surface is the interface where ice sheet is exposed to heat fluxes, temperature gradients, snow accumulation, wind and atmosphere. When insolation provides heat flux in summer, vapour flux should occur at the surface in both the upper and lower directions due to the gradient of temperature and vapour pressure.

5 The short wave radiation can penetrate and heat the surface few millimetres of the firn (e.g., Colbeck, 1983). Thus, the surface is a source of vapour production in the daytime. To verify this hypothesis, a set of data was obtained on the day of the summer solstice during the JASE traverse. The temperature within very shallow snow at $1 \mathrm{~cm}, 3 \mathrm{~cm}$ and $10 \mathrm{~cm}$ was measured every few hours, and shown in Fig. 14 along with 10 the continuous data of the air temperature at $3.9 \mathrm{~m}$ height. Although this period was not a typical clear sky day (see Fig. 2 for meteorological conditions), temperature and wind speed show diurnal cycles typical of summer in this area. We see in Fig. 14 that surface temperature is the highest in the daytime compared with firn underneath and air above. In particular, around the time of local noon (10:00 11:00 UTC), the surface $151-\mathrm{cm}$ temperature is markedly high. On the contrary, at night time (white night) when the elevation angle of the sun is low, the surface $1 \mathrm{~cm}$ has the lowest temperature compared to the air and deeper snow. This means that at night time (indicated by letters $C$ in Fig. 14), condensation of vapour is concentrated at the surface because the cooling air releases condensed water here.

The initial formation of snow strata at and near the surface of the ice sheet has long been a topic of discussion (e.g., Alley, 1988; Dang et al., 1997; Li and Zwally, 2004; Zhou et al., 2002) in attempts to explain the density strata in numerical models. We note that densification of firn at the surface in summer of observed large scale of values from $\sim 300 \mathrm{~kg} \mathrm{~m}^{-3}$ to $\sim 370 \mathrm{~kg} \mathrm{~m}^{-3}$ was not reproduced by earlier modelling efforts for runs for low accumulation sites even after introducing effects of the vertical movement of vapour flux in the models. Rather, some model outputs suggest that the surface layer in summer becomes the less dense layer due to heat flux and consequent vapour loss, which is opposite to the observations near Dome Fuji and Plateau Station. A frequently used assumption in earlier discussions is that the upward vapour flow escapes into

\section{TCD}

$6,1205-1267,2012$

\section{Metamorphism of firn in Dronning Maud Land, East Antarctica}

S. Fujita et al.

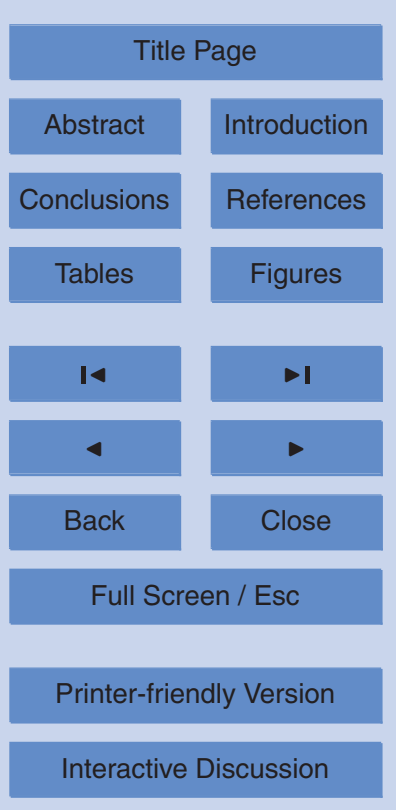


the surface atmosphere, so no contribution is assumed for firn layer densification from upward vapour reaching the surface. However, it seems natural that in diurnal cycles in summer, the firn and the near surface atmosphere continually exchange vapour: vapour saturated in the near surface atmosphere in the daytime would condense at 5 and near the surface of the firn at night time. This diurnal cycle repeats every day over a larger seasonal cycle of temperature that is highest within a few days of the summer solstice. In days before and after the summer solstice, evaporation and condensation should dominate at the surface, respectively, because of the background seasonal temperature cycle. We propose that the cause of the observed late-summer densification is 10 condensation of vapour on the surface. Vapour flux to the surface partly enhances crystal growth by providing vapour to the existing firn matrix. The vapour flux concentrated on the ice sheet surface also partly appears as frost hoar on the surface. The JASE traverse teams observed the frost hoar sometimes at night, as reported in an earlier study (lizuka et al., 2004). Surface frost is fragile and easily redistributed by weak wind 15 as observed by Koerner (1971) at Plateau Station. For dune-formation events, high wind speeds $\left(>10 \mathrm{~m} \mathrm{~s}^{-1}\right)$ are necessary (Birnbaum et al., 2010). However, for the frost hoar on the surface, weak wind (wind velocity $>\sim 4 \mathrm{~m} \mathrm{~s}^{-1}$ ) is sufficient for redistribution of fine particles (Koerner, 1971). Such weak wind blows almost every day (see Fig. 2). On the ice sheet, such fragmented fine particles redistribute every night forming a thin 20 surface deposition of them. We again note that there is no seasonality in the accumulation rate at present DF: two independent data sets are given in Fig. 15. According to these, the monthly accumulation rate at DF is of the order of $\sim 2 \mathrm{~kg} \mathrm{~m}^{-2}$ month $^{-1}$ in December and January in the present climate. We comment here that a recent claim by Laepple et al. $(2011 \mathrm{a}, \mathrm{b})$ that there is a strong seasonality in the accumulation rate 25 (more than $\pm 30 \%$ ) in plateau of East Antarctica at present climate is not the case at DF or near EPICA DML (Reijmer and Van den Broeke, 2003). Even under dominance of surface sublimation (evaporation) from the surface in the daytime, a positive increment of the snow surface has been detected. The redistributed fine particles can be closely packed because they are fragmented; therefore, nearest neighbours touching

\section{Metamorphism of firn in Dronning Maud Land, East Antarctica}

S. Fujita et al.

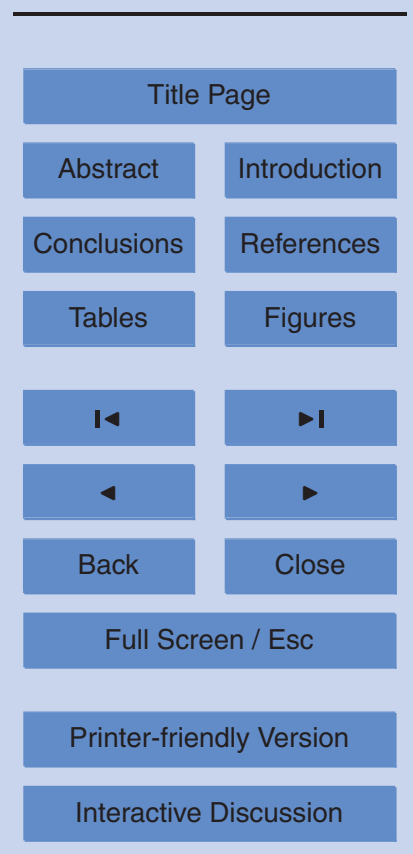


each other sinter together and make the snow mechanically stable and hard within a short time. Even without fragmentation of the surface hoar, densification by condensation connects grains with each other, constricting grain growth. Such surface layers repeatedly receive heat flux in the daytime. We propose that the typical correlation be5 tween higher $\rho$ and smaller $D$ is associated with this densification that occur at the surface. Further grain growth is restricted in such firn because neighbouring grains constrict growth with each other. In contrast, in the ILDF, there are more pore spaces where grains can grow to be coarser. This proposed process is an interplay of heat flux with insolation, temperature gradient both in the firn and in the air caused by insolation, 10 and quite ordinary weak wind in diurnal cycles over the polar plateau in summer. Thus, we suggest that the key factor for the entire process is insolation. We summarized the proposed process in Fig. 16 and Table 7.

A question then arises whether or not the snow accumulation rate influences the initial densification process on the high elevation ice divides such as DF. Here, we do 15 not discuss sites with very different conditions, such as sites characterized with very windy conditions on the slope of the katabatic wind zone, much warmer coastal sites or sites where the accumulation regime is highly synoptically induced. There are too many factors to consider when we compare data from such a variety of sites. We simply consider halving or doubling of the accumulation rate compared with the low accumulation rate of the present DF. We note that the proposed surface densification is an interfacial process, rather than processes that occur in the volume of firn. Major portion of densification is highly limited spatially within the very surface centimetres of the ice sheet. In addition, the monthly accumulation rate at DF is as small as $\sim 2 \mathrm{~kg} \mathrm{~m}^{-2}$ month $^{-1}$ in December and January in the present climate (Kameda et al., 2008; Fujita and Abe, 2006). Either halving or doubling of the accumulation rate would result in shifts of the depths of densification by less than a few millimetres. Therefore, we propose that the initial densification at the surface is virtually unaffected by changes in the accumulation rate.

\section{TCD}

$6,1205-1267,2012$

\section{Metamorphism of firn in Dronning Maud Land, East Antarctica}

S. Fujita et al.

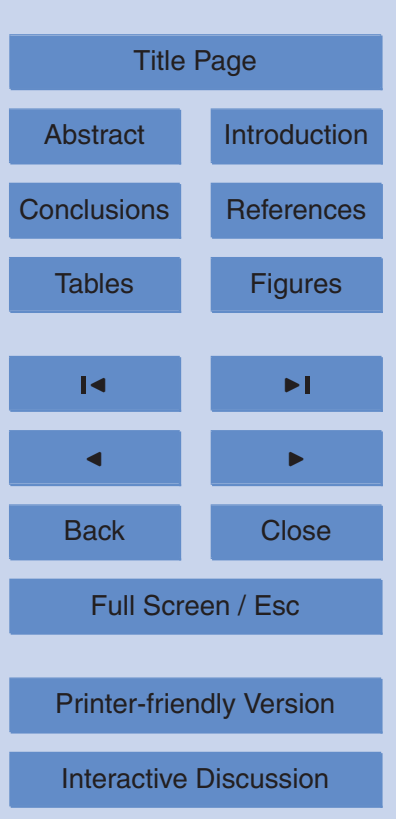




\subsection{Implications for modelling a phase link between summer insolation and ice core gas records}

Based on the results and discussion in this study, we suggest that a physically based model that calculates insolation-induced relative changes in metamorphism requires an initial densification process of the ice sheet surface in addition to the exposure of firn layers to temperature gradient. More correctly, processes summarized in Fig. 16 and Table 7 need to be considered. Without the critical initial process of densification at the surface, the models could result in unreliable, highly hypothetical estimation of the phase shift between the development of metamorphism and local summer soldominant imprint of insolation of physically based simulations, in addition to comments made in Sect. 1.3. Moreover, wind clearly plays various roles for both formation and postdepositional metamorphism of the firn layers. Based on the proposed processes in Fig. 16 and Table 7, the most influential factor is always local summer insolation, which 15 implies that the real phase shift between the development of metamorphism and local summer solstice insolation is rather small, compared with the modelling using only vapour flux within firn in the calculation.

We also note that we need to model a relation between the local summer solstice insolation and duration of the bubble formation zone, to reliably interpret local insolation proxies used for astronomical dating of deep ice cores. This is a complex causal chain, as described in Sect. 1.2. We need to study the still poorly understood highresolution mechanical processes within the IHDF and the ILDF throughout the densification from the surface to pore close-off. The crossover of density is an essential process to consider. The potential of the chemical impurities as an enhancement facseems unlikely that the destructive deformation within the ILDF during the crossover of density is explicable by chemistry.
Metamorphism of firn in Dronning Maud Land, East Antarctica

S. Fujita et al.

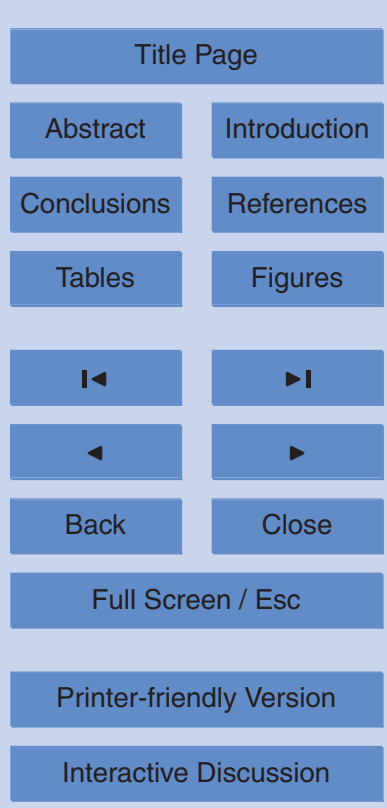


Another implication of this study is that metamorphism strength could be highly influenced by wind conditions. Then, $\mathrm{O}_{2} / \mathrm{N}_{2}$-based orbital tuning dating and TAC-based orbital tuning dating will be affected by wind conditions. Stronger wind at some stage of the climate cycle may produce more fluctuations in the density strata of firn, and thus 5 result in bias or disturbance in the $\mathrm{O}_{2} / \mathrm{N}_{2}$ ratio data and TAC data. In the present late Holocene condition, DF is a site characterized by weak wind compared with surrounding sites in DML such as DK190, MP and EPICA DML (e.g., Fujita et al., 2011; Lenaerts and Van den Broeke, 2012; Van den Broeke and Van Lipzig, 2003; Van Lipzig et al., 2004). Nevertheless, we propose that wind speed is one factor to be considered when 10 examining the $\mathrm{O}_{2} / \mathrm{N}_{2}$ data and TAC data from deep ice cores from multiple locations or from different ages of the climate cycles.

\section{Concluding remarks}

Based on thorough observations of snow surface conditions, pit studies, laboratory measurements and meteorological observations, we investigated the initial stage of 15 postdepositional metamorphism in polar firn at sites located under spatial variations of accumulation rate and wind speed along the East Antarctic ice divide near Dome Fuji. The major findings and suggestions are summarized as follows.

1. Formation of the initial strata occurs at the surface of the firn. And then, postdepositional metamorphism occurs most strongly within $\sim 0.1 \mathrm{~m}$ of the surface. Initial formation of the density strata at the surface determines the strength of development of metamorphism due to the temperature gradient. Development of metamorphism is directly correlated to the mechanical strength of the firn, causing crossover of density in deeper firn.

2. For the initial formation of the density strata at the surface, the heat flux, temperature gradient and the exchange of vapour between the air and firn in both

\section{Metamorphism of firn in Dronning Maud Land, East Antarctica}

S. Fujita et al.

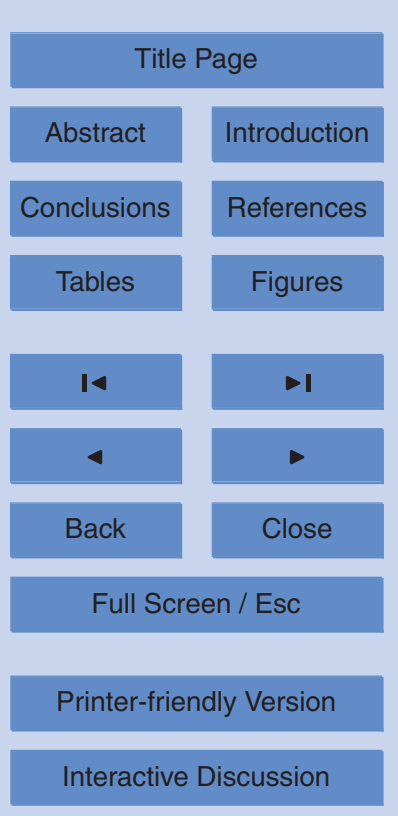


directions are essentially due to insolation. This condition explains why the insolation signature is retained throughout the firn, influencing gas trasnport during bubble close-off. In addition, the initial formation of the density strata is an interfacial phenomena, which is virtually unaffected by changes (such as doubling or halving) in low accumulation rate.

3. The insolation-based temperature gradient enhances postdepositional metamorphism within subsurface volume of firn depending on its initial density. The accumulation rate modulate residence time of firn in the zone of the diurnal and seasonal cycles of temperature gradient. This influences development of metamorphism with efficiency estimated in Table 7.

4. Wind also play important roles in various ways. Average wind speed in summer can modulate amplitude of the diurnal cycles of temperature gradient. As a result, higher average wind speed influences development of metamorphism with efficiency estimated in Table 7 . In addition, even weak wind can cause fragmentation of the frost hoar that occur at summer nights. Moreover, at sites with more windy conditions, the strata contain more layers of compacted snow with higher $\rho$ and $\Delta \varepsilon$ due to wind slabs and dunes, and thus have larger amplitude of density fluctuations.

5. The processes summarized in Fig. 16 and Table 7 need to be considered in models of the density strata formation. In addition, development of metamorphism in polar ice sheet can also be investigated using $\Delta \varepsilon, \rho, R$ and $D$ as useful measures at many other sites. Then, effects of many controlling factors can be better understood.

6. Possible phase differences between development of metamorphism and local summer solstice insolation, which potentially occurs with a probability of less than a few percent, were proposed in a previous study (Hutterli et al., 2009) without consideration of the surface densification. In addition, the causal chain from in-

\section{Metamorphism of firn in Dronning Maud Land, East Antarctica}

S. Fujita et al.

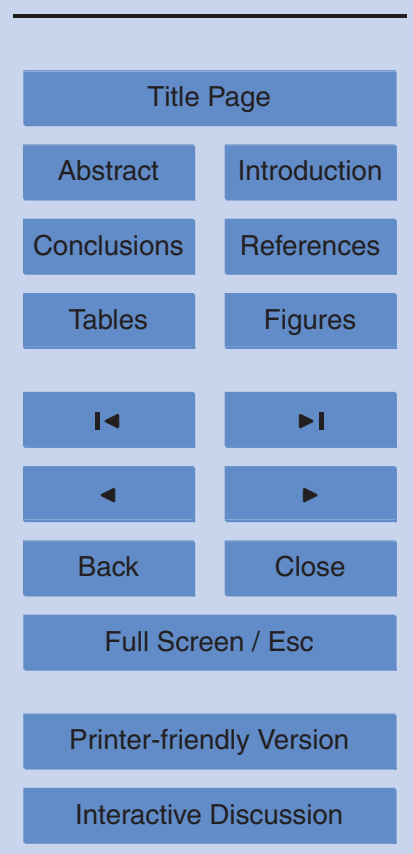

\section{6}


solation to $\mathrm{O}_{2} / \mathrm{N}_{2}$ and TAC is quite long and complex, including processes of formation, metamorphism and deformation. Thus, future modelling works should include these essential processes; it seems premature to assert some absolute numbers of the phase shift. The possible phase shift could be even smaller than first claimed because of the dominant interfacial densification effect due to insolation, which was missing from previous studies. Considering all the discussions in this work, for most of $\mathrm{O}_{2} / \mathrm{N}_{2}$ time markers of deep ice cores at least at $D F$, the possible phase shift is less than 1 or $2 \mathrm{ka}$.

7. Another topic to be developed in future is counting annual layers of the Holocene part of ice cores using $\Delta \varepsilon, \rho, R$ and/or $D$. We now understood that how these parameters behave in layered strata. Even if accumulation rate is low, if the site is characterized by weak wind, it is worth the attempt to count annual layers to deeper depths to understand the accumulation rate history at DF over the Holocene.

15 Acknowledgements. The JASE traverse was lead by National Institute of Polar Research (NIPR), Tokyo, the Swedish Polar Research Secretariat (SPRS), Stockholm University and other institutes. The traverse was fully supported by the teams of the 48th and 49th Japanese Antarctic Research Expeditions led by H. Miyaoka and S. Imura, respectively. Special thanks go to members of the traverse, $\mathrm{H}$. Kaneko, K. Taniguchi and N. Shiga, for their very generous

20 support during the traverse. The production of this paper was supported by an NIPR publication subsidy. This research was supported by a Grant-in-Aid for Scientific Research (A) 20241007 from the Japan Society for the Promotion of Science (JSPS).

\section{References}

Alley, R. B.: Concerning the deposition and diagenesis of strata in polar firn, J. Glaciol., 34, $25 \quad 283-290,1988.1207,1221,1225$

Alley, R. B., Bolzan, J. F., and Whillans, I. M.: Polar firn densification and grain growth, Ann. Glaciol., 3, 7-11, 1982. 1207, 1221, 1231

\section{Metamorphism of firn in Dronning Maud Land, East Antarctica}

S. Fujita et al.

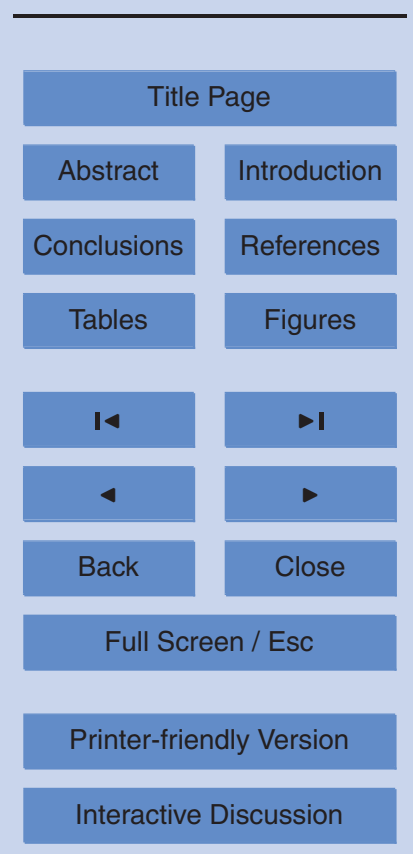


Aoki, T., Aoki, T., Fukabori, M., Hachikubo, A., Tachibana, Y., and Nishio, F.: Effects of snow physical parameters on spectral albedo and bidirectional reflectance of snow surface, J. Geophys. Res., 105, 10219-10236, doi:10.1029/1999JD901122, 2000. 1219, 1223

Arnaud, L., Barnola, J.-M., and Duval, P.: Physical modeling of the densification of snow/firn 5 and ice in the upper part of the polar ice sheets, in: Physics of Ice Core Records, Hondoh, T. (ed.), Hokkaido University Press, Sapporo, 285-305, 2000. 1207

Bamber, J. L., Gomez-Dans, J. L., and Griggs, J. A.: Antarctic $1 \mathrm{~km}$ Digital Elevation Model (DEM) from Combined ERS-1 Radar and ICESat Laser Satellite Altimetry, in: National Snow and Ice Data Center, Digital media, Boulder, Colorado, USA, 2009. 1255

10 Bender, M. L.: Orbital tuning chronology for the Vostok climate record supported by trapped gas composition, Earth Planet. Sci. Lett., 204, 274-289, doi:10.1016/S0012-821X(02)00980-9, 2002. 1208, 1211

Birnbaum, G., Freitag, J., Brauner, R., König-Langlo, Schulz, G. E., Schulz, E., Kipfstuhl, S., Oerter, H., Reijmer, C. H., Schlosser, E., Faria, S. H., Ries, H., Loose, B., 15 Herber, A., Duda, M. G., Powers, J. G., Manning, K. W., and Van den Broeke, M. R.: Strong-wind events and their influence on the formation of snow dunes: observations from Kohnen Station, Dronning Maud Land, Antarctica, J. Glaciol., 56(199), 891-902, doi:10.3189/002214310794457272, 2010. 1213, 1214, 1229, 1232

Colbeck, S. C.: Theory of metamorphism of dry snow, J. Geophys. Res., 88, 5475-5482, doi:10.1029/JC088iC09p05475, 1983. 1207, 1231

Courville, Z. R., Albert, M. R., Fahnestock, M. A., Cathles, L. M. I., and Shuman, C. A.: Impacts of an accumulation hiatus on the physical properties of firn at a low-accumulation polar site, J. Geophys. Res., 112, F02030, doi:10.1029/2005JF000429, 2007. 1207, 1226

Dang, H., Genthon, C., and Martin, E.: Numerical modeling of snow cover over polar ice sheets, Ann. Glaciol., 25, 170-176, 1997. 1207, 1231

Freitag, J., Wilhelms, F., and Kipfstuhl, S.: Microstructure-dependent densification of polar firn derived from X-ray microtomography, J. Glaciol., 50, 243-250, doi:10.3189/172756504781830123, 2004. 1207, 1221, 1224

Freitag, J., Kipfstuhl, S., and Faria, S. H.: The connectivity of crystallite agglomerates in lowdensity firn at Kohnen station, Dronning Maud Land, Antarctica, Ann. Glaciol., 49, 114-120, doi:10.3189/172756408787814852, 2008. 1223, 1224

Fujita, K. and Abe, O.: Stable isotopes in daily precipitation at Dome Fuji, East Antarctica, Geophys. Res. Lett., 33, L18503, doi:10.1029/2006GL026936, 2006. 1233, 1266

\section{Metamorphism of firn in Dronning Maud Land, East Antarctica}

S. Fujita et al.

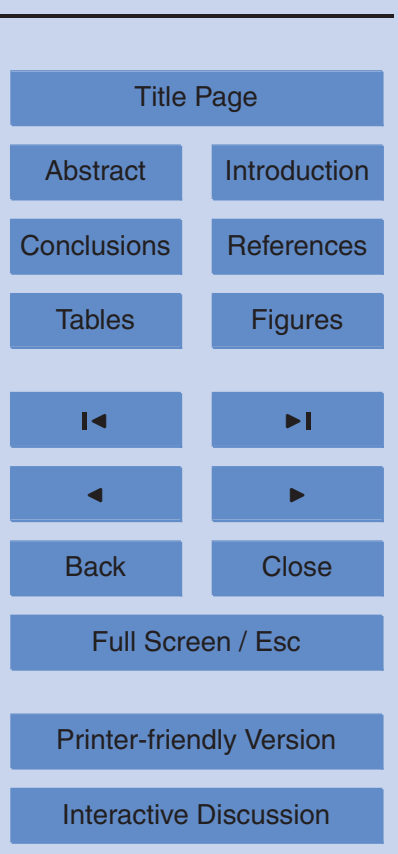


Fujita, S., Enomoto, H., Kameda, T., Motoyama, H., and Sugiyama, S.: Changes of surface snow density in a summer in the Antarctic Dome Fuji region, paper presented at SCAR/IASC IPY Open Science Conference, 1.9/O06, 273-274, ISBN:978-5-98364-013-09, Assoc. of Polar Early Career Sci., St. Petersburg, Russia, 8-11 July 2008. 1211, 1230

5 Fujita, S., Okuyama, J., Hori, A., and Hondoh, T.: Metamorphism of stratified firn at Dome Fuji, Antarctica: a mechanism for local insolation modulation of gas transport conditions during bubble close off, J. Geophys. Res., 114, F03023, doi:10.1029/2008JF001143, 2009. 1207, 1208, 1209, 1211, 1217, 1224

Fujita, S., Holmlund, P., Andersson, I., Brown, I., Enomoto, H., Fujii, Y., Fujita, K., Fukui, K., Furukawa, T., Hansson, M., Hara, K., Hoshina, Y., Igarashi, M., lizuka, Y., Imura, S., Ingvander, S., Karlin, T., Motoyama, H., Nakazawa, F., Oerter, H., Sjöberg, L. E., Sugiyama, S., Surdyk, S., Ström, J., Uemura, R., and Wilhelms, F.: Spatial and temporal variability of snow accumulation rate on the East Antarctic ice divide between Dome Fuji and EPICA DML, The Cryosphere, 5, 1057-1081, doi:10.5194/tc-5-1057-2011, 2011. 1212, 1220, 1235, 1245, 1255

Gerland, S., Oerter, H., Kipfstuhl, J., Wilhelms, F., Miller, H., and Miners, W. D.: Density log of a $181 \mathrm{~m}$ long ice core from Berkner Island, Antarctica, Ann. Glaciol., 29, 215-219, doi:10.3189/172756499781821427, 1999. 1207, 1224

Gow, A. J.: On the accumulation and seasonal stratification of snow at the South Pole, J. Glaciol., 5, 467-477, 1965. 1207, 1221

Hawley, R. L. and Morris, E. M.: Borehole optical stratigraphy and neutronscattering density measurements at Summit, Greenland, J. Glaciol., 52, 491-496, doi:10.3189/172756506781828368, 2006. 1207

Holmlund, P. and Fujita, S.: Japanese-Swedish Antarctic Expedition JASE, in: Swedish Polar Secretariat Year Book 2008, edited by: Thorén A., Swedish Polar Research Secretariat, Stockholm, 18(E1), ISSN:1402-2613, ISBN:978-91-973879-8-9, 2009. 1212

Hondoh, T.: Physics of Ice Core Records, Hokkaido University Press, Sapporo, 459 pp., 2000. 1207

Hörhold, M. W., Albert, M., and Freitag, J.: The impact of accumulation rate on anisotropy and air permeability of polar firn at a high-accumulation zone, J. Glaciol., 55, 625-630, doi:10.3189/002214309789471021, 2009. 1207

6, 1205-1267, 2012

\section{Metamorphism of firn in Dronning Maud Land, East Antarctica}

S. Fujita et al.

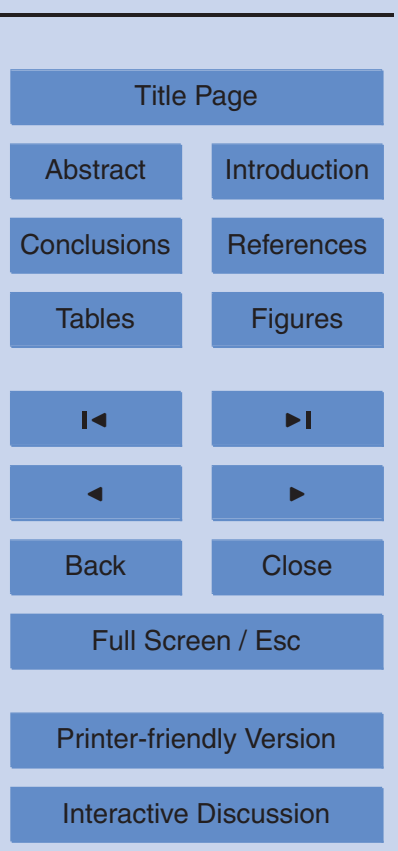


Hörhold, M. W., Kipfstuhl, S., Wilhelms, F., Freitag, J., and Frenzel, A.: The densification of layered polar firn, J. Geophys. Res., 116, F01001, doi:10.1029/2009JF001630, 2011. 1207, 1209, 1211, 1224, 1234

Huber, C., Beyerle, U., Leuenberger, M., Schwander, J., Kipfer, R., Spahni, R., Severinghaus, J. P., and Weiler, K.: Evidence for molecular size dependent gas fractionation in firn air derived from noble gases, oxygen, and nitrogen measurements, Earth Planet. Sc. Lett., 243, 61-73, doi:10.1016/j.epsl.2005.12.036, 2006. 1208

Hutterli, M. A., Freitag, J., Kipfstuhl, S., Schneebeli, M., and Röthlisberger, R.: Orbital tuning of ice core age scales: improvements with a physically based model, Geophys. Res. Abstr.,

10 EGU General Assembly 2008, 10, EGU2008-A-04142, Vienna, Austria, 13-18 April 2008, 2008. 1208

Hutterli, M. A., Schneebeli, M., Freitag, J., Kipfstuhl, J., and Röthlisberger, R., Impact of local insolation on snow metamorphism and ice core records, in: Physics of Ice Core Records II : Papers collected after the 2nd International Workshop on Physics of Ice Core Records, Kagaku T., Hondoh, T. (eds.), Sapporo, Japan, 2-6 February 2007, 223-232, 2009. 1211, 1226, 1236

lizuka, Y., Fujii, Y., Hirasawa, N., Suzuki, T., Motoyama, H., Furukawa, T., and Hondoh, T.: $\mathrm{SO}_{4}^{2-}$ minimum in summer snow layer at Dome Fuji, Antarctica, and the probable mechanism, J. Geophys. Res., 109, D04307, doi:10.1029/2003JD004138, 2004. 1232

20 Ikeda-Fukazawa, T., Fukumizu, K., Kawamura, K., Aoki, S., Nakazawa, T., and Hondoh, T.: Effects of molecular diffusion on trapped gas composition in polar ice cores, Earth Planet. Sc. Lett., 229, 183-192, doi:10.1016/j.epsl.2004.11.011, 2005. 1208

Ingvander, S., Jansson, P., Brown, I. A., Fujita, S., Sugyama, S., Surdyk, S., Enomoto, H., and Holmlund, P.: Snow particle sizes and its distributions in Dronning Maud Land, Antarctica, at sample, local and regional scales, Polar Res., submitted, 2012. 1212

Jones, R. G.: The measurement of dielectric anisotropy using a microwave open resonator, J. Phys. D. Appl. Phys., 9, 819-827, doi:10.1088/0022-3727/9/5/015, 1976. 1217, 1218, 1247

Kameda, T., Motoyama, H., Fujita, S., and Takahashi, S.: Temporal and spatial variability of surface mass balance at Dome Fuji, East Antarctica, by the stake method from 1995 to $30 \quad$ 2006, J. Glaciol., 54, 107-116, doi:10.3189/002214308784409062, 2008. 1214, 1233, 1266 Kawamura, K., Nakazawa, T., Aoki, S., Fujii, Y., Watanabe, O., and Severinghaus, J.: Close resemblance between local summer insolation, $\mathrm{O}_{2} / \mathrm{N}_{2}$ and total air content from the Dome

\section{Metamorphism of firn in Dronning Maud Land, East Antarctica}

S. Fujita et al.

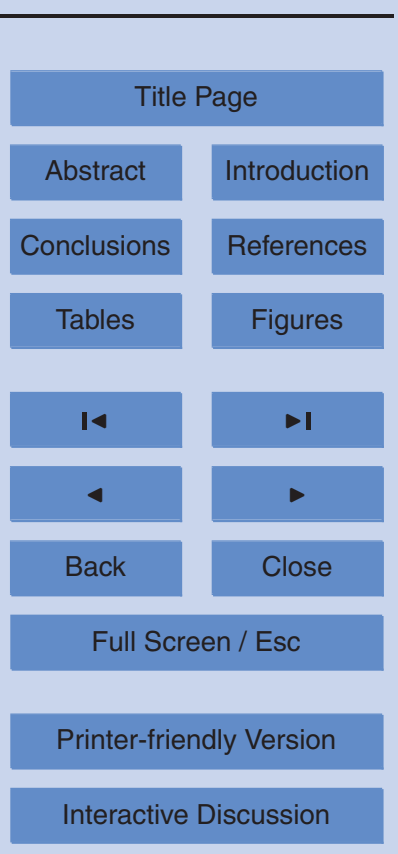


Fuji ice core, Antarctica, Eos Trans. AGU, 85, Fall Meet. Suppl., Abstract C33C-0356, 2004. 1208

Kawamura, K., Parrenin, F., Lisiecki, L., Uemura, R., Vimeux, F., Severinghaus, J. P., Hutterli, M. A., Nakazawa, T., Aoki, S., Jouzel, J., Raymo, M. E., Matsumoto, K., Nakata, H.,

$5 \quad$ Motoyama, H., Fujita, S., Azuma, K., Fujii, Y., and Watanabe, O.: Northern Hemisphere forcing of climatic cycles over the past 360000 yrs implied by accurately dated Antarctic ice cores, Nature, 448, 912-916, doi:10.1038/nature06015, 2007. 1208, 1211, 1226

Keller, L. M., Lazzara, M. A., Thom, J. E., Weidner, G. A., and Stearns, C. R.: Antarctic Automatic Weather Station data for the calendar year 2009, Space Science and Engineering

10 Center, University of Wisconsin, Madison, Wisconsin, 2010. 1245

Koerner, R. M.: A stratigraphic method of determining the snow accumulation rate at Plateau Station, Antarctica, and application to South Pole-Queen Maud Land Traverse 2, 19651966, in: Antarctic ice studies II, edited by: Crary, A. P., AGU, Washington DC, 225-238, doi:10.1029/AR016p0225, 1971. 1209, 1211, 1222, 1230, 1232

15 Komiyama, B., Kiyokawa, M., and Matsui, T.: Open resonator for precision dielectric measurements in the $100 \mathrm{GHz}$ band, IEEE Trans. Microwave Theory Tech., 39, 1792-1796, doi:10.1109/22.88556, 1991. 1217, 1247

Kovacs, A., Gow, A. J., and Morey, R. M.: The in-situ dielectric constant of polar firn revisited, Cold Reg. Sci. Technol., 23, 245-256, doi:10.1016/0165-232X(94)00016-Q, 1995. 1222, $20 \quad 1259$

Laepple, T., Werner, M., and Lohmann, G.: Synchronicity of Antarctic temperatures and local solar insolation on orbital timescales, Nature, 471, 91-94, doi:10.1038/nature09825, 2011a. 1232

Laepple, T., Werner, M., and Lohman, G.: Antarctic accumulation seasonality reply, Nature, 479, E2-E4, 2011b. 1232

Lenaerts, J. T. M., and Van den Broeke, M. R: Modeling drifting snow in Antarctica with a regional climate model, part II: results, J. Geophys. Res., 117, D05109, doi:10.1029/2010JD015419, 2012. 1235

$\mathrm{Li}, \mathrm{J}$. and Zwally, H. J.: Modeling the density variation in the shallow firn layer, Ann. Glaciol., 38, 309-313, doi:10.3189/172756404781814988, 2004. 1231

Lipenkov, V. Y., Raynaud, D., Loutre, M.-F., and Duval, P.: On the potential of coupling air content and $\mathrm{O}_{2} / \mathrm{N}_{2}$ from trapped air for establishing an ice core chronology tuned on local insolation,

\section{Metamorphism of firn in Dronning Maud Land, East Antarctica}

S. Fujita et al.

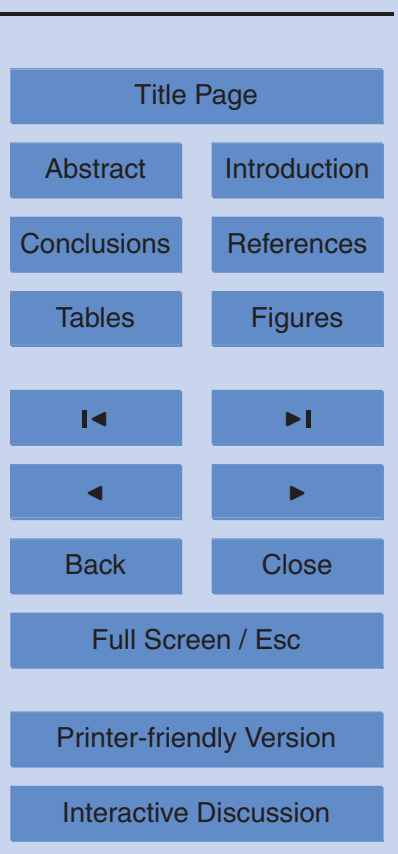


Quaternary Research Reviews, 30, 3280-3289, doi:10.1016/j.quascirev.2011.07.013, 2011. 1208, 1209, 1211

Lipenkov, V. Y.: Air bubbles and air-hydrate crystals in the Vostok ice core, in: Physics of Ice Core Records, Hondoh, T. (ed.), Hokkaido University Press, Sapporo, 327-358, 2000. 1210

5 Lytle, V. I. and Jezek, K. C.: Dielectric permittivity and scattering measurements of Greenland firn at 26.5-40 GHz, IEEE Trans. Geosci. Remote Sens., 32, 290-295, doi:10.1109/36.295044, 1994. 1217, 1222

Maeno, N. and Ebinuma, T.: Pressure sintering of ice and its implications to the densification of snow at polar glaciers and ice sheets, J. Phys. Chem., 87, 4103-4110, 10 doi:10.1021/j100244a023, 1983. 1207

Matsuoka, T., Fujita, S., Morishima, S., and Mae, S.: Precise measurement of dielectric anisotropy in ice Ih at $39 \mathrm{GHz}$, J. Appl. Phys., 81, 2344-2348, doi:10.1063/1.364238, 1997. $1217,1218,1247$

Matsuoka, T., Mae, S., Fukazawa, H., Fujita, S., and Watanabe, O.: Microwave dielectric prop15 erties of the ice core from Dome Fuji, Antarctica, Geophys. Res. Lett., 25, 1573-1576, doi:10.1029/98GL01225, 1998. 1217, 1218

Matzl, M. and Schneebeli, M.: Measuring specific surface area of snow by near-infrared photography, J. Glaciol., 52, 558-564, doi:10.3189/172756506781828412, 2006. 1219, 1223

Moore, J. C., Mulvaney, R., and Paren, J. G.: Dielectric stratigraphy of ice: a new technique 20 for determining total ionic concentrations in polar ice, Geophys. Res. Lett., 16, 1177-1180, doi:10.1029/GL016i010p01177, 1989. 1218

Motoyama, H.: The Second Deep Ice Coring Project at Dome Fuji, Antarctica, Scientific Drilling, 5, 41-43, doi:10.2204/lodp.sd.5.05.2007, 2007. 1217

Pfeffer, W. T. and Mrugala, R.: Temperature gradient and initial snow density as controlling factors in the formation and structure of hard depth hoar, J. Glaciol., 48, 485-494, doi:10.3189/172756502781831098, 2002. 1228

Raynaud, D., Lipenkov, V., Lemieux-Dudon, B., Duval, P., Loutre, M.-F., and Lhomme, N.: The local insolation signature of air content in Antarctic ice. A new step toward an absolute dating of ice records, Earth Planet. Sci. Lett., 261, 337-349, doi:10.1016/j.epsl.2007.06.025, 2007.

$30 \quad 1208,1209,1211$

Reijmer, C. and Van den Broeke, M. R.: Temporal and spatial variability of the surface mass balance in Dronning Maud Land, Antarctica, as derived from automatic weather stations, J. Glaciol., 49, 512-520, doi:10.3189/172756503781830494, 2003. 1232

\section{Metamorphism of firn in Dronning Maud Land, East Antarctica}

S. Fujita et al.

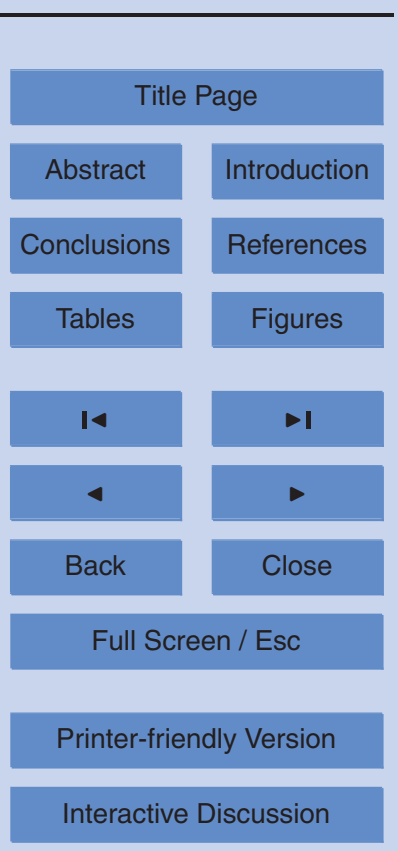


Salamatin, A. N. and Lipenkov, V. Y.: Simple relations for the close-off depth and age in dry-snow densification, Ann. Glaciol., 49, 71-76, doi:10.3189/172756408787814889, 2008. 1207

Salamatin, A. N., Lipenkov, V. Y., Barnola, J.-M., Hori, A., Duval, P., and Hondoh, T.: Impact of local insolation on snow metamorphism and ice core records, in: Physics of lce Core Records II : Papers collected after the 2nd International Workshop on Physics of Ice Core Records, edited by: Kagaku, T. and Hondoh, T., Sapporo, Japan, 2-6 February, 2007, 195-222, 2009. 1207

Severinghaus, J. P. and Battle, M. O.: Fractionation of gases in polar ice during bubble closeoff: new constraints from firn air Ne, Kr and Xe observations, Earth Planet. Sci. Lett., 244, 474-500, doi:10.1016/j.epsl.2006.01.032, 2006. 1208

Shiraiwa, T., Shoji, H., Saito, T., Yokoyama, K., and Watanabe, O.: Structure and dielectric properties of surface snow along the traverse route from coast to Dome Fuji Station, Queen Maud Land, Antarctica., Proc. NIPR Symp. Polar Meteorol. Glaciol., 10, 1-12, National Institute of Polar Research, Tokyo, Japan, 18-19 July 1995, 1996. 1209, 1222, 1230

Sinvola, A. H. and Tiuri, M.: Snow Fork for field determination of the density and wetness profiles of a snow pack, IEEE Trans. Geosci. Remote Sens., GE-24, 717-720, doi:10.1109/TGRS.1986.289619, 1986. 1215, 1218, 1246, 1256

Sugiyama, S., Enomoto, H., Fujita, S., Fukui, K., Nakazawa, F., Holmlund, P., and Surdyk, S.: Dielectric permittivity of snow measured along the route traversed in the Japanese-Swedish Antarctic Expedition 2007/08, J. Glaciol., 51, 9-15, doi:10.3189/172756410791392745, 2010. 1212, 1215, 1222, 1246, 1256, 1259

Sugiyama, S., Enomoto, H., Fujita, S., Fukui, K., Nakazawa, F., Holmlund, P., and Surdyk, S.: Snow density along the route traversed in the Japanese-Swedish Antarctic Expedition 2007/08, J. Glaciol., in press, 2012. 1212, 1221, 1222, 1245, 1255

Suwa, M. and Bender, $\mathrm{M} .: \mathrm{O}_{2} / \mathrm{N}_{2}$ ratios of occluded air in the GISP2 ice core, J. Geophys. Res., 113, D11119, doi:10.1029/2007JD009589, 2008. 1208, 1211

Takahashi, S., Kameda, T., Enomoto, H., Motoyama, H., and Watanabe, O.: Automatic Weather Station (AWS) data collected by the 33rd to 42nd Japanese Antarctic Research Expeditions during 1993-2001 in: JARE data reports, Meteorology, National Institute of Polar Research, Tokyo, 416 pp., 2004. 1245

Takahashi, S. and Kameda, T.: Snow density for measuring surface mass balance using the stake method, J. Glaciol., 53, 677-680, doi:10.3189/002214307784409360, 2007. 1266

\section{Metamorphism of firn in Dronning Maud Land, East Antarctica}

S. Fujita et al.

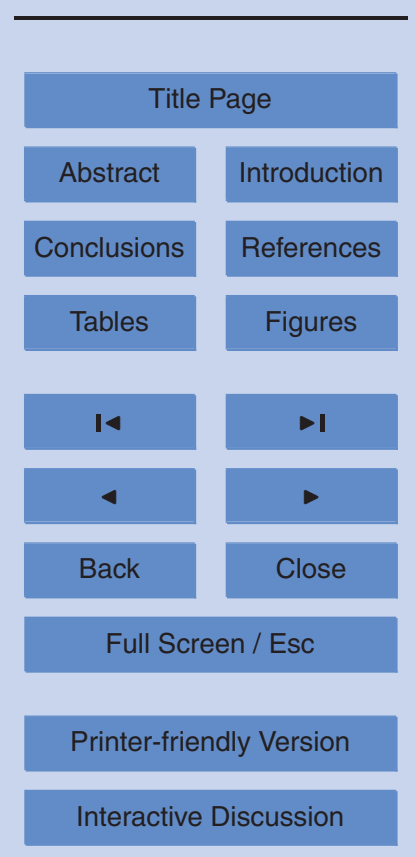


Takata, M., lizuka, Y., Hondoh, T., Fujita, S., Fujii, Y., and Shoji, H.: Stratigraphic analysis of Dome Fuji Antarctic ice core using an optical scanner, Ann. Glaciol., 39, 467-472, doi:10.3189/172756404781813899, 2004. 1219

Tanikawa, T., Hori, M., Stamnes, K., Aoki, T., Kuchiki, K., and Niwano, M.: Critical snow depth 5 on visible and near-infrared radiation - toward a high accuracy on GCOM-C/SGLI snow products, JSSI \& JSSE Joint Conference, Nagaoka, Japan, P1-35, 19-23 September 2011, 2011. 1220

Tiuri, M. E., Sihvola, A. H., Nyfors, E. G., and Hallikainen, M. T.: The complex dielectric constant of snow at microwave frequencies., IEEE J. Ocean. Eng., 9, 377-382, doi:10.1109/JO E.1984.1145645, 1984. 1222

Van As, M. R., Van den Broeke, M. R., and Helsen, M.: Strong-wind events and their impact on the near-surface climate at Kohnen Station on the Antarctic Plateau, Antarct. Sci., 19, 507-519, doi:10.1017/S095410200700065X, 2007. 1214

Van den Broeke, M. R. and Van Lipzig, N. P. M.: Factors controlling the near15 surface wind field in Antarctica, Mon. Weather Rev., 131, 733-743, doi:10.1175/15200493(2003)131<0733:FCTNSW>2.0.CO;2, 2003. 1235

Van Lipzig, N. P. M., Turner, J., Colwell, S. R., and Van den Broeke, M. R.: The near-surface wind field over the Antarctic continent, Int. J. Climatol., 24, 1973-1982, doi:10.1002/joc.1090, 2004. 1235

Watanabe, O., Shimada, W., Narita, H., Miyamoto, A., Tayuki, K., Hondoh, T., Kawamura, T., Fujita, S., Shoji, H., Enomoto, H., Kameda, T., Kawada, K., and Yokoyama, K.: Preliminary discussion of physical properties of the Dome Fuji shallow ice core in 1993, Antarctica., Proc. NIPR Symp. Polar Meteorol. Glaciol., 11, 1-8, National Institute of Polar Research, Tokyo, 10-11 July 1996, 1997. 1245, 1257

Wilhelms, F., Kipfstuhl, J., Miller, H., Heinloth, K., and Firestone, J.: Precise dielectric profiling of ice cores: a new device with improved guarding and its theory, J. Glaciol., 44, 171-174, 1998. 1218

Wiscombe, W. J. and Warren, S. G.: A model for the spectral albedo of snow, 1: pure snow, J. Atmos. Sci., 37, 2712-2733, doi:10.1175/1520-0469(1980)037<2712:AMFTSA>2.0.CO;2, 1980. 1219, 1223

Zhou, Y., Azuma, N., and Kameda, T.: A stratification model of surface snow at Dome Fuji Station, Antarctica, Polar Meteorol. Glaciol., 16, 61-73, 2002. 1231

\section{Metamorphism of firn in Dronning Maud Land, East Antarctica}

S. Fujita et al.

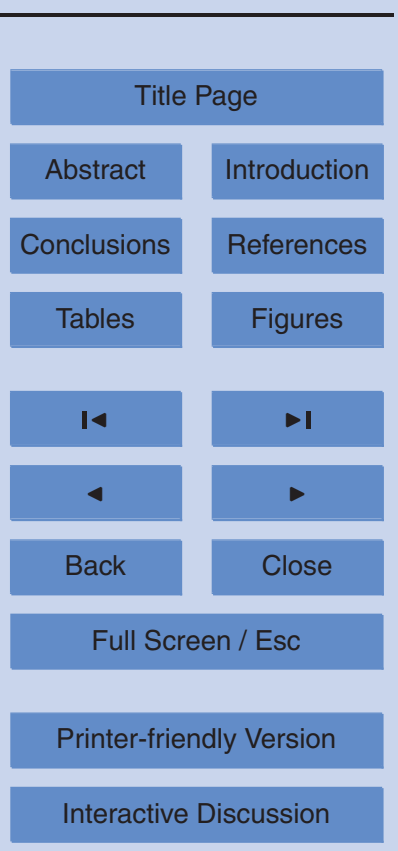


Table 1. Basic information of the three sites for the pit studies.

\begin{tabular}{|c|c|c|c|}
\hline Items & DF & DK190 & MP \\
\hline Latitude $\left({ }^{\circ} \mathrm{S}\right)$ & 77.298 & 76.794 & 75.888 \\
\hline Longitude ( $\left.{ }^{\circ} \mathrm{E}\right)$ & 39.786 & 31.900 & 25.834 \\
\hline Elevation (m) & 3800 & 3761 & 3661 \\
\hline Bottom depth $(\mathrm{m})$ & 4.1 & 2.2 & 4.2 \\
\hline $\begin{array}{l}\text { Depth }(\mathrm{m}) \text { of deposition of Pinatubo } \\
1991 \text { eruption as 1992/1993 } \\
\text { time marker (Fujita et al., 2011) }\end{array}$ & 1.15 & 1.39 & 1.75 \\
\hline $\begin{array}{l}\text { Annual accumulation rate }\left(\mathrm{kg} \mathrm{m}^{-2} \mathrm{a}^{-1}\right) \\
\text { between } 1992 / 1993 \mathrm{AD} \text { and } \\
\text { 2007/2008 AD (Fujita et al., 2011) }\end{array}$ & $25.6 \pm 1.7$ & $34.1 \pm 2.3$ & $41.9 \pm 2.8$ \\
\hline $10 \mathrm{~m}$ snow temperature $\left({ }^{\circ} \mathrm{C}\right)$ & $-58.6^{\mathrm{a}}$ & no data & -54.2 \\
\hline $\begin{array}{l}4 \mathrm{~m} \text { snow temperature }\left({ }^{\circ} \mathrm{C} \text { on }\right. \\
\text { the days of the pit studies) }\end{array}$ & -57.4 & $-55.5^{b}$ & -54.1 \\
\hline Average wind speed (S.D.) $\left(\mathrm{m} \mathrm{s}^{-1}\right)$ & $2.8( \pm 1.7)^{\mathrm{C}}$ & $\begin{array}{c}(\mathrm{DF}+\sim 2.0) \\
\operatorname{or}(\mathrm{MP}+\sim 0.8)^{\mathrm{d}}\end{array}$ & $4.8( \pm 2.6)^{e}$ \\
\hline
\end{tabular}

a Watanabe et al. (1997).

${ }^{\mathrm{b}}$ Extrapolation of data at shallower depths. See Fig. 6.

${ }^{c}$ Data at $2 \mathrm{~m}$ height during years from 1994 to 2001 (Takahashi et al., 2004). Data at hourly intervals were used.

${ }^{d}$ There is no observational data. However, these values are derived from average snow density in the vicinity of DK190 and a coefficient between average density and average wind speed $\left(13.5 \mathrm{~kg} \mathrm{~m}^{-3}\left(\mathrm{~m} \mathrm{~s}^{-1}\right)^{-1}\right)$ studied by Sugiyama et al. (2012).

${ }^{\mathrm{e}}$ Data at $3 \mathrm{~m}$ height during the year 2009. The observational data is from the Automatic Weather Station (AWS) JASE2007 (Keller et al., 2010).

\section{Metamorphism of firn in Dronning Maud Land, East Antarctica}

S. Fujita et al.

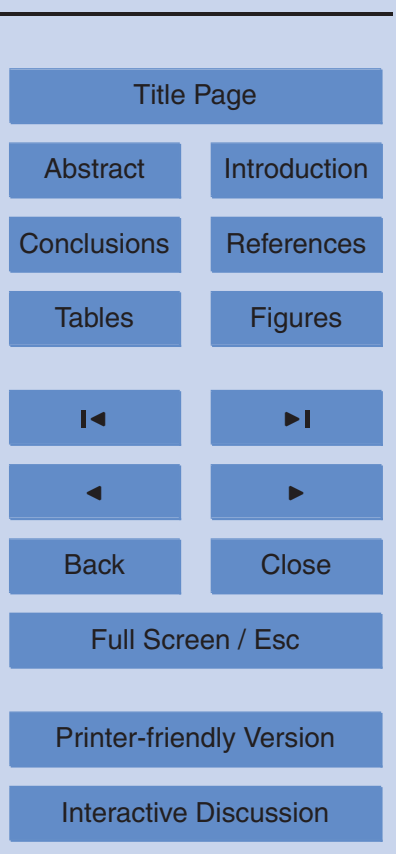


Table 2. Methods used in the pit studies to understand the depth profile of the physical strata of firn in Antarctica.

\begin{tabular}{|c|c|c|}
\hline Method & Depth and resolution & Target physical properties \\
\hline $\begin{array}{l}\text { Density measurement us- } \\
\text { ing } 100 \mathrm{~cm}^{3} \text { box-type snow } \\
\text { samplers and balance }\end{array}$ & $\begin{array}{l}3 \mathrm{~cm} \text { resolution along the } \\
\text { entire depth of the pits }\end{array}$ & Bulk density $\rho$ \\
\hline $\begin{array}{l}\text { Dielectric permittivity mea- } \\
\text { surement at } 500-900 \mathrm{MHz} \\
\text { using a snow fork }\end{array}$ & Same as above & $\begin{array}{l}\text { High frequency limit permit- } \\
\text { tivity } \varepsilon \text { and bulk density } \rho \\
\text { estimated from } \varepsilon \text { (Sihvola } \\
\text { and Tiuri, 1986; Sugiyama } \\
\text { et al., 2010) }\end{array}$ \\
\hline $\begin{array}{l}\text { Visual observation of the } \\
\text { strata }\end{array}$ & $\begin{array}{l}\text { Continuous along the en- } \\
\text { tire depth of the pits }\end{array}$ & $\begin{array}{l}\text { Stratification, grain size } D \\
\text { and snow type. } D \text { reflects } \\
\text { diameter of agglomerates, } \\
\text { rather than sizes of grains } \\
\text { on the surface of cross sec- } \\
\text { tion images. }\end{array}$ \\
\hline $\begin{array}{l}\text { Temperature measurement } \\
\text { with a thermometer and a } \\
\text { Pt100 sensor, with errors of } \\
\pm 0.3^{\circ} \mathrm{C}\end{array}$ & Every $10 \mathrm{~cm}$ & $\begin{array}{l}\text { Temperature profile within } \\
\text { firn }\end{array}$ \\
\hline
\end{tabular}

6, 1205-1267, 2012

\section{Metamorphism of firn in Dronning Maud Land, East Antarctica}

S. Fujita et al.

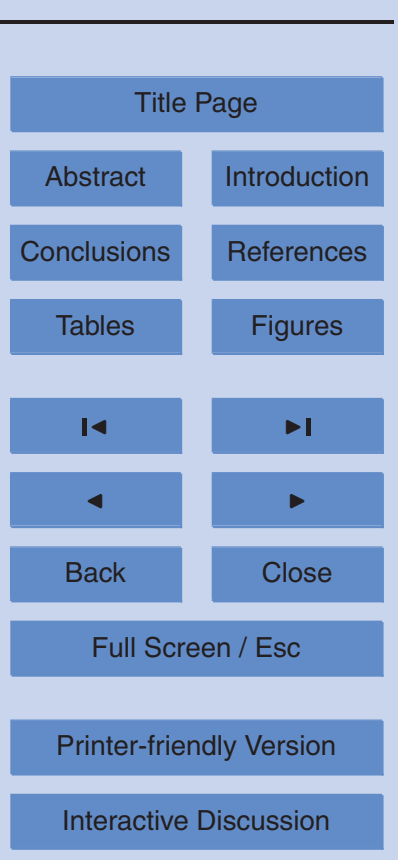

Interactive Discussion 
Table 3. Methods used in the laboratory measurements of the firn blocks.

\begin{tabular}{|c|c|c|c|}
\hline Method & Depth and resolution & $\begin{array}{l}\text { Sample } \\
\text { thick- } \\
\text { ness }\end{array}$ & $\begin{array}{l}\text { Target physical prop- } \\
\text { erties }\end{array}$ \\
\hline $\begin{array}{l}\text { Dielectric permittivity ten- } \\
\text { sor measurement using an } \\
\text { open resonator (Komiyama } \\
\text { et al., 1991; Jones, 1976; } \\
\text { Matsuoka et al., 1997) }\end{array}$ & $\begin{array}{l}\text { At } 5 \mathrm{~mm} \text { intervals with a } \\
\text { resolution of } 20 \mathrm{~mm}\end{array}$ & $7 \mathrm{~mm}$ & $\begin{array}{l}\text { Dielectric permittivity } \\
\text { along the vertical and } \\
\text { horizontal, } \varepsilon_{\mathrm{v}} \text { and } \varepsilon_{\mathrm{h}} \\
\text { Dielectric anisotropy, } \\
\Delta \varepsilon=\left|\varepsilon_{\mathrm{v}}-\varepsilon_{\mathrm{h}}\right|\end{array}$ \\
\hline $\begin{array}{l}\text { Density measurement us- } \\
\text { ing the gamma-ray trans- } \\
\text { mission }\end{array}$ & $\begin{array}{l}\text { At } 3.3 \mathrm{~mm} \text { intervals with } \\
\text { a resolution of } 3.3 \mathrm{~mm} \\
\text { in depth and } 20 \mathrm{~mm} \text { in } \\
\text { width }\end{array}$ & $50 \mathrm{~mm}$ & $\begin{array}{l}\text { Bulk density, } \rho \text { with } \\
\text { errors of less than } \\
1 \% \text {. }\end{array}$ \\
\hline $\begin{array}{l}\text { Reflectance of the Near In- } \\
\text { frared (NIR) light at a wave- } \\
\text { length of } 940 \mathrm{~nm}\end{array}$ & $\begin{array}{l}\text { Continuous measure- } \\
\text { ment with resolution of } \\
\text { less than } 1 \mathrm{~mm} \text {. Data } \\
\text { were averaged over } \\
\text { every } 2.5 \mathrm{~mm} \text { in depth } \\
\text { and } 45 \mathrm{~mm} \text { in width. }\end{array}$ & $\begin{array}{l}50 \mathrm{~mm} \\
\text { and } \\
65 \mathrm{~mm}\end{array}$ & $\begin{array}{l}\text { A qualitative measure } \\
\text { of the grain size }\end{array}$ \\
\hline $\begin{array}{l}\text { Imaging of the firn structure } \\
\text { using Large Area Scanning } \\
\text { Macrosocope (LASM) }\end{array}$ & Continuous, $5 \mu \mathrm{m}$ & $50 \mathrm{~mm}$ & $\begin{array}{l}\text { Grain size and shape, } \\
\text { distributuion of pore } \\
\text { space }\end{array}$ \\
\hline
\end{tabular}

$6,1205-1267,2012$

\section{Metamorphism of firn in Dronning Maud Land, East Antarctica}

S. Fujita et al.

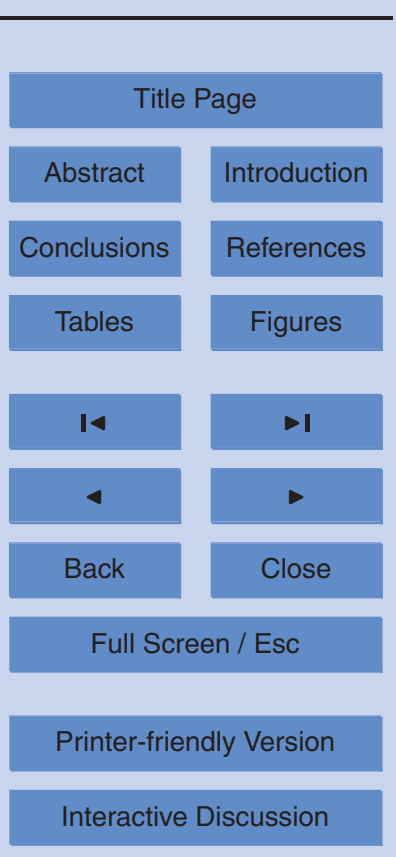


Table 4. Statistics of physical properties of firn at the three pits.

\begin{tabular}{|c|c|c|c|c|}
\hline Items & Depth (range) (m) & DF & DK190 & MP \\
\hline \multirow{4}{*}{ 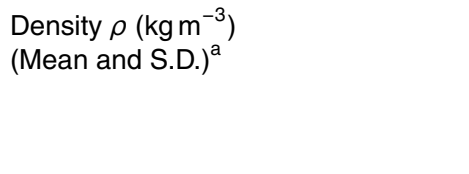 } & $0.0-1.0$ & $333(30)$ & $360(56)$ & $349(30)$ \\
\hline & $1.0-2.0$ & $355(25)$ & 378 (27) & $372(18)$ \\
\hline & $2.0-2.5$ & $384(49)$ & - & $384(29)$ \\
\hline & surface-pit bottom & $364(38)$ & $370(43)$ & $373(29)$ \\
\hline \multirow[t]{3}{*}{$\varepsilon_{\mathrm{h}}$ (Mean and S.D.) } & $0.0-1.0$ & $1.51(0.03)$ & $1.69(0.09)$ & - \\
\hline & $1.0-2.0$ & $1.55(0.05)$ & $1.65(0.05)$ & $1.63(0.03)$ \\
\hline & $2.0-2.5$ & $1.57(0.03)$ & - & $1.63(0.03)$ \\
\hline \multirow[t]{3}{*}{$\varepsilon_{\mathrm{v}}$ (Mean and S.D.) } & $0.0-1.0$ & $1.55(0.03)$ & $1.74(0.10)$ & - \\
\hline & $1.0-2.0$ & $1.60(0.06)$ & $1.70(0.05)$ & $1.67(0.03)$ \\
\hline & $2.0-2.5$ & $1.61(0.04)$ & - & $1.67(0.04)$ \\
\hline \multirow[t]{3}{*}{$\Delta \varepsilon$ (Mean and S.D.) } & $0.0-1.0$ & $0.038(0.003)$ & $0.049(0.009)$ & - \\
\hline & $1.0-2.0$ & $0.047(0.007)$ & $0.044(0.007)$ & $0.041(0.007)$ \\
\hline & $2.0-2.5$ & $0.040(0.004)$ & - & $0.046(0.007)$ \\
\hline \multirow[t]{3}{*}{ Maximum and minimum $\Delta \varepsilon$} & $0.0-1.0$ & $0.047,0.030$ & $0.066,0.031$ & - \\
\hline & $1.0-2.0$ & $0.067,0.034$ & $0.060,0.028$ & $0.065,0.031$ \\
\hline & $2.0-2.5$ & $0.048,0.032$ & - & $0.062,0.034$ \\
\hline$\Delta \varepsilon_{365}: \Delta \varepsilon$ at $\rho=365 \mathrm{~kg} \mathrm{~m}^{-3 \mathrm{~b}}$ & - & $0.057(0.005)$ & $0.041(0.005)$ & $0.045(0.005)$ \\
\hline \multirow[t]{2}{*}{ Grain size, $D(\mathrm{~mm})$ (Mean and S.D. $)^{\mathrm{c}}$} & near $z=2.0 \mathrm{~m}^{\mathrm{d}}$ & $1.31(0.30)$ & $1.15(0.18)$ & $1.07(0.12)$ \\
\hline & at $\sim 15$ yr ago layer ${ }^{\mathrm{e}}$ & $1.19(0.30)$ & $1.07(0.18)$ & $0.99(0.12)$ \\
\hline \multirow[t]{2}{*}{$R$ (Mean and S.D.) } & near $z=2.0 \mathrm{~m}^{\mathrm{d}}$ & $0.63(0.03)$ & $0.67(0.02)$ & $0.67(0.02)$ \\
\hline & at $\sim 15 \mathrm{yr}$ ago layer ${ }^{\mathrm{e}}$ & $0.67(0.03)$ & $0.67(0.02)$ & $0.67(0.02)$ \\
\hline$\Delta R / \Delta \rho\left(\times 10^{-4} \mathrm{~kg}^{-1} \mathrm{~m}^{3}\right)^{f}$ & - & 9.6 & 3.1 & 4.4 \\
\hline
\end{tabular}

${ }^{a}$ These density values are from data of $\rho$ at the pit wall in the field, using a box-type snow sampler.

b These values were derived from regression lines in Fig. 10.

${ }^{\mathrm{c}}$ These values of $D$ are from observational data on the pit wall in the field, reflecting grain agglomerates.

${ }^{\mathrm{d}}$ Mean values at a depth of $2 \mathrm{~m}$ on fitted curves

e Depths for the 1992/1993 AD layers (15yr before 2007/2008 AD) are given in Table 1.

${ }^{f}$ See gradients of short scale fluctuations of the $R-\rho$ plot in Fig. 13. Estimated error for the gradient is less than $10 \%$.
$6,1205-1267,2012$

\section{Metamorphism of firn in Dronning Maud Land, East Antarctica}

S. Fujita et al.

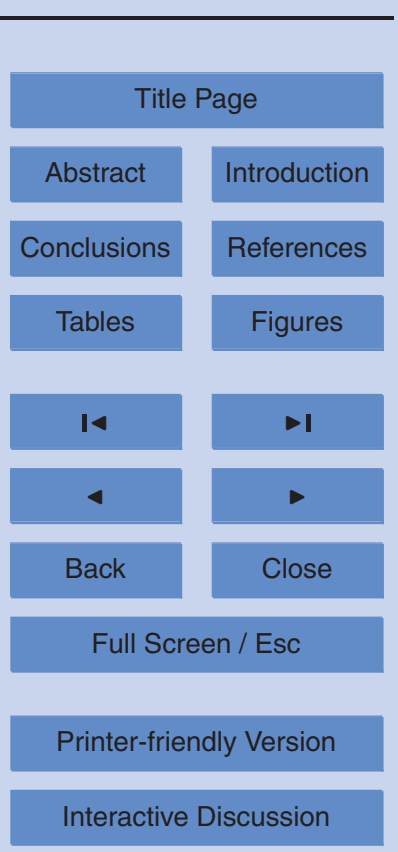




\section{TCD}

$6,1205-1267,2012$

\section{Metamorphism of firn in Dronning Maud \\ Land, East Antarctica}

S. Fujita et al.

Table 5. Regression lines for the $\varepsilon_{\mathrm{h}}-\Delta \varepsilon$ plot of Fig. 10.

\begin{tabular}{ll}
\hline Site & Regression lines \\
\hline DF & $\Delta \varepsilon=-0.085( \pm 0.012)+0.083( \pm 0.008) \times \varepsilon_{\mathrm{h}}$ \\
DK190 & $\Delta \varepsilon=-0.072( \pm 0.010)+0.070( \pm 0.006) \times \varepsilon_{\mathrm{h}}$ \\
MP & $\Delta \varepsilon=-0.198( \pm 0.028)+0.148( \pm 0.017) \times \varepsilon_{\mathrm{h}}$ \\
\hline
\end{tabular}

Title Page

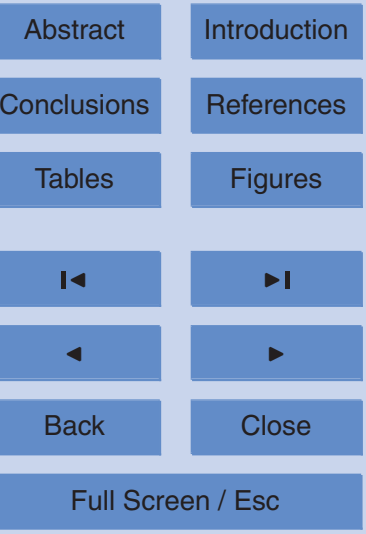

Printer-friendly Version

Interactive Discussion 
Table 6. Coefficients for accumulation rate and wind speed to explain variations of measures of postdepositional metamorphism.

\begin{tabular}{lccccc}
\hline Items $^{\mathrm{a}}$ & $y$-intercepts & $\begin{array}{c}\text { Accumulation rate } \\
\text { coefficient }\end{array}$ & $\begin{array}{c}\text { Wind speed } \\
\text { coefficient }\end{array}$ & $\begin{array}{c}\text { Accumulation rate } \\
\text { fraction }^{\mathrm{b}}\end{array}$ & $\begin{array}{c}\text { Wind speed } \\
\text { fraction }^{\mathrm{b}}\end{array}$ \\
\hline$\Delta \varepsilon_{365}$ & 0.084 & -0.0003 & -0.0067 & 0.3 & 0.7 \\
$\Delta R / \Delta \rho\left(\times 10^{-4}\right)$ & 20.3 & -0.12 & -2.8 & 0.3 & 0.7 \\
$D_{2 \mathrm{~m}}$ & 1.71 & -0.013 & -0.025 & 0.8 & 0.2 \\
$R_{2 \mathrm{~m}}$ & 0.56 & 0.0017 & 0.011 & 0.6 & 0.4 \\
\hline
\end{tabular}

${ }^{\text {a }}$ Concrete values of these quantities at the three sites are given in Table 4.

${ }^{b}$ Approximate fraction of variations explained by variations of accumulation rate or by variations of wind speed.

\section{Metamorphism of firn in Dronning Maud Land, East Antarctica}

S. Fujita et al.

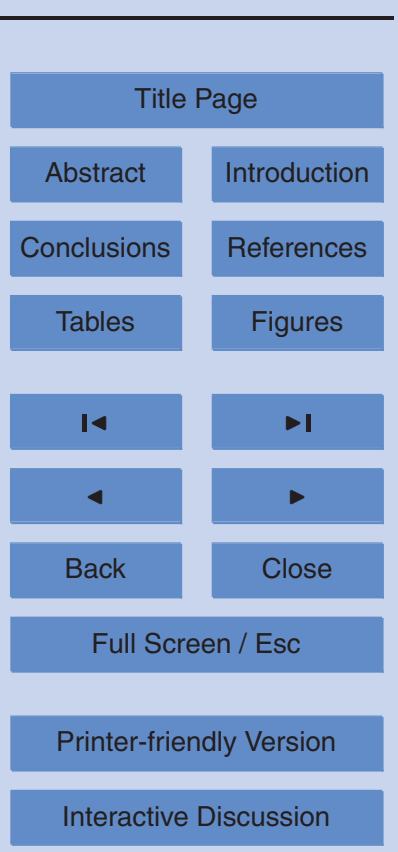

Interactive Discussion 
Table 7. Factors controlling formation of firn strata and initial stage of postdepositional metamorphism: II. The other controlling factors in various time scales, in addtion to processes of diurnal cycles caused by insolation in summer.

\begin{tabular}{|c|c|c|c|}
\hline Factors & Controlled processes & $\begin{array}{l}\text { Does it give effects to for- } \\
\text { mation and evolution of lay- } \\
\text { ers and interfaces (FELI), } \\
\text { temperature gradient meta- } \\
\text { morphism (TGM) in the firn } \\
\text { volume or both? }\end{array}$ & $\begin{array}{l}\text { Related figures and } \\
\text { tables }\end{array}$ \\
\hline Surface accumulation rate & $\begin{array}{l}\text { Mass input on the surface without seasonality } \\
\text { Residence time of firn layers near the surface }\end{array}$ & $\begin{array}{l}\text { No major simple effect } \\
\text { TGM }\end{array}$ & $\begin{array}{l}\text { Fig. } 15 \\
\text { Fig. } 11 \mathrm{a} \text { and Table } 6\end{array}$ \\
\hline Wind & $\begin{array}{l}\text { Weakening both surface heating and surface } \\
\text { cooling } \\
\text { Compaction of surface snow } \\
\text { Fragmentation, drift, deposition and packing } \\
\text { of surface hoar }\end{array}$ & $\begin{array}{l}\text { FELI and TGM } \\
\text { FELI } \\
\text { FELI }\end{array}$ & $\begin{array}{l}\text { Figs. } 2,11 \mathrm{~b} \text { and } \\
\text { Table } 6 \\
\text { Fig. } 4 \text { and Table } 4\end{array}$ \\
\hline Strong wind events & Forming dune layers and wind-slabs & FELI & $\begin{array}{l}\text { Figs. } 5,7,9,10 \text { and } \\
13\end{array}$ \\
\hline Strata of IHDF and ILDF & $\begin{array}{l}\text { Heterogeneous flow of vapour and heat within } \\
\text { stratified firn }\end{array}$ & $\begin{array}{l}\text { TGM strongly dependent } \\
\text { on physical properties of } \\
\text { firn caused by FELI }\end{array}$ & $\begin{array}{l}\text { Figs. } 5,7,9,10 \text { and } \\
13\end{array}$ \\
\hline $\begin{array}{l}\text { Local summer insolation } \\
\text { due to Milankovitch cycles } \\
\text { or temporal changes in so- } \\
\text { lar activities }\end{array}$ & $\begin{array}{l}\text { Effective strength of the diurnal/seasonal cy- } \\
\text { cles indicated in Fig. } 16 .\end{array}$ & FELI and TGM & Fig. 16 \\
\hline Degree of cloudiness & Weakening effect of the insolation & FELI and TGM & Fig. 2 \\
\hline
\end{tabular}

\section{Metamorphism of firn in Dronning Maud Land, East Antarctica}

S. Fujita et al.

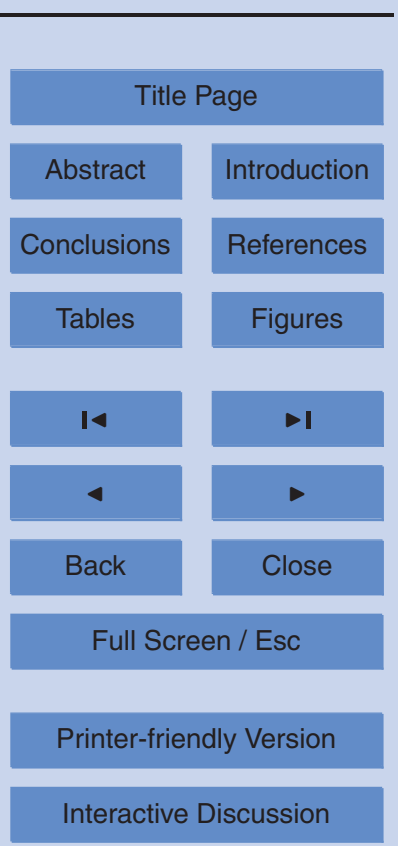




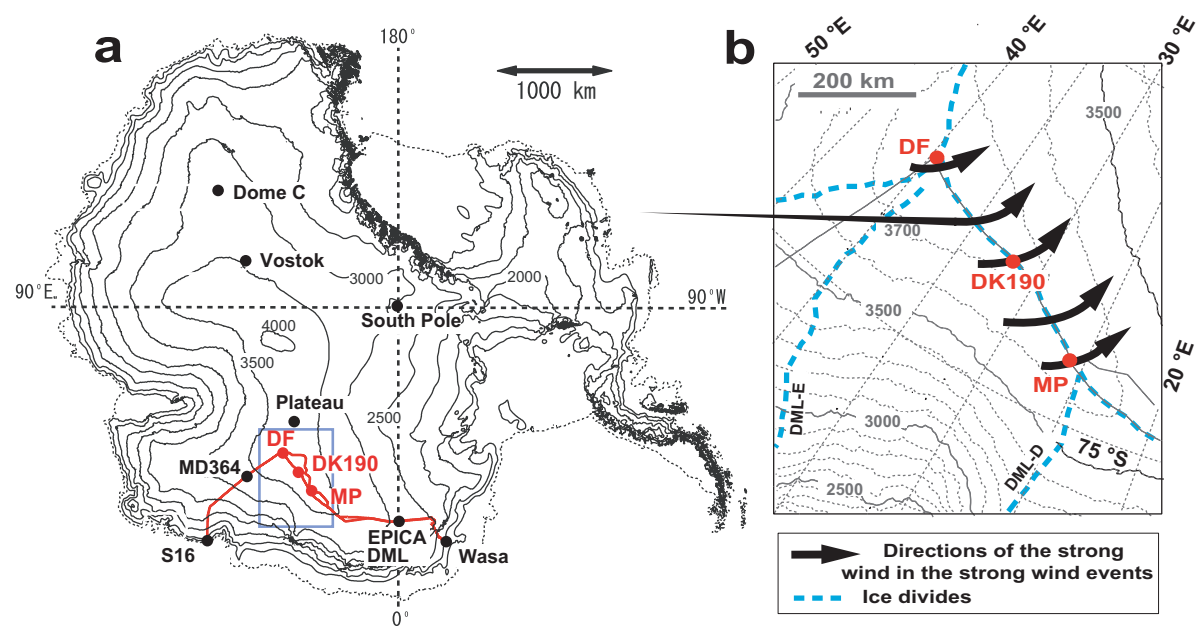

Fig. 1. Topographic map of Antarctica. (a) Red solid circles indicate locations of the pit sites. Routes of the JASE traverse are shown as red lines on the map. (b) Studied area. Surface elevation contour lines have a spacing of $100 \mathrm{~m}$. Bold blue dashed curves indicate ice divides on the ice sheet surface. For convenience, we labelled the ice divides DML-D and DML-E (see Fujita et al., 2011). Thick black arrows are the suggested prevailing directions of the strong winds of the strong wind events (see Fujita et al., 2011). Measured average wind speeds at DF and MP are given in Table 1. Based on spatial variation of the snow density, approximate mean wind speed at $2 \mathrm{~m}$ height was deduced. It is later given in Fig. 4. Spatial distribution of wind speed is correlated to the location on the ice divide with respect to trough shape of the ice sheet topography between the ice divides DML-D and DML-E. Upslope component of the strong wind can converge into regions between DK190 and MP.

\section{TCD}

6, 1205-1267, 2012

\section{Metamorphism of firn in Dronning Maud Land, East Antarctica}

S. Fujita et al.

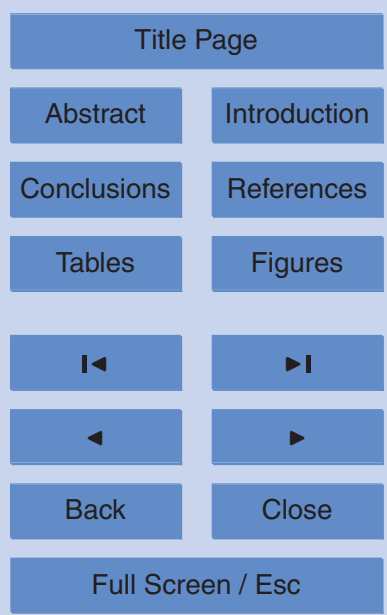

Printer-friendly Version

Interactive Discussion

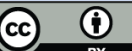




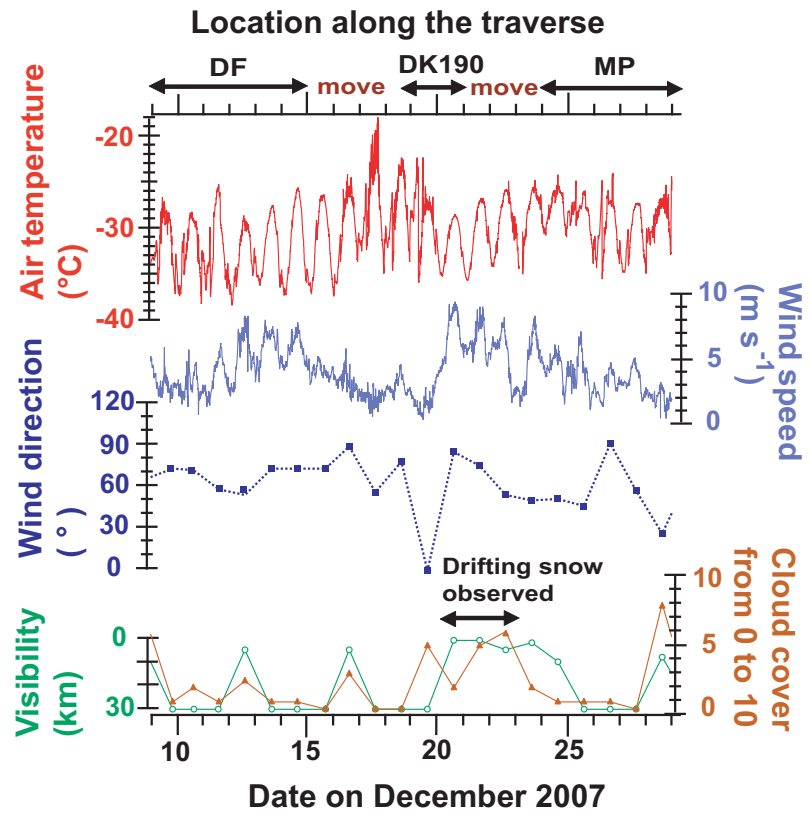

Fig. 2. Meteorological conditions observed during the investigation period. Date and location of the observation are given on the bottom and top axis, respectively. Both air temperature and wind speed was measured by the onboard Automatic Weather Station (AWS) which was calibrated with manual observations every day. The temperature sensor and the wind sensor of the onboard AWS were at a height of $3.9 \mathrm{~m}$ and $4.5 \mathrm{~m}$, respectively. At every noon UTC, manual observations provided data of wind direction, visibility (in $\mathrm{km}$ ), cloud cover (from 0 to 10) and meteorological phenomena. Weather was clear sky in most of the days. But cloud cover sometimes increased and visibility decreased, in particular when northerly component of the wind direction increased. Drifting snow was observed in a period between 20 and 23 December. Diurnal cycles are apparent both in air temperature and in wind speed.

\section{TCD}

6, 1205-1267, 2012

\section{Metamorphism of firn in Dronning Maud Land, East Antarctica}

S. Fujita et al.

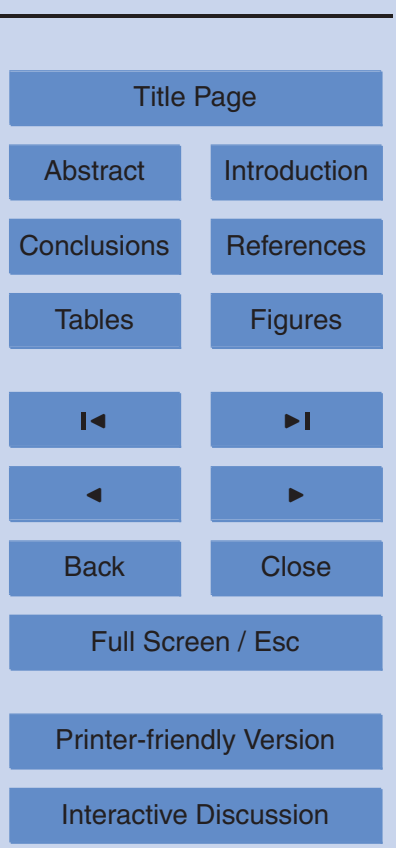




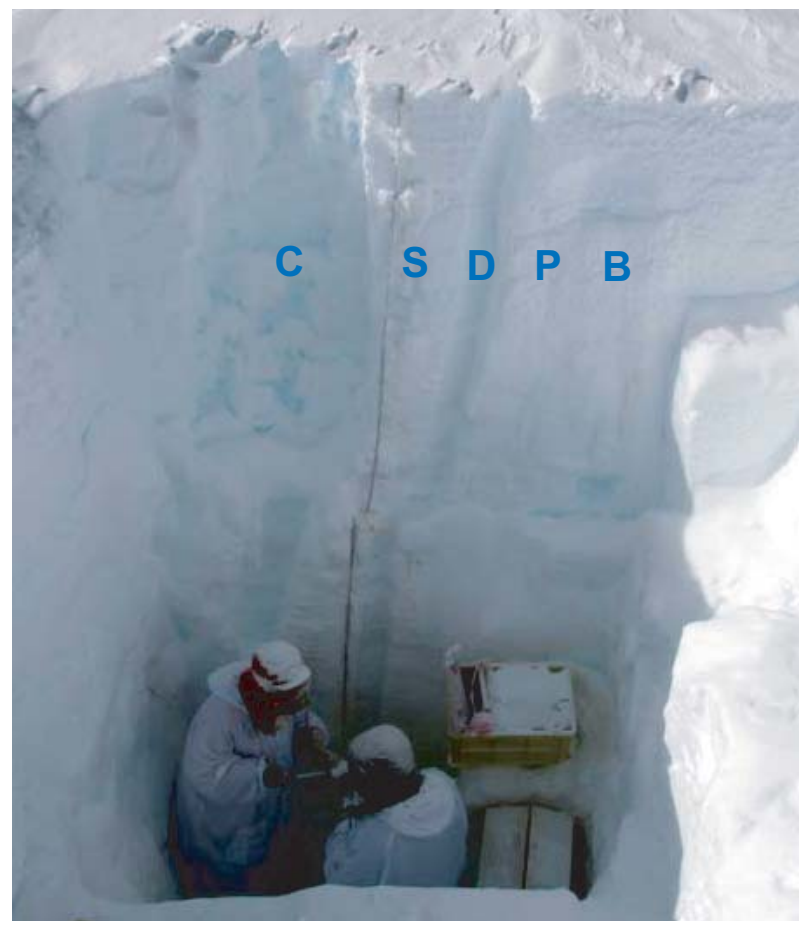

\section{TCD}

$6,1205-1267,2012$

\section{Metamorphism of firn in Dronning Maud Land, East Antarctica}

S. Fujita et al.

Fig. 3. A picture of the pit wall at DF on 10 December, 2007. Two scientists are collecting firn samples in the pit. Letters indicate positions of measurements or sampling for different purposes. $P$ is for the permittivity measurements with the snow fork. $D$ is for density measurements using a box sampler. $S$ is for observing stratigraphy and temperature measurements. $B$ is for sampling firn blocks for analyses of physical properties. $\mathrm{C}$ is for sampling snow for chemistry purposes.

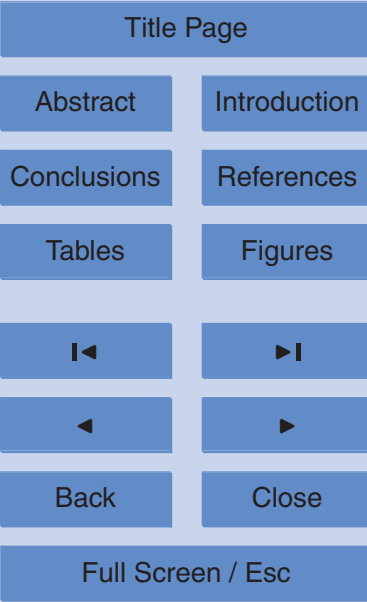

Printer-friendly Version

Interactive Discussion

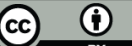



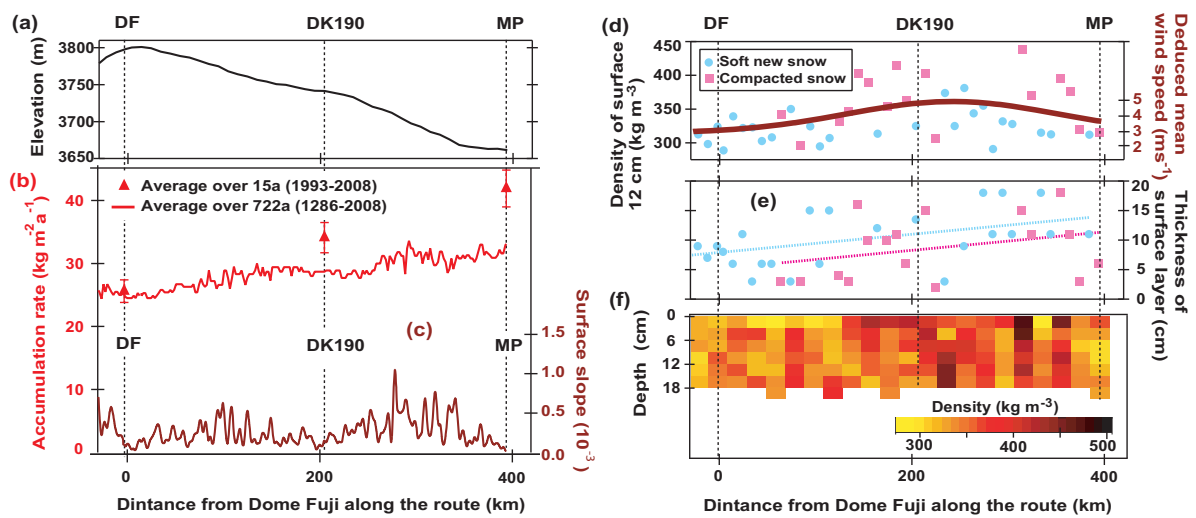

Fig. 4. Variations of the ice sheet environment between Dome Fuji (DF) and the JASE meeting point (MP) through DK190. The abscissa is distance from Dome Fuji Station along the JASE traverse route. (a) Surface elevation from the Digital Elevation Model (DEM) (Bamber et al., 2009). (b) Accumulation rate averaged over 722 a and 15 a (Fujita et al., 2011). (c) Surface slope derived from the DEM. (d) Using left axis, we show density of surface firn averaged over $11 \mathrm{~cm}$ or $12 \mathrm{~cm}$ thickness. When the surface was soft new snow and compacted hard snow, cyan solid circle markers and magenta solid square markers are used, respectively. A brown fitting curve is given. We suggest that density is highest near DK190. Based on this average snow density and a coefficient between average density and average wind speed $\left(13.5 \mathrm{~kg} \mathrm{~m}^{-3}\left(\mathrm{~m} \mathrm{~s}^{-1}\right)^{-1}\right.$, (Sugiyama et al., 2012), we deduced spatial distribution of the annual average wind speed. The scale for the wind speed converted from the density scale is given in the right axis. We suggest that DK190 is the windiest site among the three due to topographic effect of the ice sheet. (e) Thickness of homogeneous layers covering the surface. Markers are the same as in (d). A regression line is given for each type of surface firn, showing a slightly increasing trend as we move away from DF. (f) Density profile of 22 shallow pits at 3-cm resolution.

\section{Metamorphism of firn in Dronning Maud Land, East Antarctica}

S. Fujita et al.

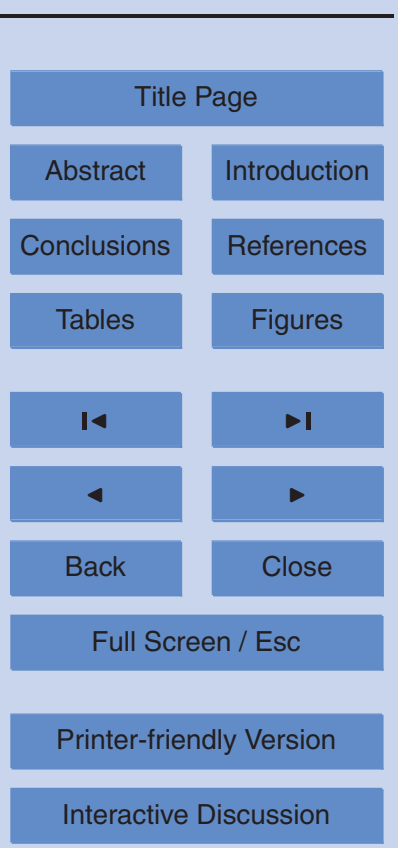


(a) DF

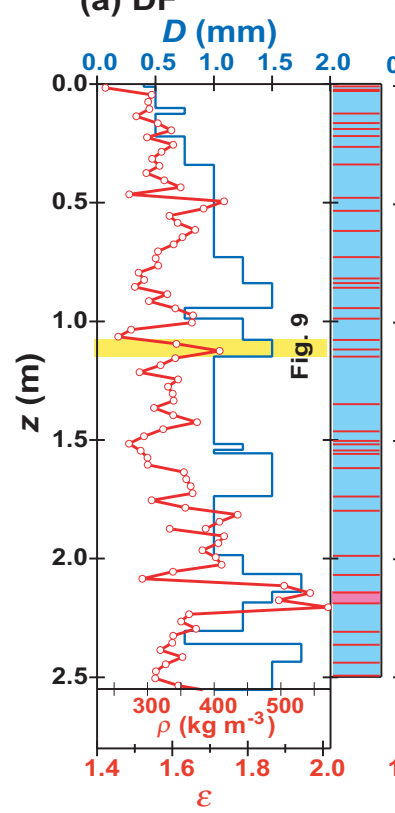

(b) DK190

$D(\mathrm{~mm})$

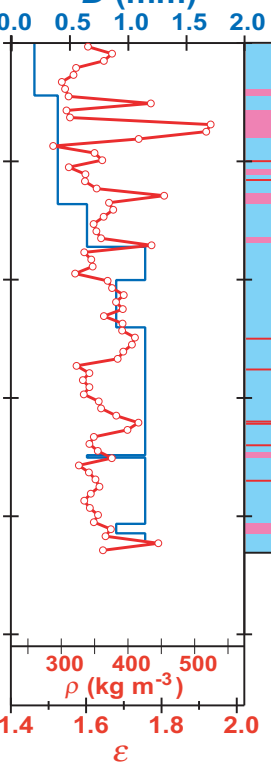

(c) MP

$$
D(\mathrm{~mm})
$$

$\begin{array}{lllll}0.0 & 0.5 & 1.0 & 1.5 & 2.0\end{array}$

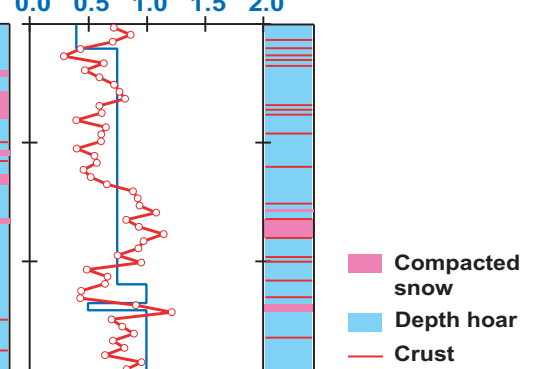

6, 1205-1267, 2012

\section{Metamorphism of firn in Dronning Maud Land, East Antarctica}

S. Fujita et al.

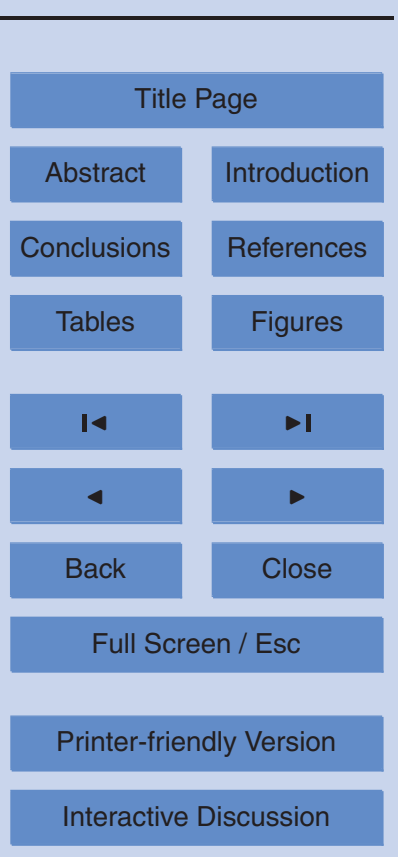

Interactive Discussion 


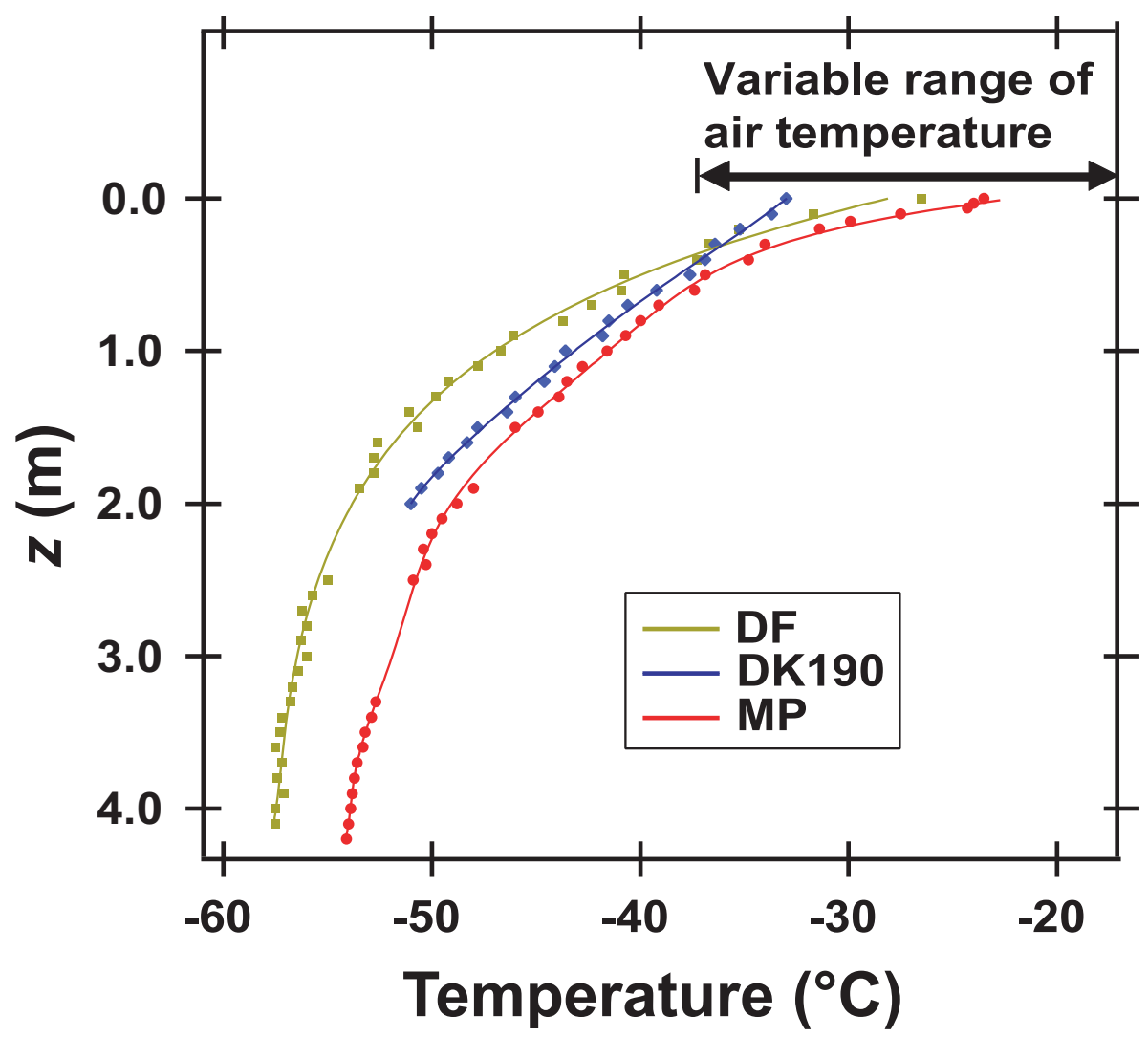

Fig. 6. Temperature profiles in the three pits measured using the wall of the pits. The variable range of the air temperature in the period of mid to late December (Fig. 2) is shown at the top as a reference. $10 \mathrm{~m}$ snow temperature is $-58.6^{\circ} \mathrm{C}$ (Watanabe et al., 1997) at DF and $-54.2^{\circ} \mathrm{C}$ at MP, respectively. At 4-m depth, temperatures are close to these values.
TCD

$6,1205-1267,2012$

Metamorphism of firn in Dronning Maud Land, East Antarctica

S. Fujita et al.

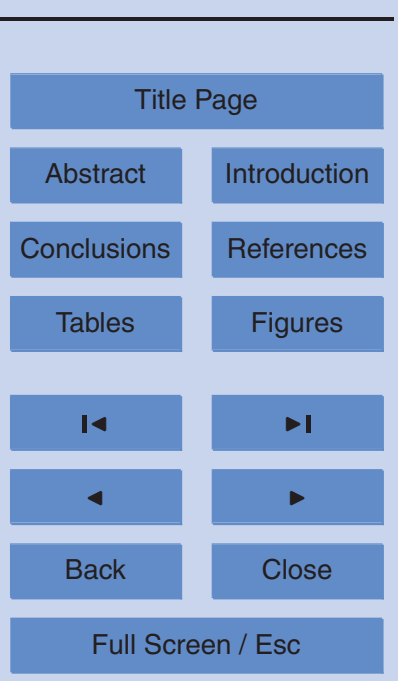

Printer-friendly Version

Interactive Discussion 


\section{TCD}

$6,1205-1267,2012$

(a) DF

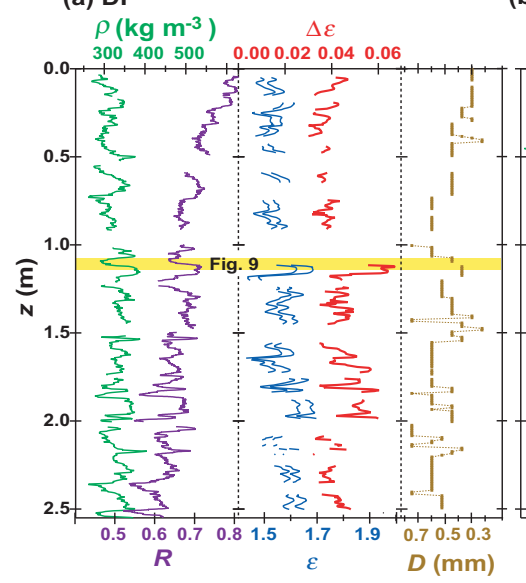

(b) DK190

$\rho\left(\mathrm{kg} \mathrm{m}^{-3}\right)$ $300400500 \quad 0.000 .020 .040 .06$

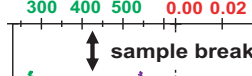

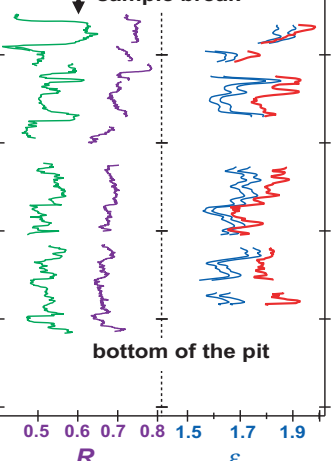

(c) MP

$\rho\left(\mathrm{kg} \mathrm{m}^{-3}\right) \quad \Delta \varepsilon$ $\begin{array}{lllllll}300 \quad 400 \quad 500 \quad 0.00 & 0.02 & 0.04 \quad 0.06\end{array}$

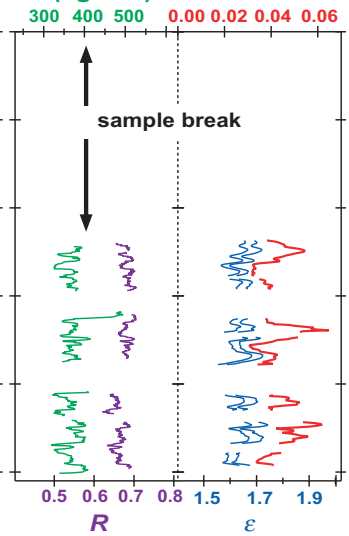

Fig. 7. Physical properties of the firn blocks at (a) DF, (b) DK190 and (c) MP. Density $\rho$ with $3.3 \mathrm{~mm}$ resolution is shown as the green line with the top axis. Near-Infrared reflectance $R$ is given as a purple line with a scale on the bottom axis. Two components of the microwave dielectric permittivity, $\varepsilon_{\mathrm{v}}$ and $\varepsilon_{\mathrm{h}}\left(\varepsilon_{\mathrm{v}}>\varepsilon_{\mathrm{h}}\right)$, are shown with a blue line and on the bottom axis. The dielectric anisotropy $\Delta \varepsilon\left(=\left|\varepsilon_{\mathrm{v}}-\varepsilon_{\mathrm{h}}\right|\right)$ is shown with a red line and the top axis. For DF, measured grain size from LASM images (see text) is given as yellow-brown lines and the bottom axis. An example of the LASM image at the depth portion with yellow shading is given in Fig. 9.

\section{Metamorphism of firn in Dronning Maud Land, East Antarctica}

S. Fujita et al.

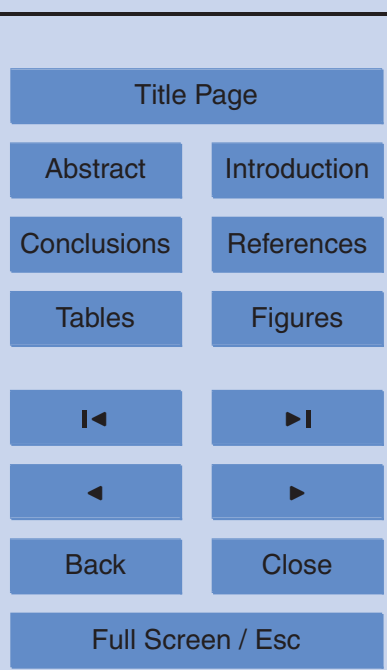

Printer-friendly Version

Interactive Discussion 

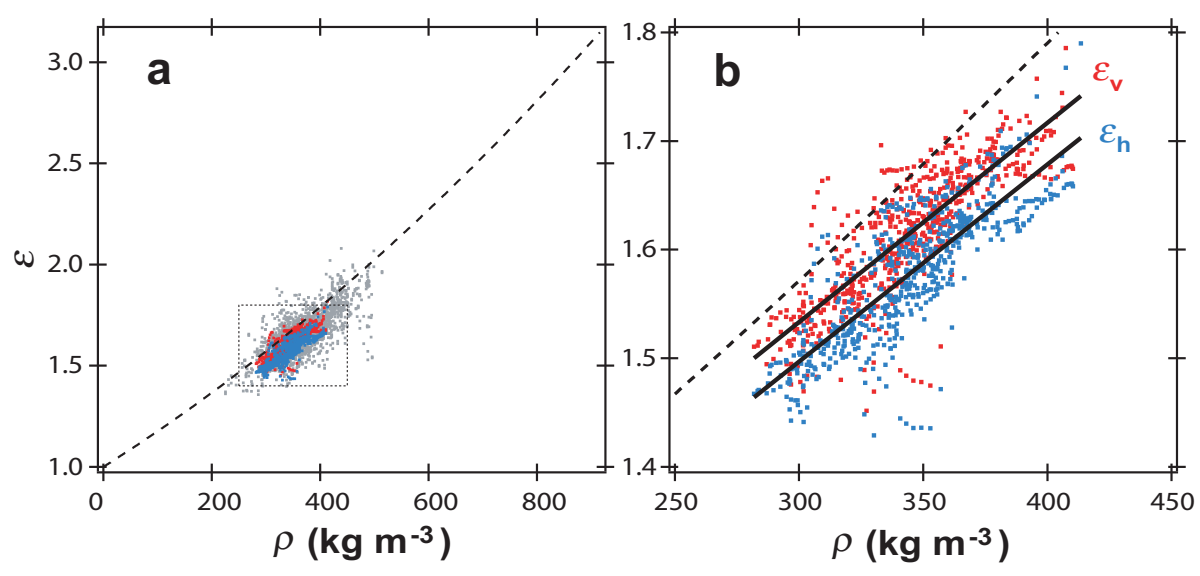

Fig. 8. Relation between the two components of permittivity values $\left(\varepsilon_{\mathrm{v}}\right.$ and $\varepsilon_{\mathrm{h}}$ on the ordinate) and the density values ( $\rho$ on the abscissa) at the DF pit. (a) Blue and red dots are the horizontal components $\varepsilon_{\mathrm{h}}$ and the vertical components $\varepsilon_{\mathrm{v}}$, respectively. Grey dots are permittivity equivalent to $\varepsilon_{\mathrm{h}}$ measured using the snow fork in 1-m pits along the JASE traverse (Sugiyama et al., 2010). The dashed curve is a relation proposed for the Antarctic firn (Kovacs et al., 1995). (b) Same plot as (a) for the graph area indicated by the box in (a). The two regression lines are as follows: $\varepsilon_{\mathrm{h}}=0.00181( \pm 0.00005) \rho+0.953( \pm 0.018)$ and $\varepsilon_{\mathrm{v}}=0.00184( \pm 0.00005) \rho+0.983( \pm 0.017)$.

\section{Metamorphism of firn in Dronning Maud Land, East Antarctica}

S. Fujita et al.

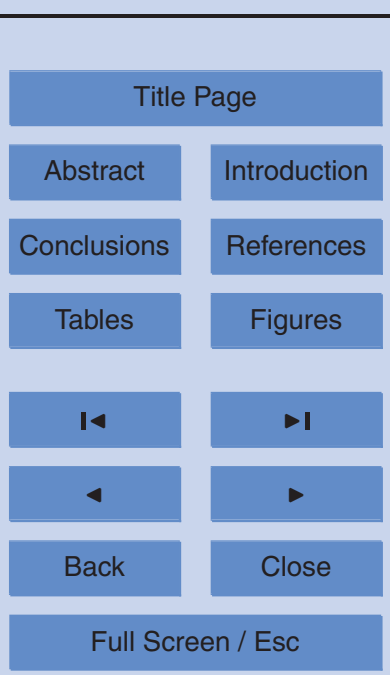

Printer-friendly Version

Interactive Discussion 


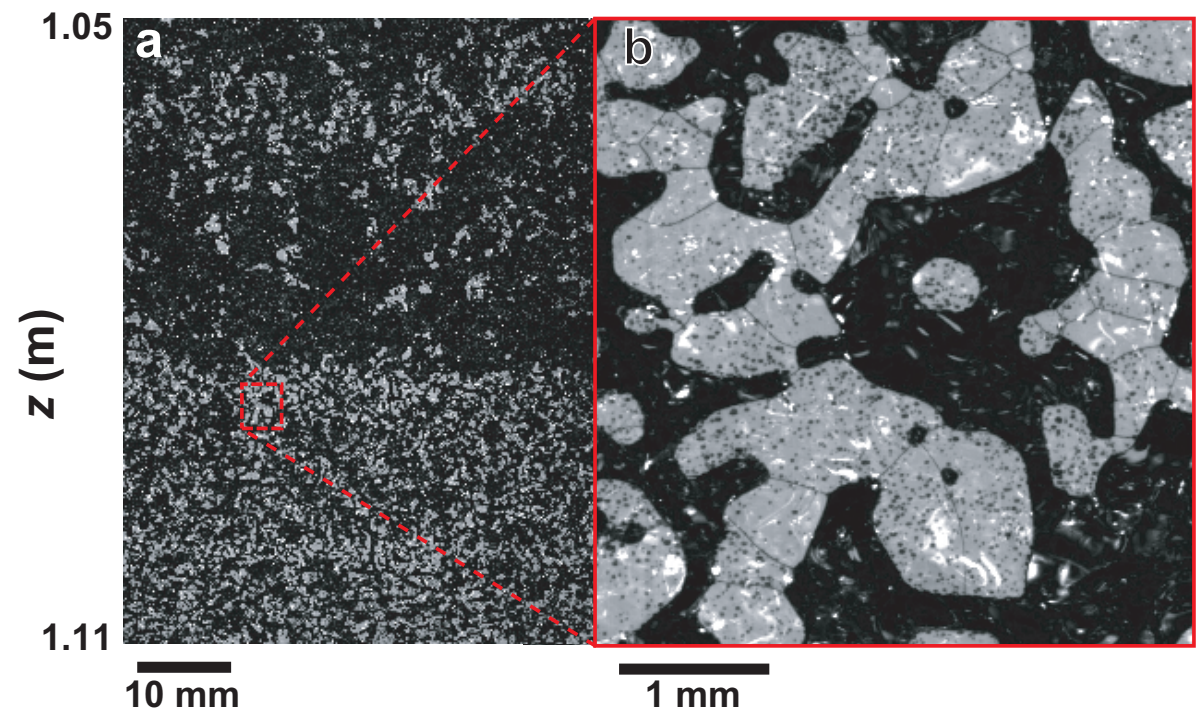

Fig. 9. (a) An example of the Large Area Scan Macroscope (LASM) image at 1.05-1.11 m depth at DF. The depth range of this image is indicated in Figs. 5a and 7a. Brighter grey parts are reflections from microtomed ice parts and dark parts are pore spaces on the microtomed surface. The upper and lower portions are less dense firn and dense firn, respectively. Strata are clearly visible. (b) Enlarged image of the portion of compacted snow. Grain size, grain boundaries and micro-bubbles within ice can be determined from the images. Very white parts result from the effects of scattered light within the firn sample.

\section{TCD}

$6,1205-1267,2012$

\section{Metamorphism of firn in Dronning Maud Land, East Antarctica}

S. Fujita et al.

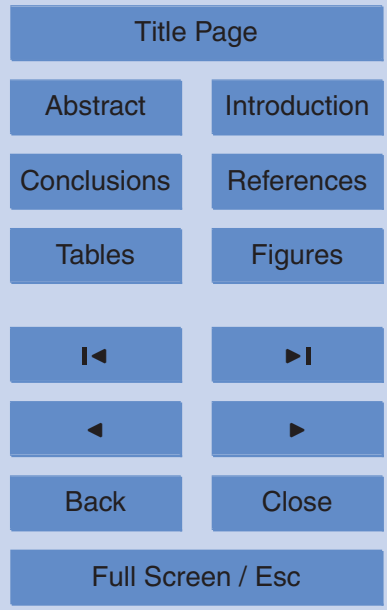

Printer-friendly Version

Interactive Discussion

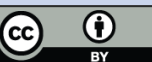




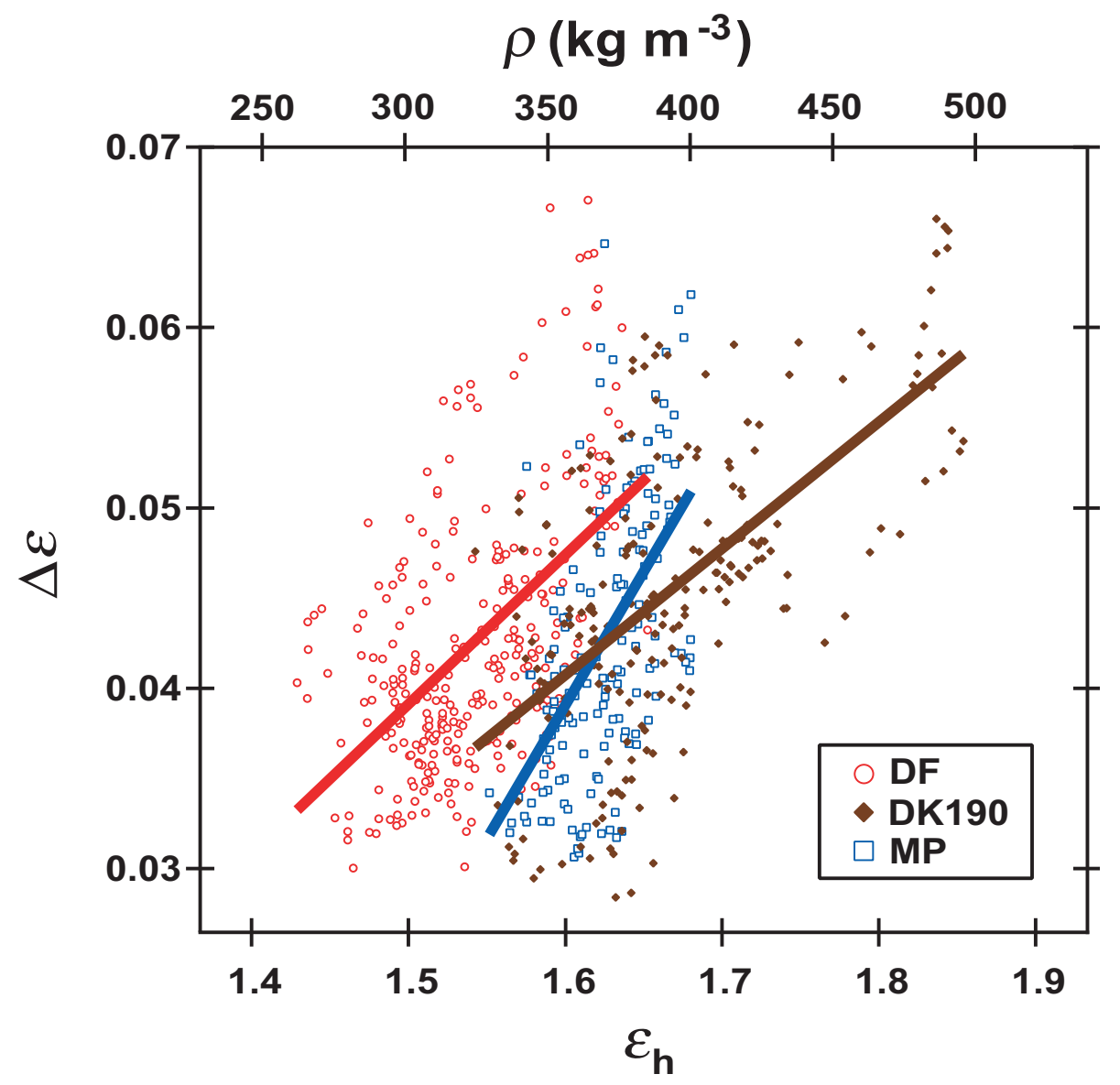

TCD

$6,1205-1267,2012$

\section{Metamorphism of} firn in Dronning Maud Land, East Antarctica

S. Fujita et al.

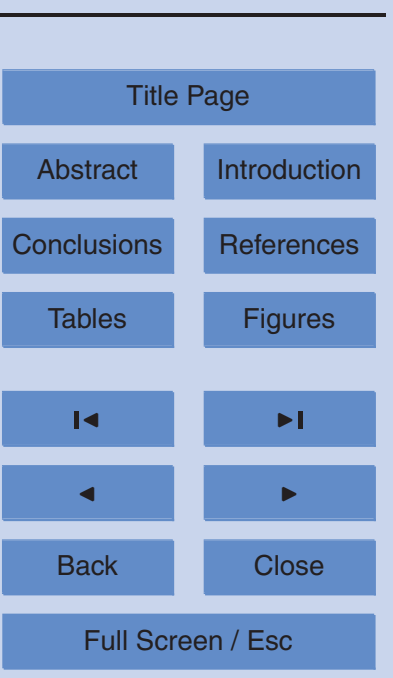

Printer-friendly Version

Fig. 10. Relation between the permittivity values $\left(\varepsilon_{\mathrm{h}}\right.$ on the abscissa) and the dielectric anisotropy values ( $\Delta \varepsilon$ on the ordinate) for the three sites. The top axis is a reference scale for density converted from $\varepsilon_{\mathrm{h}}$ using the regression line in Fig. $8 \mathrm{~b}$. 
Annual accumulation rate $\left(\mathrm{kg} \mathrm{m}^{-2} \mathrm{a}^{-1}\right)$
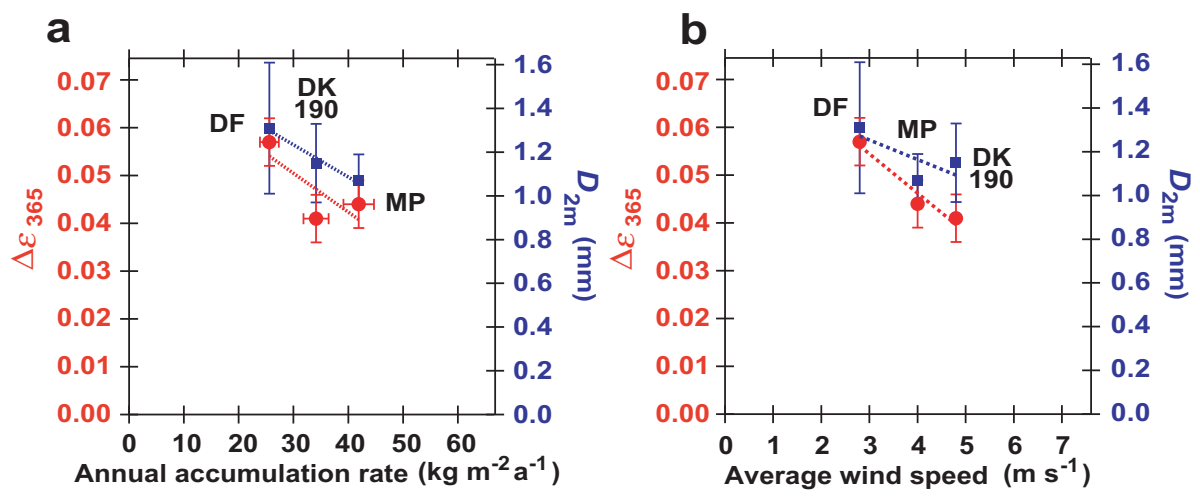

Fig. 11. Two graphs show relation between measures of post metamorphism versus accumulation rate or annual average wind speed. (a) Red symbol markers with left axis show relation between $\Delta \varepsilon$ values for $\rho=365 \mathrm{~kg} \mathrm{~m}^{-3}\left(\Delta \varepsilon_{365}\right.$ on the left axis) and the 15 a average of annual accumulation rate at the three sites. Also, blue symbol markers with right axis show relation between mean $D$ values at $z=2 \mathrm{~m}\left(D_{2 \mathrm{~m}}\right.$ on the right axis) and the accumulation rate. $\Delta \varepsilon_{365}$ was used as an approximate mean value of $\Delta \varepsilon$ for the three sites. The $15 \mathrm{yr}$ average of annual accumulation rate was used as a measure of recent accumulation rate covering depth range of the pits. Depths of the time markers are given in Table 1 . The averaged $D$ values at $z=2(\mathrm{~m})$ were used as a depth where temperature gradient metamorphism are more or less completed. (b) $\Delta \varepsilon_{365}$ and $D_{2 m}$ are plotted versus annual average wind speed at the three sites. Wind speed is based on observations at DF and MP and estimation at DK190 (see text).

\section{Metamorphism of firn in Dronning Maud Land, East Antarctica}

S. Fujita et al.

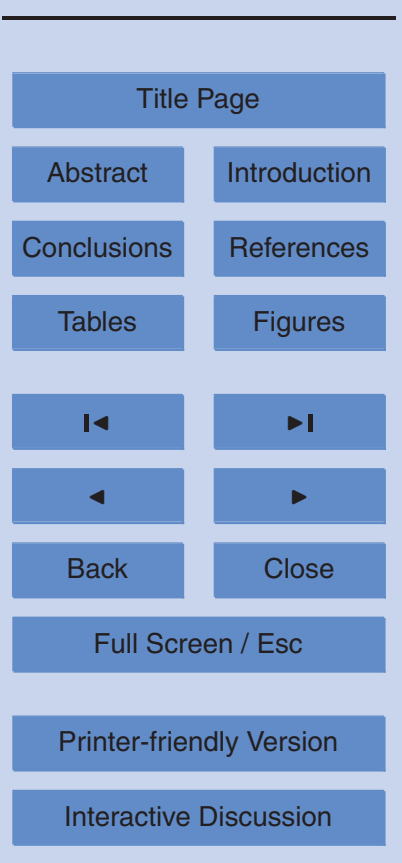



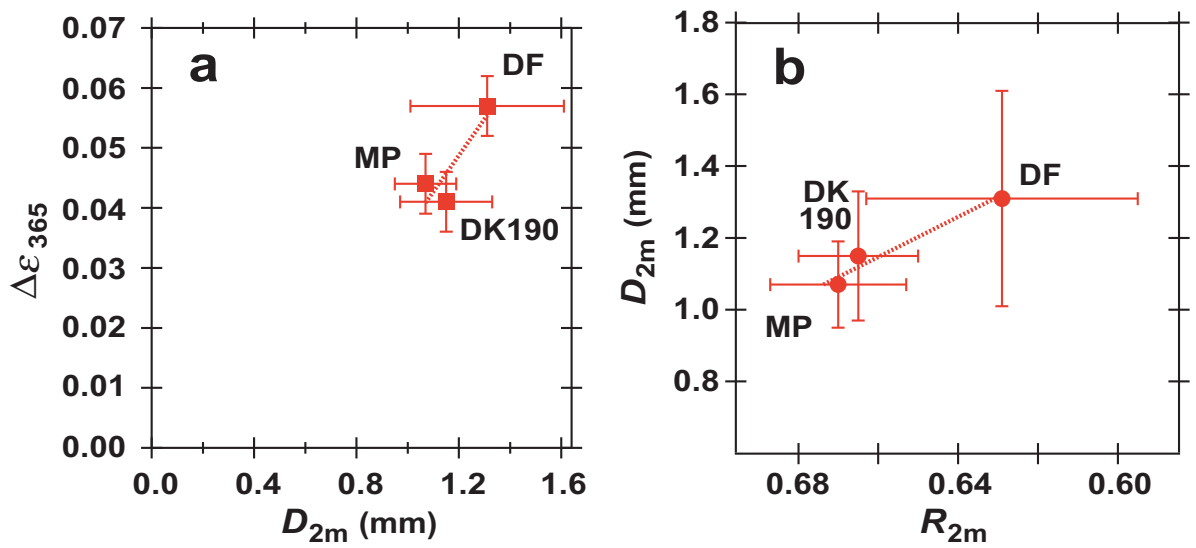

Fig. 12. (a) A relation between $\Delta \varepsilon$ values for $\rho=365 \mathrm{~kg} \mathrm{~m}^{-3}\left(\Delta \varepsilon_{365}\right.$ on the left axis) and the averaged $D$ values at $z=2(\mathrm{~m})\left(D_{2 \mathrm{~m}}\right.$ on the abscissa) for the three sites. A linear correlation is suggested. (b) A relation between $D_{2 \mathrm{~m}}$ and the averaged $R$ values at $z=2(\mathrm{~m})\left(R_{2 \mathrm{~m}}\right.$ on the abscissa) for the three sites. A linear correlation is observed.

$6,1205-1267,2012$

Metamorphism of firn in Dronning Maud Land, East Antarctica

S. Fujita et al.

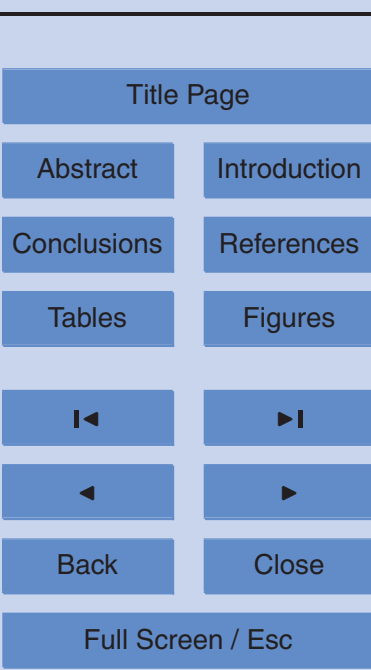

Printer-friendly Version

Interactive Discussion 


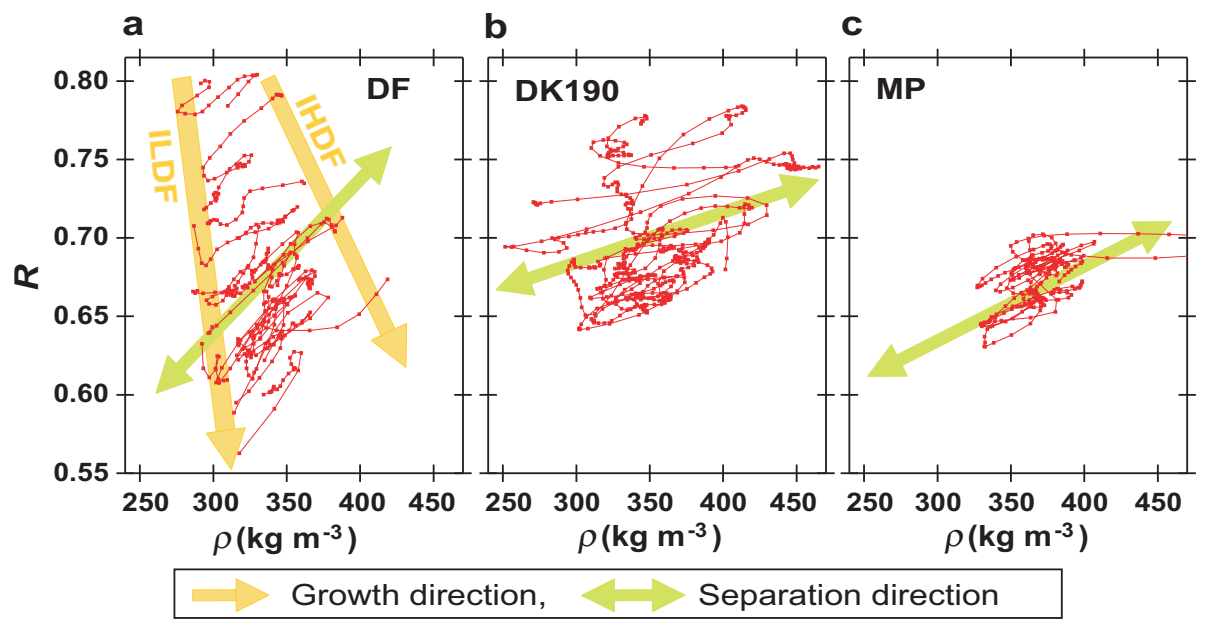

Fig. 13. Trajectories of $R-\rho$ relation for the three pits. The abscissa and the ordinate are $\rho$ and $R$, respectively. Data points (dots) are connected by lines along depths to emphasize how the $R-\rho$ relation evolves with increasing depth. Raw data were smoothed over every $10 \mathrm{~mm}$ to remove noise in the original data. Light green arrows show suggested directions of separation (contrasted evolution) between IHDF with higher density and finer grains and ILDF with lower density and coarser grains. Light orange arrows show suggested direction of evolution of grain properties for IHDF and ILDF. At DF, a cyclic feature is more clearly observed in the trajectory. At DK190 and MP, gradients of the $\Delta R / \Delta \rho$, that is, the gradient of the light green arrows are apparently lower than that of DF. Cyclic features tend to be disturbed by very dense ( $>$ $380 \mathrm{~kg} \mathrm{~m}^{-3}$ ) layers caused by strong wind events. The gradients of $\Delta R / \Delta \rho$ are given in Table 4 .

\section{TCD}

6, 1205-1267, 2012

\section{Metamorphism of firn in Dronning Maud Land, East Antarctica}

S. Fujita et al.

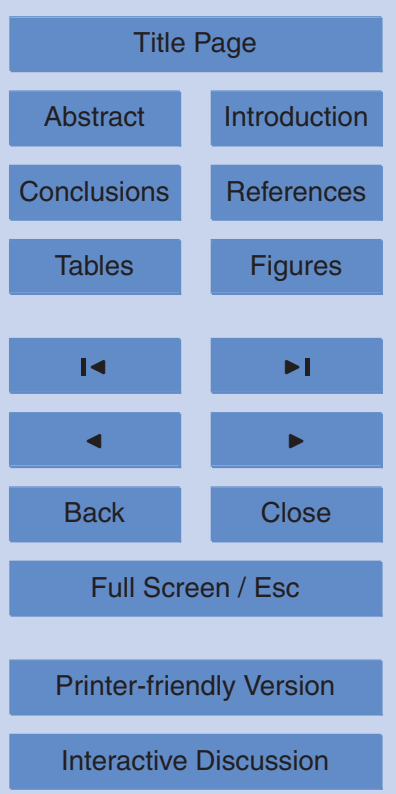




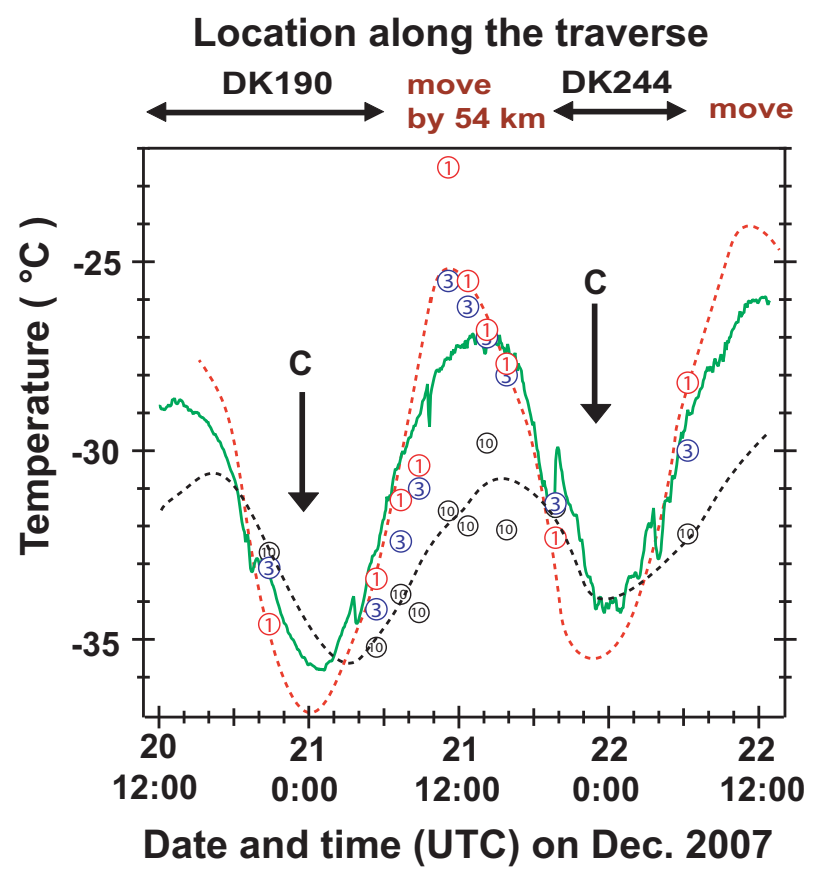

Air temperature at $3 \mathrm{~m}$

Snow temperature at $1 \mathrm{~cm}$ (1), $3 \mathrm{~cm}$ (3), and $10 \mathrm{~cm}$ (10).

"C": timing for condensation at the surface.

Fig. 14. Temperature within the surface snow on the day of the summer solstice (see Fig. 2). At three depths of $1 \mathrm{~cm}, 3 \mathrm{~cm}$ and $10 \mathrm{~cm}$, temperature was measured using a calibrated thermometer and a local Pt100 sensor. Data are plotted with the measured values of the air temperature. In the daytime around the noon, surface temperature is the highest, which means that the ice sheet surface is source of evaporation. In the night time, condensation should dominate at the surface because of the radiative cooling.

\section{Metamorphism of firn in Dronning Maud} Land, East Antarctica

S. Fujita et al.

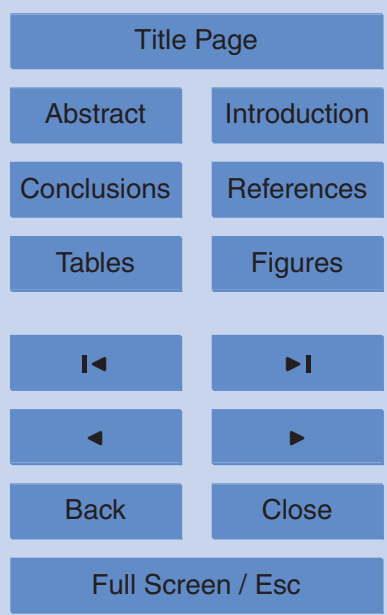

Printer-friendly Version

Interactive Discussion 

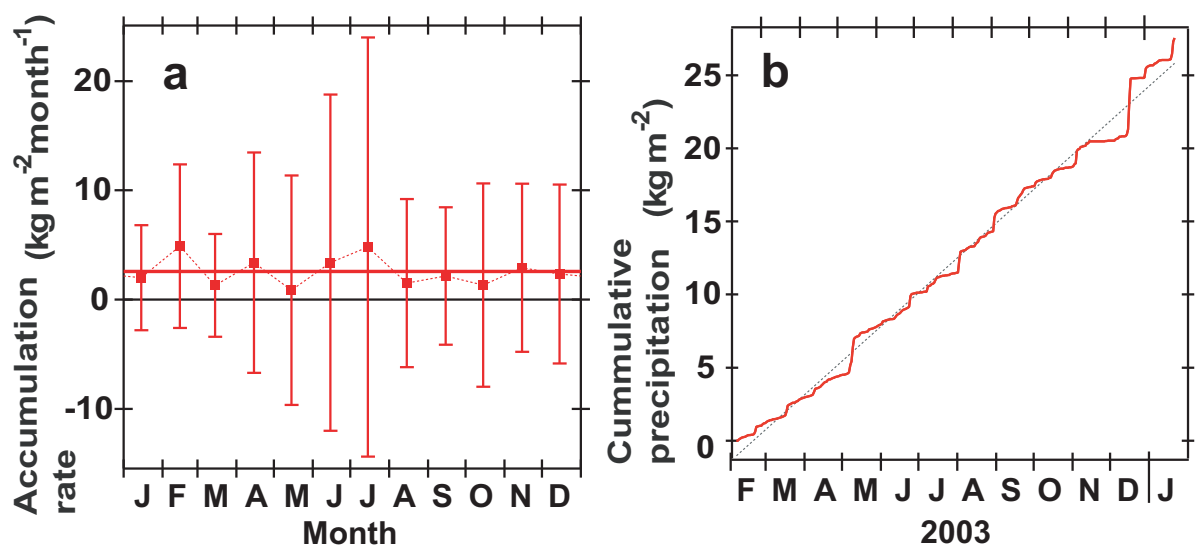

\section{$6,1205-1267,2012$}

\section{Metamorphism of firn in Dronning Maud Land, East Antarctica}

S. Fujita et al.

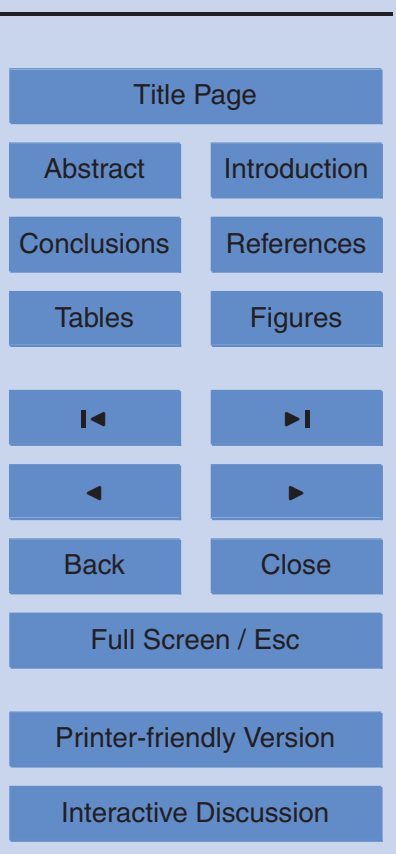

Fig. 15. Two independent data sets commonly show no seasonality in surface mass balance at DF under present climate. (a) Average monthly surface mass balance at DF from January to December in four years (1995-97 and 2003) with the SD of the data. Data are from 36 snowstake farm compiled by Kameda et al. (2008) with small corrections for the seasonal changes of surface snow density by up to $10 \%$ as observed by Takahashi and Kameda (2007). Fitting with periodical functions (red curve) indicated no seasonality. (b) Daily cumulative precipitation at the roof of DF from February 2003 to January 2004 (Fujita and Abe, 2006). Note that this data set already contains evaporation effects because the sampler was exposed in the outside of the Dome Fuji Station. The cumulative snow in winter 6 months (from April until September) is the same as that in summer 6 months (from October until March) within a difference of $3 \%$. The former data set (a) is influenced by wind-driven undulations of the snow surface. We see effects of wind as SD of the data. In contrast, the latter data set (b) is not influenced by any effects of wind-driven undulations of the snow surface.

Interactive Discussion 


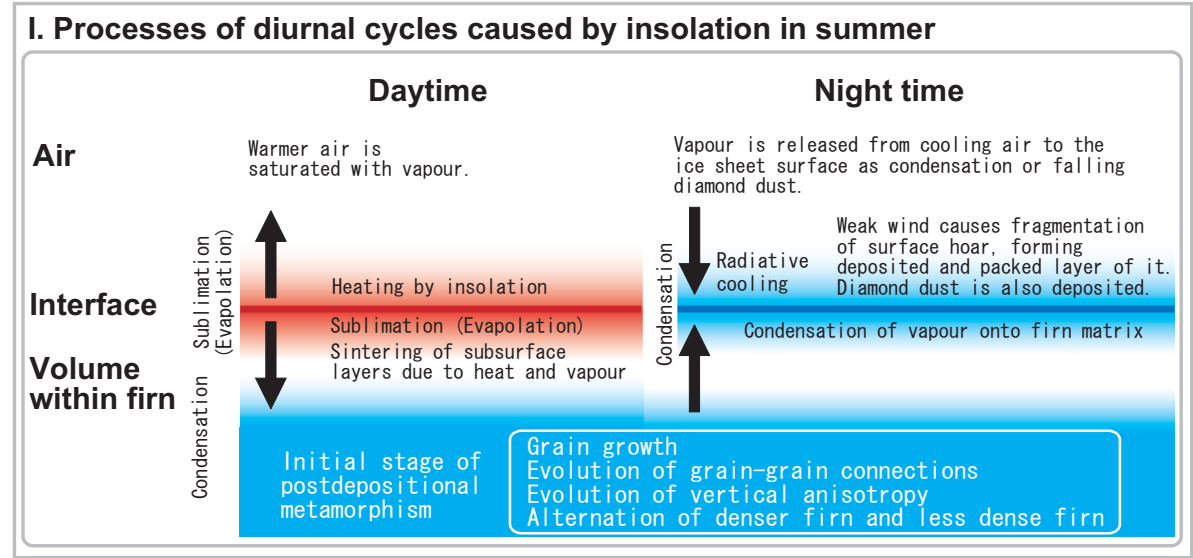

Fig. 16. Factors controlling formation of firn strata and initial stage of postdepositional metamorphism: I. Processes of diurnal cycles caused by insolation in summer. Schematic figure shows processes at plateau sites characterized by low accumulation rate and weak wind, such as DF. The items in the column indicates locations in the vertical at the ice sheet surface. The items in the row indicates daytime (left) and night time (right). Red colour and blue colour show warm and cold conditions, respectively. Arrows indicate vertical directions of vapour flow and heat flow. Diurnal cycles apparently cause evolution of interfaces and layers at the surface of the ice sheet, which is buried later with time by accumulation. Diurnal cycles also cause temperature gradient in the volume of the firn. The summer day processes should work more strongly than the summer night processes in the period before summer solstice because of the increasing trend of air temperature day by day. However, the summer night processes should appear more in the late summer because of cooling trend of the air temperature and warmed firn by heat conduction during the summer. In addition to these processes associated with diurnal cycles, Table 7 shows processes that should operate in various time scales.
$6,1205-1267,2012$

\section{Metamorphism of firn in Dronning Maud Land, East Antarctica}

S. Fujita et al.

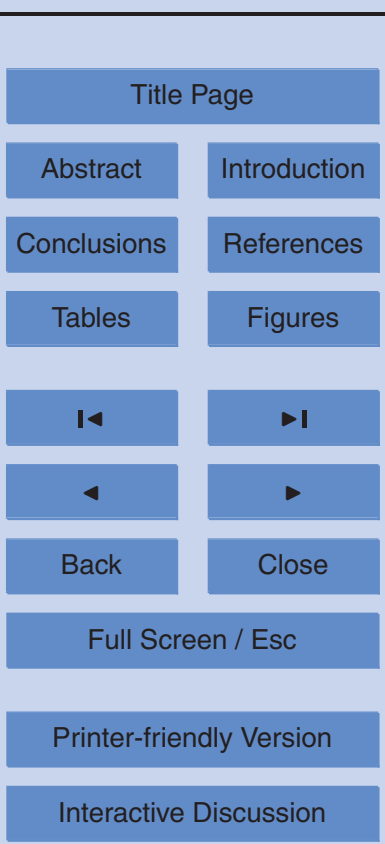

